\title{
Impact of Low Coagulant Dosages on Protein Fouling of Ultrafiltration Membranes
}

by

Chun Kei Tang

A thesis submitted in conformity with the requirements

for the degree of Master of Applied Science

Department of Civil and Mineral Engineering University of Toronto

๑) Copyright by Chun Kei Tang 2018 


\title{
IMPACT OF LOW COAGULANT DOSAGES ON PROTEIN FOULING OF ULTRAFILTRATION MEMBRANES
}

\author{
Chun Kei Tang \\ Master of Applied Science \\ Department of Civil and Mineral Engineering \\ University of Toronto \\ 2018
}

\begin{abstract}
Ultrafiltration fouling in drinking water treatment has been primarily attributed to the biopolymer fraction (e.g., proteins) of organic matter in source waters. This bench-scale study examined the use of coagulation to mitigate fouling in three model protein solutions. Similar to results from studies conducted with natural waters, a low coagulant dose $(2 \mu \mathrm{M} A \mathrm{Al})$ was identified to significantly reduce membrane fouling relative to zero coagulant addition for two proteins (BSA and ovalbumin). It is hypothesized that the low dosages alter the surface hydrophobicity of proteins in both the bulk solution and fouling layer, resulting in weakened intermolecular interactions, reducing fouling.
\end{abstract}

The impacts of applying coagulation only during the initial stages of a permeation cycle (phased coagulation) on membrane fouling were investigated at pilot-scale. Coagulant application during the first half of the cycle resulted in fouling rates similar to that of continuous addition, which could translate to significant cost savings. 


\section{ACKNOWLEDGEMENTS}

This work was funded by the Natural Sciences and Engineering Research Council of Canada (NSERC) Chair in Drinking Water Research at the University of Toronto, and the Ontario Research Fund (ORF).

I would like to sincerely thank my supervisor, Professor Robert C. Andrews for sharing his immense knowledge and experience in research, writing, and professional pursuits. I credit him for converting my piquing interest in water treatment into a much deeper appreciation and passion for the field. I would also like to thank my co-supervisors, Professor Pierre Bérubé and Professor Nicolas Peleato for their guidance, encouragement, and their excellent ideas that significantly improved the quality of my research.

Thank you to Liz Taylor-Edmonds for always being someone I can talk to for advice (and go to lunch with!). Her support and guidance were crucial during this process. I would also like to thank DWRG staff, Jim Wang, Jennifer Lee, and Gabbie Galbraith for their assistance in the lab and in the office. Thanks to Kerry Evans-Tokaryk for her invaluable advice.

I would also like to thank the staff at the Barrie Surface Water Treatment Plant, Dave Johnston, Natalia Contreras, Jamey Adams, and Kari-Anne Last, for their assistance in conducting the pilot-scale experiments.

It has been a great pleasure to be a part of the Drinking Water Research Group since my first day as a summer student in May 2011 and I would like to thank all my colleagues past and present that have played a part in shaping this amazing experience. I am especially grateful for my classmates Caroline, Ken, Tyler, Nathan, Husein, Ian, and Mustafa for their friendship and encouragement over the course of my degree. Thanks to Mike for being a great officemate and always willing to offer sage advice on just about anything.

Finally, thanks to my friends and family for their love, encouragement, and support during my degree. A big shout out to Kim for being my biggest supporter and motivator. I could not have asked for a better person to accompany me on this journey. 


\section{TABLE OF CONTENTS}

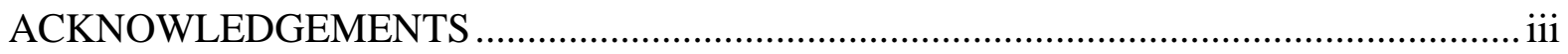

TABLE OF CONTENTS ......................................................................................... iv

LIST OF TABLES ................................................................................................ vii

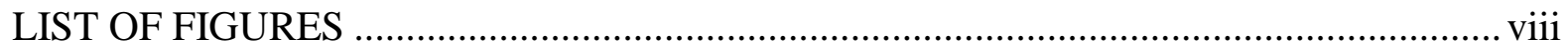

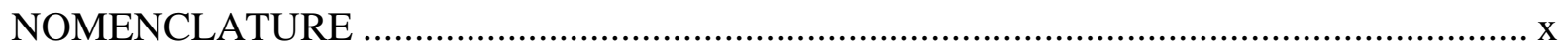

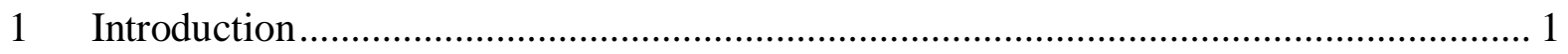

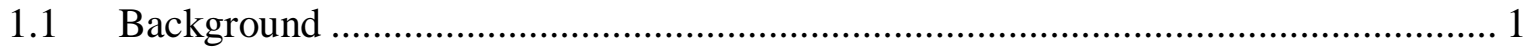

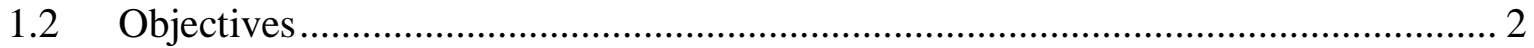

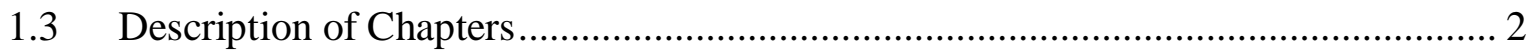

2 Literature Review ........................................................................................... 3

$2.1 \quad$ Ultrafiltration Overview ............................................................................ 3

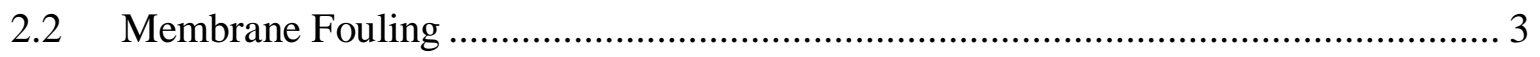

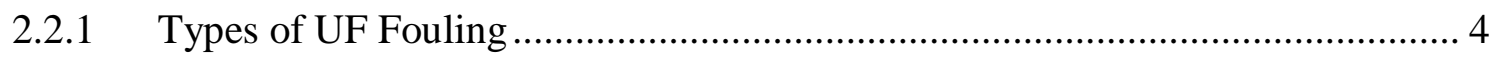

$2.3 \quad$ Identification of Foulants .............................................................................. 5

$2.4 \quad$ Fouling Control Strategies ............................................................................. 6

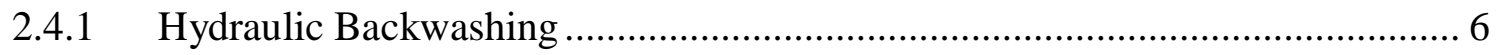

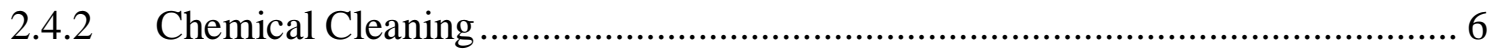

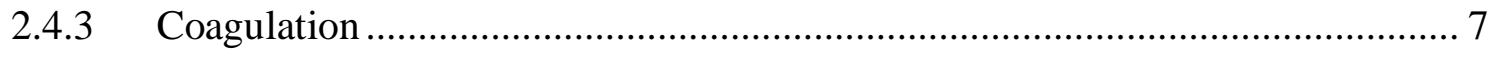

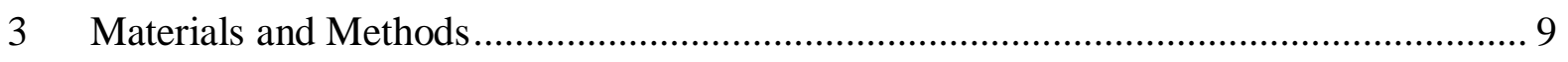

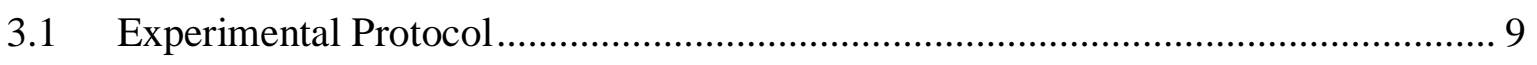

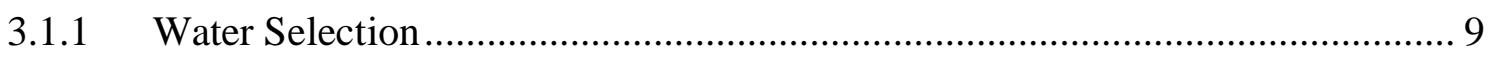

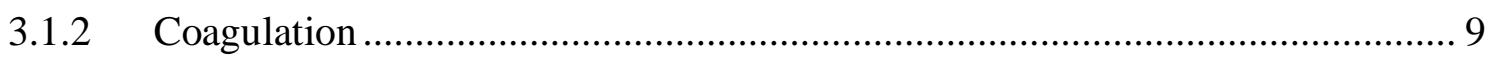




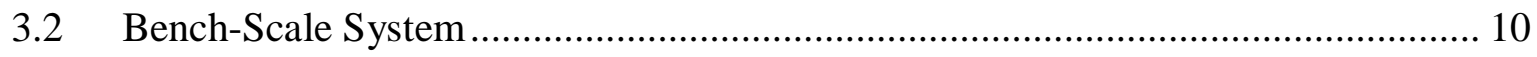

3.3 Pilot-Scale System....................................................................................... 12

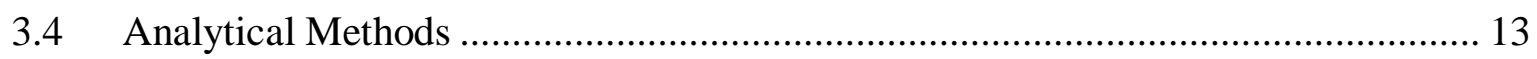

3.4.1 Protein Quantification ............................................................................... 13

3.4.2 Protein Size and Surface Charge ..................................................................... 13

3.4.3 Fluorescence Spectroscopy …………………........................................... 13

3.4.4 Protein Surface Hydrophobicity Fluorescence Assay ....................................... 14

3.4.5 Dissolved Organic Carbon ........................................................................ 15

3.4.6 Liquid Chromatography-Organic Carbon Detection ....................................... 17

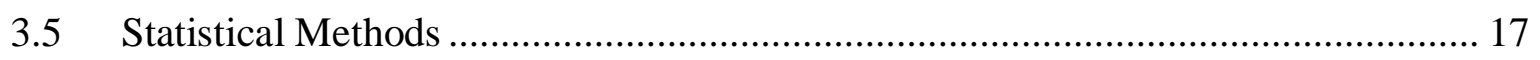

4 Impact of Low Coagulant Dosages on the Protein Fouling of Ultrafiltration Membranes 18

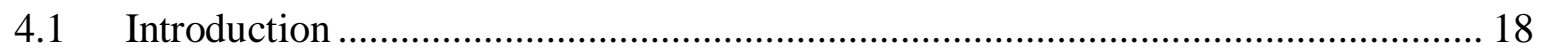

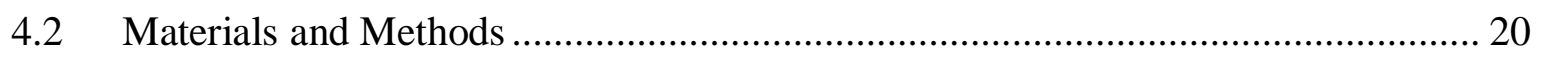

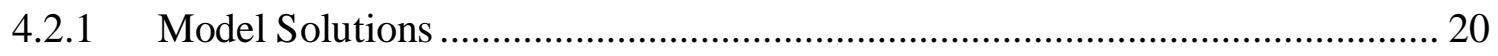

4.2.2 Membrane Filtration ............................................................................. 20

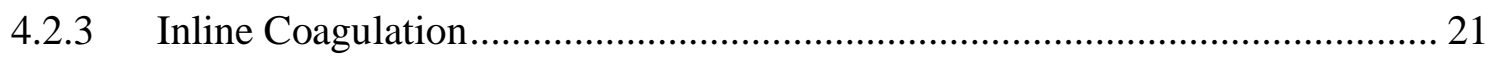

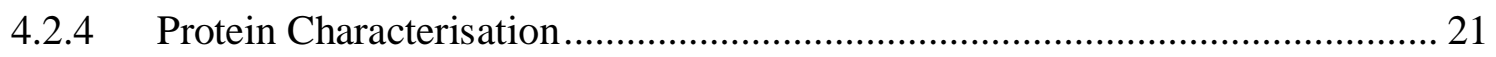

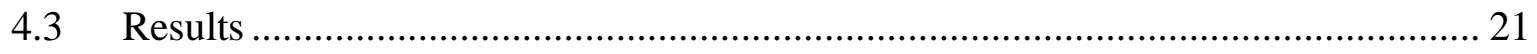

4.3.1 Membrane Fouling ............................................................................. 21

4.3.2 Protein Rejection................................................................................. 23

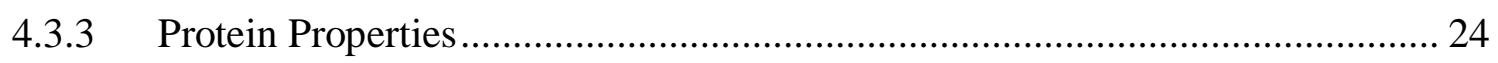

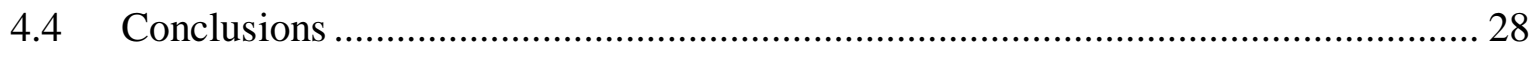

5 Impact of Phased Coagulation on Membrane Fouling …………………………......... 29

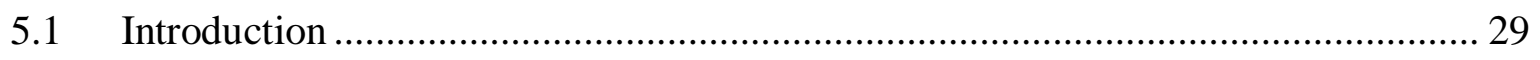


5.2 Materials and Methods ……………………………................................... 30

5.2.1 Membrane Filtration ………………………........................................... 30

5.2.2 Water Quality and Membrane Fouling ......................................................... 32

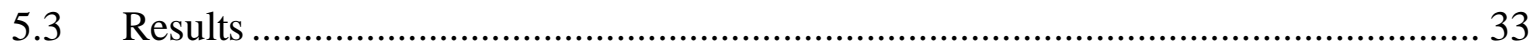

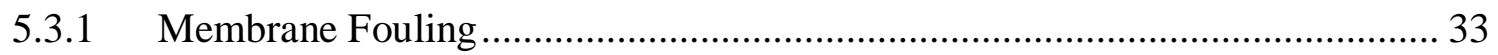

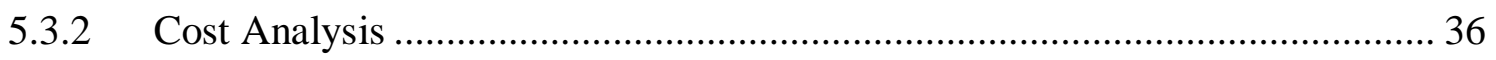

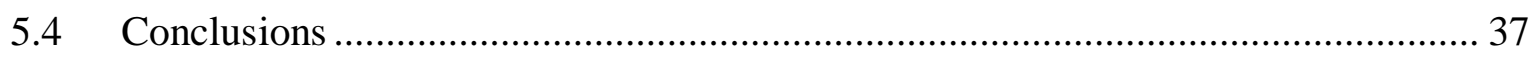

6 Summary, Conclusions, and Recommendations ............................................................ 38

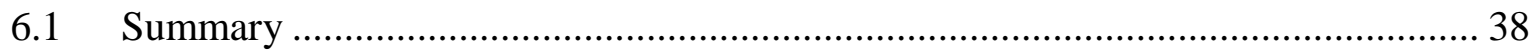

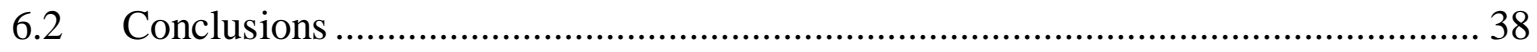

6.3 Recommendations for Future Research ................................................................. 39

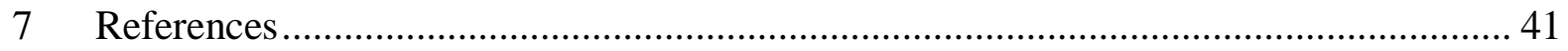

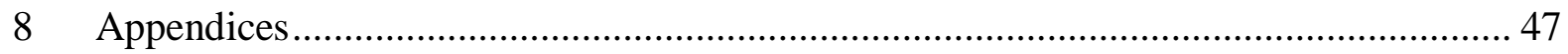

8.1 Procedure and Sample Calculation for Pure Water Permeability of a Membrane ... 47

8.2 Procedure and Sample Calculation for Surface Hydrophobicity of Proteins ........... 49

8.3 Cost Savings Estimation Procedure ………………………………………..... 51

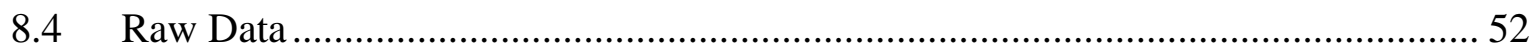

8.4.1 Protein Solution Fouling Resistance ................................................................. 52

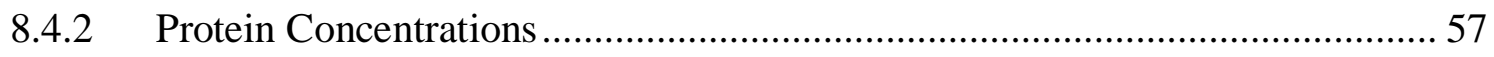

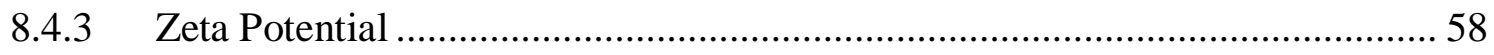

8.4.4 ANS Fluorescence Assay ………………….................................................. 59

8.4.5 Pilot-Scale Fouling Resistance …………………........................................... 60

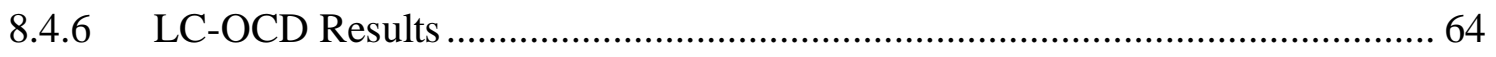




\section{LIST OF TABLES}

Table 2-1: Types of chemical used for membrane cleaning and foulants targeted................ 7

Table 3-1: Alum dosages examined for model protein solutions ...................................... 10

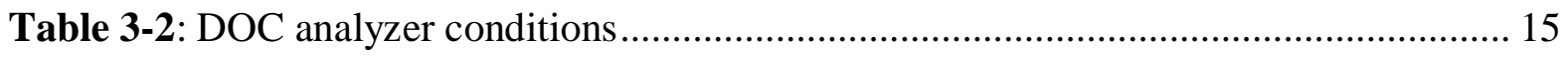

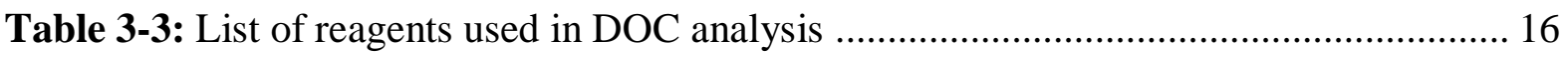

Table 5-1: Operating parameters for pilot-scale filtration experiments............................ 31

Table 5-2: Comparison of cleaning frequency, operational lifetime, and replacement costs of different phased coagulation conditions .................................................................. 36

Table 8-1: Measured TMP as a function of permeate flow/flux ...................................... 47

Table 8-2: Example dilution scheme for ANS fluorescence assay .................................... 49

Table 8-3: Concentrations $(\mathrm{mg} / \mathrm{L})$ of BSA in feed, permeate, and reject water during $1^{\text {st }}$

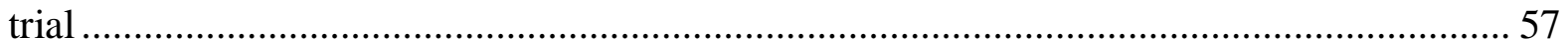

Table 8-4: Concentrations (mg/L) of BSA in feed, permeate, and reject water during $2^{\text {nd }}$

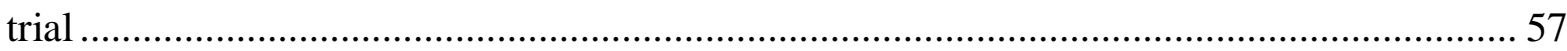

Table 8-5: Concentrations (mg/L) of BLG in feed, permeate, and reject water .................. 57

Table 8-6: Concentrations (mg/L) of OVA in feed, permeate, and reject water during $1^{\text {st }}$ trial

Table 8-7: Concentrations (mg/L) of OVA in feed, permeate, and reject water during $2^{\text {nd }}$ trial 58

Table 8-8: Zeta potential $(\mathrm{mV})$ of BSA for different coagulant dosages............................ 58

Table 8-9: Zeta potential $(\mathrm{mV})$ of OVA for different coagulant dosages ........................... 58

Table 8-10: Fluorescent intensity at ex/em 370/490 nm (average of triplicate measurements) of BSA solutions titrated with ANS

Table 8-11: Concentration $(\mu \mathrm{g} / \mathrm{L})$ of NOM fractions (via LC-OCD) in feed, permeate, and reject water for different phased coagulation conditions 


\section{LIST OF FIGURES}

Figure 2-1: Types of ultrafiltration fouling (a) cake layer formation, (b) pore narrowing, and (c) pore blocking .

Figure 2-2: Representation of contributions of intrinsic membrane resistance $\left(\mathrm{R}_{\mathrm{m}}\right)$, reversible fouling resistance $\left(\mathrm{R}_{\mathrm{rev}}\right)$, and irreversible fouling resistance $\left(\mathrm{R}_{\text {irr }}\right)$ during UF with

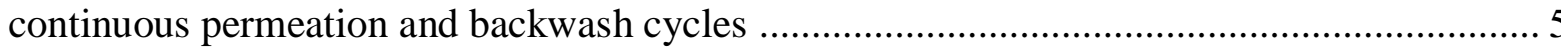

Figure 3-1: Schematic of typical bench-scale UF system................................................ 11

Figure 3-2: Schematic of pilot-scale UF system at Barrie Surface WTP .......................... 12

Figure 3-3: Example calibration curve for protein quantification via colorimetric assay ..... 13

Figure 3-4: Raw and processed (via Savitzky-Golay filter) sample spectra of BSA fluorescence emission at $230 \mathrm{~nm}$ excitation

Figure 3-5: Variation in fluorescence emission spectrum of ANS (ex $370 \mathrm{~nm}$ ) at various OVA concentrations $(0-20 \mathrm{mg} / \mathrm{L})$.

Figure 3-6: Example DOC calibration curve using potassium hydrogen phthalate

Figure 4-1: (a) Hydraulically irreversible and (b) reversible fouling rates associated with $20 \mathrm{mg} / \mathrm{L}$ of bovine serum albumin (BSA), $20 \mathrm{mg} / \mathrm{L}$ ovalbumin (OVA), and $10 \mathrm{mg} / \mathrm{L} \beta$ lactoglobulin (BLG) for a range of coagulant doses

Figure 4-2: (a) Rejection of proteins (\%) by UF for a range of alum dosages (as $\mu \mathrm{M} \mathrm{Al}$ ) after $24 \mathrm{~h}$ of permeation (b) Relationship between rejection of proteins by UF and irreversible fouling resistance gained during a permeation cycle ..................................... 24

Figure 4-3: Zeta potential of BSA and OVA as a function of coagulant dose ..... 25

Figure 4-4: Surface hydrophobicity of BSA in feed, permeate, and reject determined using ANS fluorescence assay

Figure 5-1: Phased coagulation conditions of pilot-scale trials

Figure 5-2: (a) Hydraulically irreversible and (b) total fouling rate of a ZW1000 UF membrane as a function of phased coagulation time.

Figure 5-3: Removals of NOM fractions characterised via LC-OCD at various phased coagulation conditions after $24 \mathrm{~h}$ of permeation.

Figure 5-4: DOC and biopolymers deposited (as \% of total DOC and biopolymers in the feed solution, respectively) on the membrane after backwash after $24 \mathrm{~h}$ of permeation........ 35

Figure 8-1: Permeate flux as a function of TMP for four ZW500 membrane fibres ............ 48 
Figure 8-2: Example fluorescence intensity of BSA in the permeate as a function of protein concentration at different coagulant dosages ....

Figure 8-3: (a) Total, (b) irreversible, and (c) reversible resistance during $1^{\text {st }}$ trial of ultrafiltration of $20 \mathrm{mg} / \mathrm{L} \mathrm{BSA}$ with respect to permeation time for different coagulant dosages $(\mu \mathrm{M} \mathrm{Al})$

Figure 8-4: (a) Total, (b) irreversible, and (c) reversible resistance during $2^{\text {nd }}$ trial of ultrafiltration of $20 \mathrm{mg} / \mathrm{L} \mathrm{BSA}$ with respect to permeation time for different coagulant dosages $(\mu \mathrm{M} \mathrm{Al})$

Figure 8-5: (a) Total, (b) irreversible, and (c) reversible resistance during ultrafiltration of $10 \mathrm{mg} / \mathrm{L}$ BLG with respect to permeation time for different coagulant dosages ( $\mu \mathrm{M} \mathrm{Al}) \ldots . .54$ Figure 8-6: (a) Total, (b) irreversible, and (c) reversible resistance during $1^{\text {st }}$ trial of ultrafiltration of $20 \mathrm{mg} / \mathrm{L} \mathrm{OVA}$ with respect to permeation time for different coagulant dosages $(\mu \mathrm{M} \mathrm{Al})$

Figure 8-7: (a) Total, (b) irreversible, and (c) reversible resistance during $2^{\text {nd }}$ trial of ultrafiltration of $20 \mathrm{mg} / \mathrm{L} \mathrm{OVA}$ with respect to permeation time for different coagulant dosages $(\mu \mathrm{M} \mathrm{Al})$

Figure 8-8: Total fouling resistance for (a) continuous, (b) $60 \mathrm{~min}$, (c) $30 \mathrm{~min}$, (d) $10 \mathrm{~min}$, and (e) no coagulant addition times during each permeation cycle

Figure 8-9: Irreversible fouling resistance for (a) continuous, (b) $60 \mathrm{~min}$, (c) $30 \mathrm{~min}$, (d)

$10 \mathrm{~min}$, and (e) no coagulant addition times during each permeation cycle 63 


\section{NOMENCLATURE}

\begin{tabular}{|c|c|}
\hline$\%$ & Percent \\
\hline${ }^{\circ} \mathrm{C}$ & Degree(s) Celsius \\
\hline$<$ & Less than \\
\hline$\leq$ & Less than or equal to \\
\hline$>$ & More than \\
\hline$\mu$ & Viscosity \\
\hline$\sim$ & Approximate \\
\hline \pm & Plus or minus \\
\hline a.u. & Arbitrary units \\
\hline $\mathrm{Al}$ & Aluminum \\
\hline ANS & 1-anilinonaphthalene-8-sulfonate \\
\hline BLG & $\beta$-lactoglobulin \\
\hline BSA & Bovine serum albumin \\
\hline $\mathrm{C}$ & Concentration \\
\hline CEB & Chemically enhanced backwash \\
\hline CIP & Clean in place \\
\hline $\mathrm{cm}$ & Centimetre(s) \\
\hline DOC & Dissolved organic carbon \\
\hline FEEM & Fluorescence excitation-emission matrix \\
\hline $\mathrm{g}$ & Gram(s) \\
\hline $\mathrm{h}$ & Hour(s) \\
\hline $\mathrm{HCl}$ & Hydrochloric acid \\
\hline $\mathrm{Hz}$ & Hertz \\
\hline in & Inches \\
\hline $\mathrm{J}$ & Flux \\
\hline KHP & Potassium hydrogen phthalate \\
\hline $\mathrm{kPa}$ & Kilopascal(s) \\
\hline $\mathrm{L}$ & Liter(s) \\
\hline
\end{tabular}


LC-OCD

$\mathrm{L} / \mathrm{h}$

$\mathrm{LMH}$

$\mathrm{L} / \mathrm{min}$

$\mathrm{m}$

$\mathrm{M}$

$\mathrm{m}^{2}$

$\mathrm{mg} / \mathrm{L}$

$\min$

$\mathrm{mL} / \mathrm{min}$

$\mathrm{mm}$

$\mathrm{mm}^{2}$

$\mathrm{mM}$

$\mathrm{m} / \mathrm{s}$

$\mathrm{mV}$

$\mathrm{NaOCl}$

$\mathrm{NaOH}$

NF

$\mathrm{nm}$

NOM

ON

OVA

$\mathrm{Pa}$

$\mathrm{PACl}$

$\mathrm{pH}$

PRODAN

psi

psig

PVC
Liquid chromatography-organic carbon detection

Liter(s) per hour

Liter(s) per square metre per hour

Liter(s) per minute

Metre(s)

Molar

Squared meter(s)

Milligram(s) per liter

Minute(s)

Milliliter(s) per minute

Millimeter(s)

Millimeter(s) squared

Millimolar

Meter(s) per second

Millivolt(s)

Sodium hypochlorite

Sodium hydroxide

Nanofiltration

Nanometer

Natural organic matter

Ontario

Ovalbumin

Pascal(s)

Polyaluminum chloride

Negative $\log$ of the hydrogen ion concentration; $\log \{\mathrm{H}+\}$

6-propionyl-2-(N,N-dimethyl-amino)naphthalene

Pounds per square inch

Pounds per square inch gauge

Polyvinyl chloride 


\begin{tabular}{|c|c|}
\hline PVDF & Polyvinylidene difluoride \\
\hline QC & Quebec \\
\hline $\mathrm{R}$ & Resistance \\
\hline $\mathrm{R}^{2}$ & Coefficient of determination \\
\hline $\mathrm{R}_{\text {irr }}$ & Irreversible resistance \\
\hline $\mathrm{Rm}_{\mathrm{m}}$ & Intrinsic membrane resistance \\
\hline $\mathrm{RO}$ & Reverse osmosis \\
\hline rpm & Revolutions per minute \\
\hline Rrev & Reversible resistance \\
\hline $\mathrm{R}_{\mathrm{T}}$ & Total resistance \\
\hline TMP & Transmembrane pressure \\
\hline TOC & Total organic carbon \\
\hline $\mathrm{TX}$ & Texas \\
\hline UF & Ultrafiltration \\
\hline$\mu \mathrm{L}$ & Microliters \\
\hline$\mu \mathrm{M}$ & Micromolar \\
\hline UV & Ultraviolet \\
\hline $\mathrm{UV}_{254}$ & UV absorbance at $254 \mathrm{~nm}$ \\
\hline WTP & Water treatment plant \\
\hline ZW500 & ZeeWeed $^{\circledR} 500$ membrane $^{-}$ \\
\hline ZW1000 & ZeeWeed $^{\circledR} 1000$ membrane \\
\hline
\end{tabular}




\section{Introduction}

\subsection{Background}

Ultrafiltration (UF) has become increasingly prevalent in drinking water treatment due to its ability to consistently remove pathogens and particulates while having a footprint smaller than conventional media filters. However, fouling caused by the accumulation of solutes on the surface and within membrane pores impedes permeate flow, adversely impacting efficiency (Zularisam et al., 2006). Although resistance due to fouling is largely reversible via hydraulic backwashing, hydraulically irreversible fouling necessitates the periodic use of chemical cleaning reagents that can permanently alter membrane properties (Abdullah and Bérubé, 2013). Therefore, there exists a demand for methods than can improve the reversibility of fouling for greater efficiency.

Natural organic matter (NOM) is a significant source of UF fouling in drinking water treatment, particularly the large macromolecules (proteins and polysaccharides) that comprise the biopolymer fraction (Amy, 2008; Zheng et al., 2012). While most studies report the contribution of the biopolymer fraction as a whole to UF fouling, several studies have identified proteins to be primarily responsible for hydraulically irreversible fouling (Peiris et al., 2010; Peldszus et al., 2011; Peleato et al., 2017). Therefore, it is worth elucidating the properties and mechanisms of proteins relevant to UF fouling which can potentially lead to the development of effective fouling mitigation strategies.

Coagulation is the most popular pretreatment method to mitigate UF fouling in drinking water treatment. While conventional treatment optimizes coagulation for turbidity or dissolved organics removal, it may be advantageous to select conditions to maximize biopolymer/protein removal prior to UF to mitigate fouling instead. Previous studies have reported reduced fouling at low coagulant doses ( $<1 \mathrm{mg}$ metal/L) (Peleato et al., 2017; Tabatabai et al., 2009), which has been associated with the point of diminishing returns for biopolymer removal (Wray and Andrews, 2014). However, the impact of coagulation, particularly at low dosages, on protein fouling remains unclear. Changes in protein conformation (Peleato et al., 2017) as well as particle size (Ma et al., 2015) have been identified as a result of coagulation with low dosages. 


\subsection{Objectives}

The main objectives of this study were to:

1. Examine the impact of low coagulant dosages on protein fouling of UF membranes

2. Assess the impact of coagulation on the properties of proteins relevant to UF fouling

3. Examine the impact of phased coagulation with respect to membrane fouling at pilotscale

\subsection{Description of Chapters}

- Chapter 2 provides background information regarding ultrafiltration in drinking water treatment, membrane fouling and coagulation pretreatment as a fouling control strategy

- Chapter 3 describes the methodology used to evaluate the effect of low coagulant dosages on protein-related fouling of UF membranes. Details regarding the model solution, experimental design, bench- and pilot-scale apparatus, and analytical methods are provided

- Chapter 4 presents the results of the bench-scale experiment about the impacts of low coagulant dosages on protein fouling of UF membranes, as well as an analysis of protein properties at different coagulant dosages

- Chapter 5 presents the results of the pilot-scale experiment regarding the impact of phased coagulation on membrane fouling and the associated cost savings

- Chapter 6 summarizes the results of this study and provides recommendations for future research

- Chapter 7 lists the references mentioned in this study

- Chapter 8 presents the appendices containing analytical procedures and raw data 


\section{Literature Review}

\subsection{Ultrafiltration Overview}

Ultrafiltration (UF) is a low pressure membrane filtration method that is commonly used in drinking water treatment because it is more economical than high pressure systems such as nanofiltration (NF) and reverse osmosis (RO) (Gao et al., 2011). They also have a smaller footprint when compared to conventional media filters, making them a popular choice for retrofits. Low pressure membranes operate via a sieving mechanism that removes any constituents larger than the membrane pores. As a result, UF membranes have been shown to be very effective in removing pathogens (Giardia and Cryptosporidium) and particulates (AWWA, 2008). Since they operate via size exclusion, UF membranes do not require precise control of water chemistry for effective removal unlike conventional filters. As a result, UF membranes are commonly implemented into newly constructed or retrofitted treatment facilities (Gao et al., 2011).

\subsection{Membrane Fouling}

Membrane fouling is the primary limitation for the broader application of UF (Gao et al., 2011). The accumulation of foulants on the membrane can form a cake/gel layer on the surface and/or narrow or block pores (Figure 2-1). As a result, fouling leads to greater energy consumption and increases maintenance frequency, all of which adversely impact efficiency (Kimura et al., 2014).

(a)

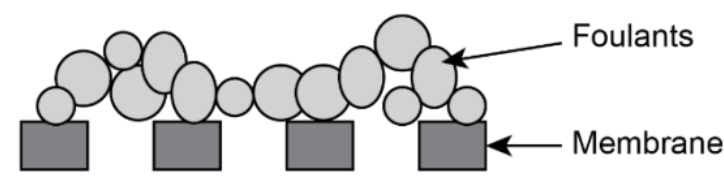

(b)

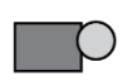

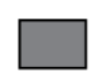
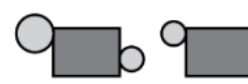

(c)

Figure 2-1: Types of ultrafiltration fouling (a) cake layer formation, (b) pore narrowing, and (c) pore blocking 
When membranes are operated under constant flux, fouling is quantified by the change in transmembrane pressure (TMP) during permeation. Fouling is often expressed using resistance $(R)$ which is calculated according to equation [2.1:

$$
R=\frac{T M P}{J \cdot \mu}
$$

where, $R$ is resistance $\left(\mathrm{m}^{-1}\right)$

$T M P$ is the transmembrane pressure $(\mathrm{Pa})$

$J$ is the permeate flux $\left(\mathrm{m}^{3} \mathrm{~m}^{-2} \mathrm{~s}^{-1}\right)$

$\mu$ is the viscosity of water $\left(\mathrm{Pa} \mathrm{s}^{-1}\right)$

\subsubsection{Types of UF Fouling}

Fouling is typically characterized as reversible or irreversible and can be further classified as hydraulically or chemically reversible and irreversible. Hydraulically reversible fouling is readily removed by physical cleaning methods such as backwashing and air sparging and is often associated with cake layer formation (Taniguchi et al., 2003). Foulants that remain on the membrane after physical cleaning, which is typically a result of adsorption or pore blocking/narrowing (Belfort et al., 1994), is defined as hydraulically irreversible and is often removable by chemical cleaning (i.e., chemically reversible fouling). Chemically irreversible fouling can cause permanent reduction in the permeable area of the membrane.

Membrane fouling is often modeled using the resistance-in-series model, which defines the total membrane resistance $\left(R_{T}\right)$ as the sum of intrinsic membrane resistance $\left(R_{m}\right)$ and resistance due to fouling, both reversible $\left(R_{r e v}\right)$ and irreversible $\left(R_{i r r}\right)$ (equation [2.2). Relative contributions of reversible and irreversible fouling resistance can be determined by removing the reversible fouling layer, either hydraulically or chemically. A representation of the different resistances contributing to total resistance for the typical operation of a hollow fibre UF for drinking water is presented in Figure 2-2.

$$
R_{T}=R_{m}+R_{\text {rev }}+R_{\text {irr }}
$$




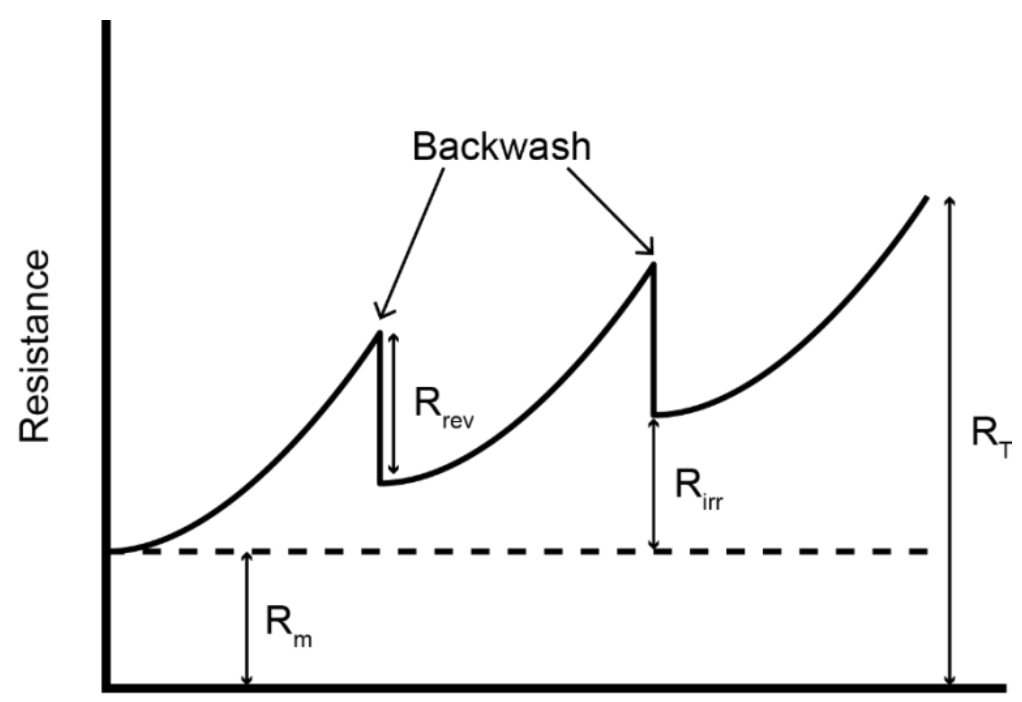

Time

Figure 2-2: Representation of contributions of intrinsic membrane resistance $\left(\mathrm{R}_{\mathrm{m}}\right)$, reversible fouling resistance $\left(R_{\text {rev }}\right)$, and irreversible fouling resistance $\left(R_{\text {irr }}\right)$ during UF with continuous permeation and backwash cycles

\subsection{Identification of Foulants}

Natural organic matter (NOM), particularly the dissolved fraction $(<0.45 \mu \mathrm{m})$, has been identified as the predominant source of membrane foulant when considering drinking water treatment (Amy, 2008; Howe and Clark, 2002). Ubiquitous in natural waters, NOM is a complex mixture of compounds ranging in size, shape, and character. Extensive research has been conducted to identify the components of NOM that are responsible for UF fouling. In particular, the biopolymer fraction has been reported to be the major source of UF foulants (Amy, 2008; Zheng et al., 2012). These include large macromolecules (>10 kDa) such as proteins and polysaccharides that are often larger than membrane pores. While the concentration of biopolymers is of importance when predicting membrane fouling, the composition of the biopolymer fraction should be considered as well (Hallé et al., 2009). Most existing research has only examined the contribution of the biopolymer fraction as a whole towards membrane fouling. It is therefore worth investigating the types of compounds that comprise the biopolymer fraction and their relative contributions to fouling since they may have unique properties that influence fouling behaviour.

Previous studies have identified proteins via fluorescence spectroscopy to be responsible for irreversible fouling (Peiris et al., 2010; Peldszus et al., 2011; Peleato et al., 
2017). Protein-related fouling of UF membranes occurs in two stages. Initially, a monolayer of proteins is adsorbed onto the membrane surface which is largely governed by proteinmembrane interactions (Huisman et al., 2000). Subsequently, deposition and/or adsorption onto this monolayer occurs, such that protein-protein interactions become significant (Wang et al., 2013). It is therefore beneficial to gain an understanding of the physicochemical properties of proteins, including size, surface charge and hydrophobicity, since these govern protein interactions (i.e., fouling potential) with both the membrane and the fouling layer (Gao et al., 2011). Fouling mechanisms can be complex as it is the result of a combination of competitive phenomena such as size exclusion, electrostatic attraction/repulsion, and hydrophobic interactions (Huisman et al., 2000). Therefore, elucidating the characteristics and mechanisms responsible for UF fouling can potentially lead to the development of effective fouling mitigation strategies.

\subsection{Fouling Control Strategies}

\subsubsection{Hydraulic Backwashing}

Hydraulic backwashing is a common component of routine membrane maintenance in which the flow of water is reversed to remove any foulants that have deposited onto the surface of the membrane (i.e., hydraulically reversible fouling). Treated water is typically used for backwash but can also be chemically-enhanced to provide more effective cleaning. Backwash frequency, flux (or pressure), and duration can be adjusted to maximize efficiency. Backwash frequency must be often enough to prevent excessive fouling resistance, but sufficiently low to minimize the volume of treated water used to perform backwashing ( $\mathrm{Li}$ et al., 2014). However, backwashing often does not fully restore permeability and are usually supplemented with other physical and/or chemical cleaning methods.

\subsubsection{Chemical Cleaning}

Another common component of a membrane maintenance program is chemical cleaning. Two procedures are typically applied at full-scale facilities: chemically enhanced backwash (CEB) and clean in place (CIP). CEB is often performed daily with oxidants such as sodium hypochlorite. CIP is performed less frequently ( $<10$ times/year) and often exposes the membrane to a variety of chemicals for intensive cleaning (Woo et al., 2013). A variety of chemicals can be used, each targeting different foulants as shown in Table 2-1 (Porcelli and 
Judd, 2010). Although chemical cleans are effective in restoring membrane permeability, its applications should be minimized because it can adversely impact membrane properties (Abdullah and Bérubé, 2013). Chemical cleans have been reported to lower the yield strength of membranes, which can result in membrane rupture allowing contaminants that otherwise would have been rejected to pass (Wang et al., 2010). Oxidants such as sodium hypochlorite have been shown to remove any surface modifications from PVDF membranes, resulting in a more hydrophilic surface that can be more prone to NOM fouling (Puspitasari et al., 2010). Therefore, methods that improve the hydraulic reversibility of fouling can reduce the frequency of chemical cleaning, which consequently increase membrane service life and lead to substantial cost savings (Li et al., 2014).

Table 2-1: Types of chemical used for membrane cleaning and foulants targeted

\begin{tabular}{|c|c|c|}
\hline Chemical Type & Examples & Target Foulants \\
\hline Acid & $\mathrm{HCl}$, Citric Acid & Metals \\
\hline Alkali & $\mathrm{NaOH}$ & $\begin{array}{c}\text { Acidic organics (phenols } \\
\text { and carboxyls) }\end{array}$ \\
\hline Oxidant & $\mathrm{NaOCl}$ & Organics \\
\hline
\end{tabular}

\subsubsection{Coagulation}

Chemical coagulation is the most popular UF pretreatment employed to reduce fouling (Matilainen et al., 2011). In principle, coagulation decreases UF fouling by agglomerating small NOM molecules via charge neutralization or sweep flocculation to prevent them from blocking or narrowing membrane pores and/or creating a looser cake layer of floc thereby allowing easier removal during backwash (i.e., greater hydraulic reversibility) (Barbot et al., 2008). Moreover, the increases in cake layer porosity was reported to decrease cake layer resistance (Lee et al., 2000).

Full-scale UF facilities often utilize inline coagulation, which does not include a sedimentation step after flocculation in order to reduce plant footprint (Zheng et al., 2012). An optimum coagulant dose for minimizing UF fouling may not be the same as that applied during conventional treatment, which often seeks to maximize dissolved organics or turbidity removal. In fact, it is advantageous to select a dose that preferentially targets UF foulants including 
biopolymers. When considering coagulant addition, Wray et al. (2014) determined that the point of diminishing returns for biopolymer removal $(0.5 \mathrm{mg} / \mathrm{L}$ alum $)$ to be much lower than the dose required to achieve charge neutralization. Furthermore, studies have reported UF fouling to be minimized at low coagulant doses $(<1 \mathrm{mg}$ metal/L) (Peleato et al., 2017; Tabatabai et al., 2009). Excess coagulant dosages typically associated with sweep flocculation have been shown to adversely impact membrane fouling. Through field emission scanning electron microscopy, Wray et al. (2016) observed aluminum precipitate deposits on the membrane surface which contributed to increase cake resistance. Moreover, it has been reported that sweep flocculation promotes a more compressible and less porous (i.e., more resistive) cake layer when compared to one under lower coagulant dosages (Lee et al., 2000).

Unfortunately, limited research exists regarding optimizing coagulation for protein removal or mitigating protein fouling. Moreover, the impact of coagulation on protein character and its fouling mechanisms is still unclear. Peleato et al. (2017) suggest that coagulation addition induces a conformational change in the protein that makes it more hydrophilic and thus less prone to fouling. Conversely, Ma et al. (2015) observed that fouling with synthetic bovine serum albumin (BSA) solutions was most severe at low coagulant concentrations due to changes in the particle size which was closer to the diameter of the membrane pores.

While coagulant dose can have a significant impact on fouling mitigation, it is also worth considering how coagulation is applied. A bench-scale experiment conducted by Pronk et al. (2016) suggested that applying ferric chloride inline only during the first half of a permeation cycle, instead of applying continuously, does not worsen fouling which in turn would reduce coagulant costs. Lok et al. (2017b) applied this strategy to a pilot-scale system using polyaluminum chloride $(\mathrm{PACl})$ and observed similar results. However, their results were highly variable which necessitates long-term (>2 days) filtration tests to comprehensively evaluate the benefits of phased coagulation. 


\section{Materials and Methods}

\subsection{Experimental Protocol}

\subsubsection{Water Selection}

Bench-scale studies were conducted with synthetically prepared solutions containing model proteins. Natural water matrices were not selected to avoid any potential interference from non-protein constituents from impacting protein fouling mechanisms. All solutions were prepared using distilled water (Elix ${ }^{\circledR}$ Advantage, Millipore Sigma). Bovine serum albumin (BSA, 66.4 kDa), ovalbumin (OVA, $42.7 \mathrm{kDa}$ ), and $\beta$-lactoglobulin (BLG, $18.4 \mathrm{kDa}$ ) were chosen as the model proteins (Millipore Sigma, Oakville, ON) due to their range in size and are commonly used as model membrane foulants in literature (Ko et al., 1993; Ma et al., 2014; Marshall et al., 1993). $20 \mathrm{mg} / \mathrm{L}$ BSA and 10mg/L BLG were dissolved in a $1 \mathrm{mM} \mathrm{NaCl}$ buffer while $20 \mathrm{mg} / \mathrm{L}$ OVA was dissolved in $10 \mathrm{mM} \mathrm{NaCl}$. Buffer concentrations were chosen to maximize protein surface hydrophobicity while remaining within the typical range of ionic strengths reported for natural waters (Haskard and Li-Chan, 1998; Luey et al., 1991). It was anticipated that increased protein surface hydrophobicity would strengthen interactions with the hydrophobic UF membrane and accelerate fouling.

\subsubsection{Coagulation}

Aluminum sulphate (alum, General Chemical) was selected as the coagulant for benchscale studies because it is the most commonly used coagulant in drinking water treatment which provides a good comparison to results reported in previous studies. Dosages (Table 3-1) were selected based on those identified in previous studies that minimized UF fouling (Peleato et al., 2017; Wray and Andrews, 2014), as well as values commonly applied at full-scale UF facilities (Wray et al., 2016). Inline coagulation was simulated by the addition of alum into the feed tanks which were continuously rapid mixed to prevent floc settling that may alter feed water quality between permeation cycles. $\mathrm{pH}$ was adjusted to $7.0 \pm 0.2$ using $\mathrm{HCl}$ and $\mathrm{NaOH}$ to counteract any reduction following coagulant addition, as protein fouling is known to be influenced by $\mathrm{pH}$ (Marshall et al., 1993). Mixing speed was monitored and adjusted if necessary throughout the experiment to avoid excessive foaming, which implies denaturation of proteins. Protein concentrations in the feed were monitored throughout the experiment and 
were verified to not have change by more than $9 \%$ between samples suggesting consistent water quality.

Table 3-1: Alum dosages examined for model protein solutions

\begin{tabular}{|c|c|}
\hline \multicolumn{2}{|c|}{ Alum Dose } \\
\hline $\boldsymbol{\mu M ~ A l}$ & $\mathbf{m g} / \mathbf{L}$ \\
\hline 0 & 0 \\
\hline 2 & 0.3 \\
\hline 10 & 1.7 \\
\hline 40 & 6.8 \\
\hline
\end{tabular}

At pilot-scale, polyaluminum chloride (PACl, PAX-XL1900, Kemira Water Solutions) was selected since the same is used at full-scale at Barrie Surface WTP. PACl is injected into the feed stream prior to flocculation (inline coagulation) before it reaches the membrane.

\subsection{Bench-Scale System}

Membrane fouling was studied at bench-scale using commercially available hollow fibre membranes (ZeeWeed ${ }^{\circledR}$ 500, SUEZ Water Technologies \& Solutions, Oakville, ON) composed of reinforced polyvinylidene fluoride (PVDF). Adapted from Lok et al. (2017a), the bench-scale system (Figure 3-1) was automated via a PLC program (WinLDR, IDEC Corporation) to cycle through the steps of a permeation cycle as follows: :1) A solenoid valve opening to fill the membrane tanks via gravity with approximately $1 \mathrm{~L}$ of water, 2) a peristaltic pump (Masterflex L/S 07528-30, Cole-Parmer) drawing feed water through the membrane, 3) reversing the flow direction of the peristaltic pump for backwash, and 4) draining the membrane tanks. Four bench-scale systems were operated in parallel to allow for multiple trials could be conducted simultaneously. TMP and permeate flux were recorded every $30 \mathrm{~s}(0.033$ $\mathrm{Hz}$ ) with a pressure transducer (PX-26, Omega Engineering, St-Eustache, QC) and an analytical balance (Symmetry 20000-41, Cole-Parmer, Montreal, QC), respectively via data logging software (LabView Signal Express 15.0, National Instruments, Vaudreuil-Dorion, QC). A five-point calibration (-5, -1, 0, 1, 5 psig) of the pressure transducers was performed prior to each trial with a Druck DPI 611 (GE Digital Solutions).

A new, 25-cm long membrane fibre was used for each trial, which has an area of approximately $0.0016 \mathrm{~m}^{2}$ and a nominal pore size of $0.04 \mu \mathrm{m}$. One end of the membrane was sealed while a $2 \mathrm{~mm}$ diameter PVC tubing (McMaster Carr, Cincinnati, OH) was attached to 
the other end with epoxy. The fibre was then cleaned by permeating an $800 \mathrm{mg} / \mathrm{L} \mathrm{NaOCl}$ solution for $3 \mathrm{~h}$ following by soaking in the same solution overnight. The integrity of each fibre was tested at the beginning and end of each trail using a bubble test at $35 \mathrm{kPa}(\sim 5 \mathrm{psi})$. If leaks were detected in the fibre, they were either resealed with epoxy or discarded. Cleaned membranes were then stored in $50 \mathrm{mg} / \mathrm{L} \mathrm{NaOCl}$ solution at $4{ }^{\circ} \mathrm{C}$ until use.

The pure water permeability (PWP) measures the maximum flux attained by a virgin membrane which in turn provides a measure of the intrinsic membrane resistance. The TMP of a membrane permeating distilled water at three different fluxes (approximately 20,30, and $40 \mathrm{LMH}$ ) for $2 \mathrm{~h}$ each was recorded and averaged. The PWP is estimated as the slope of the flux vs. TMP plot. PWP of membranes were ensured to be within $15 \%$ of each other to minimize the impact of intrinsic properties of the membrane (e.g., pore number and size) on fouling mechanisms. Sample calculations are shown in Section 8.1.

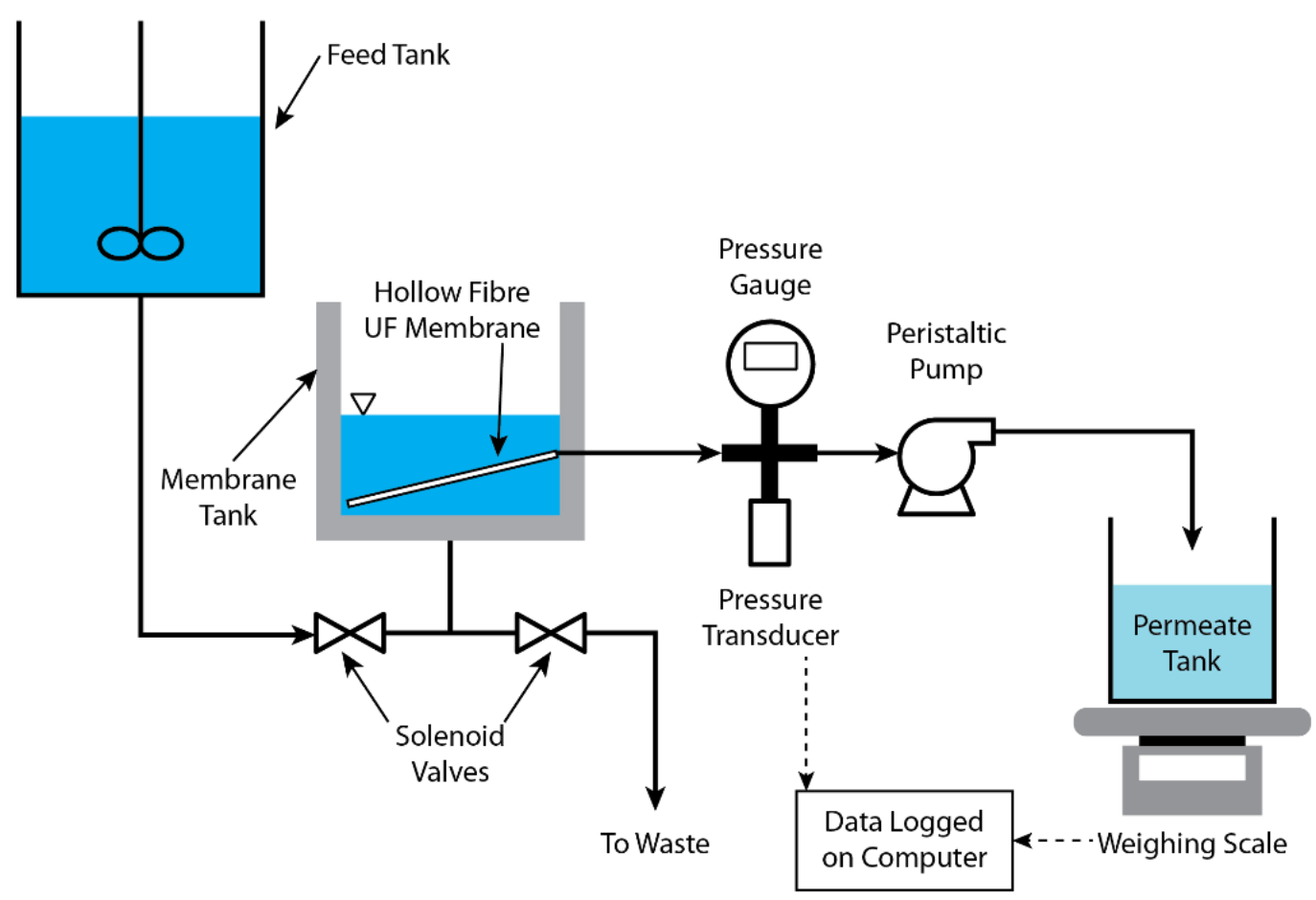

Figure 3-1: Schematic of typical bench-scale UF system 


\subsection{Pilot-Scale System}

Pilot-scale experiments were conducted at the Barrie Surface WTP (Barrie, ON). Previously described by Wray et al. (2016), the pilot plant contains a full ZeeWeed ${ }^{\circledR} 1000$ membrane module (Figure 3-2). It was fully automated to mimic full-scale treatment including inline coagulation with polyaluminum chloride (PACl, PAX-XL1900, Kemira Water Solutions), backwashing, and air sparging. Transmembrane pressure (TMP), feed and permeate turbidity, temperature, $\mathrm{pH}$, and particles counts were recorded every 5 minutes. Between each experimental trial, the membrane module was cleaned with $500 \mathrm{mg} / \mathrm{L} \mathrm{NaOCl}$ and $200 \mathrm{mg} / \mathrm{L}$ citric acid for $6 \mathrm{~h}$ each. A membrane integrity test was also conducted after every trial to identify any leaks in the system.

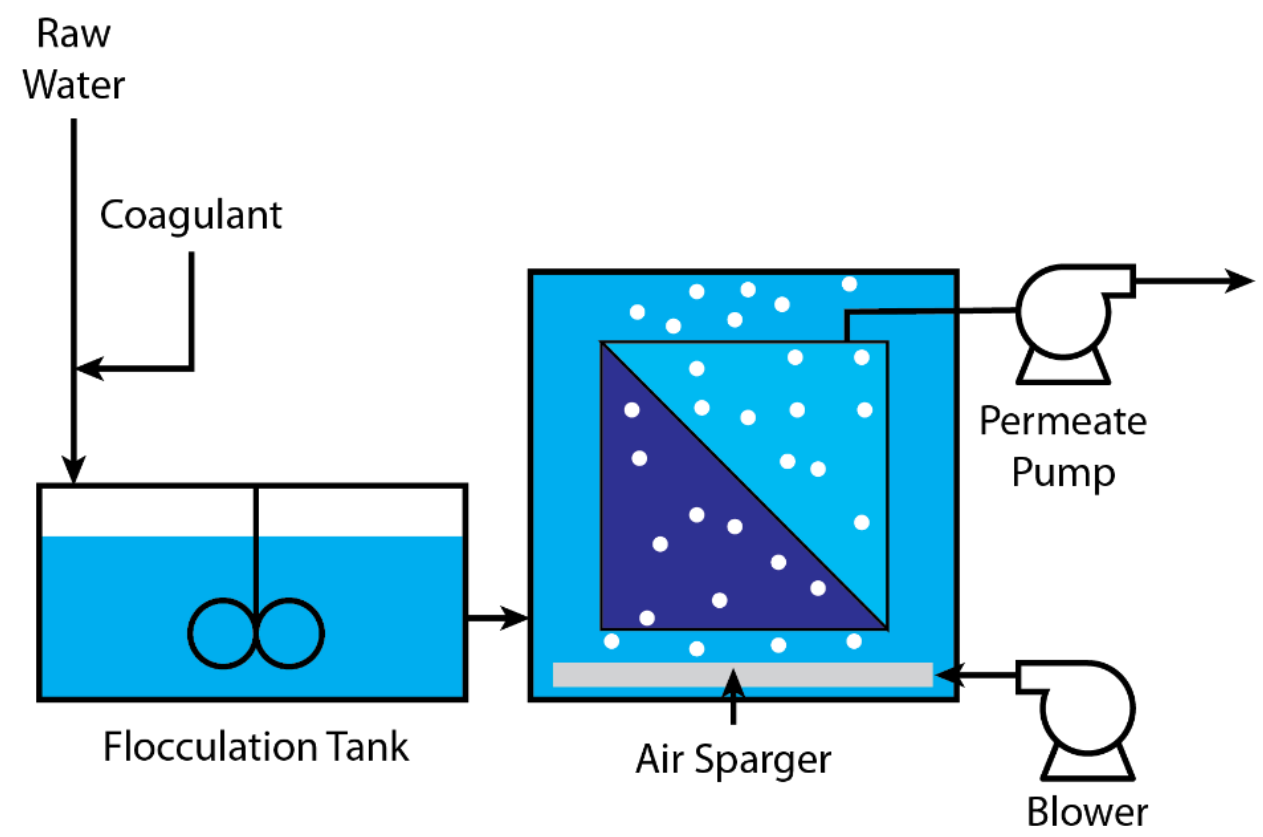

Figure 3-2: Schematic of pilot-scale UF system at Barrie Surface WTP 


\subsection{Analytical Methods}

\subsubsection{Protein Quantification}

Protein concentrations were approximated using a colorimetric assay (Micro BCA Kit, Thermo Fisher Scientific, Whitby, ON) as per manufacturer's instructions (microplate method). Each sample was prepared in duplicate. Calibration curves were obtained for each protein investigated (Figure 3-3).

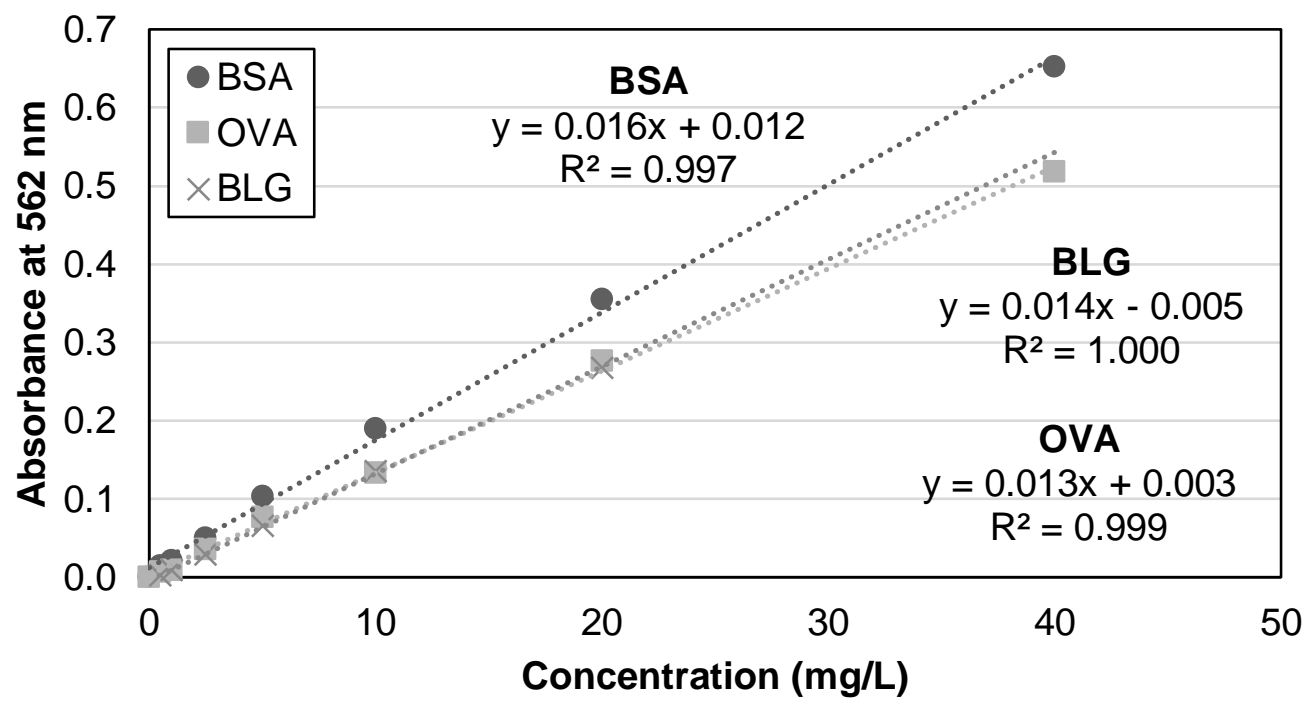

Figure 3-3: Example calibration curve for protein quantification via colorimetric assay

\subsubsection{Protein Size and Surface Charge}

The hydrodynamic radius $(\mathrm{nm})$ and zeta potential $(\mathrm{mV})$ of proteins were measured using a Horiba SZ-100 (Mississauga, ON) with disposable carbon electrode cells. Analysis consisted of 10 pulse measurements with a $5 \mathrm{~s}$ delay between measurements. Three measurements were made per sample and were all analyzed at $25^{\circ} \mathrm{C}$.

\subsubsection{Fluorescence Spectroscopy}

Fluorescence excitation-emission matrices (FEEMs) were collected using a Cary Eclipse fluorescence spectrophotometer (Agilent, Mississauga, ON) with a quartz cuvette. Excitation and emission wavelength ranges (ex/em) were $230-380 \mathrm{~nm}(5 \mathrm{~nm}$ increments) and 280-400 $\mathrm{nm}$ (2 $\mathrm{nm}$ increments) respectively. Instrument conditions such as photomultiplier tube (PMT) voltage $(450 \mathrm{~V})$ and slit widths $(10 \mathrm{~nm})$ were kept constant to maintain 
comparability between samples. Cuvettes were rinsed with Milli- $\mathrm{Q}^{\circledR}$ water between samples. The collected spectra were smoothed with Savitzky-Golay filter with a window size of 7 to reduce data noise (Savitzky and Golay, 1964) (Figure 3-4).

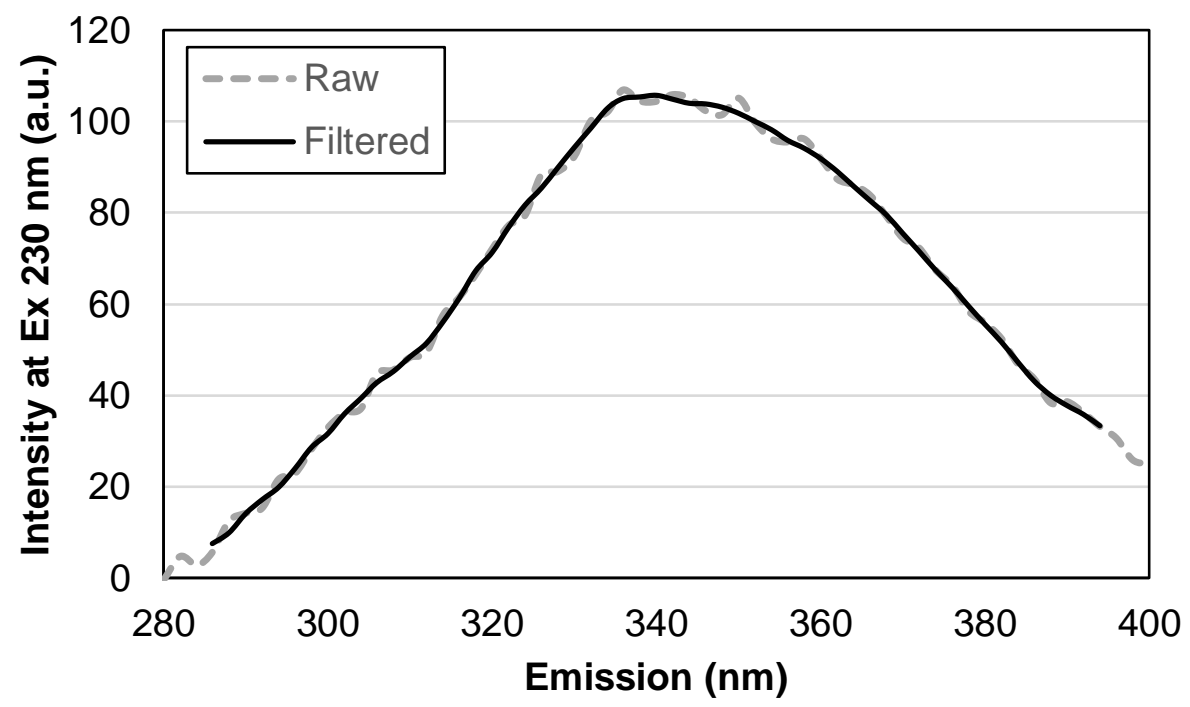

Figure 3-4: Raw and processed (via Savitzky-Golay filter) sample spectra of BSA fluorescence emission at $230 \mathrm{~nm}$ excitation

\subsubsection{Protein Surface Hydrophobicity Fluorescence Assay}

The surface hydrophobicity of a protein was measured using a fluorescence assay using 1-anilinonaphthalene-8-sulfonate (ANS) as a fluorescent probe. Upon binding of ANS to the hydrophobic areas of a protein, an increase in fluorescent intensity and blue shift is observed (Figure 3-5). Adapted from the procedure performed by Haskard and Li-Chan (1998), samples were serially diluted using the same buffer solution into $5 \mathrm{~mL}$ aliquots of different concentrations in test tubes. $20 \mu \mathrm{L}$ of $8 \mathrm{mM}$ ANS was added into each test tube and gently mixed before left to stand for $10 \mathrm{~min}$. The fluorescent intensity of each sample at ex/em $370 / 490 \mathrm{~nm}$ was measured in a quartz cuvette at a $750 \mathrm{~V}$ photomultiplier tube voltage and 10 $\mathrm{nm}$ slit width. Cuvettes were rinsed with Milli-Q ${ }^{\circledR}$ between samples. Sample calculations are detailed in Section 8.2. 


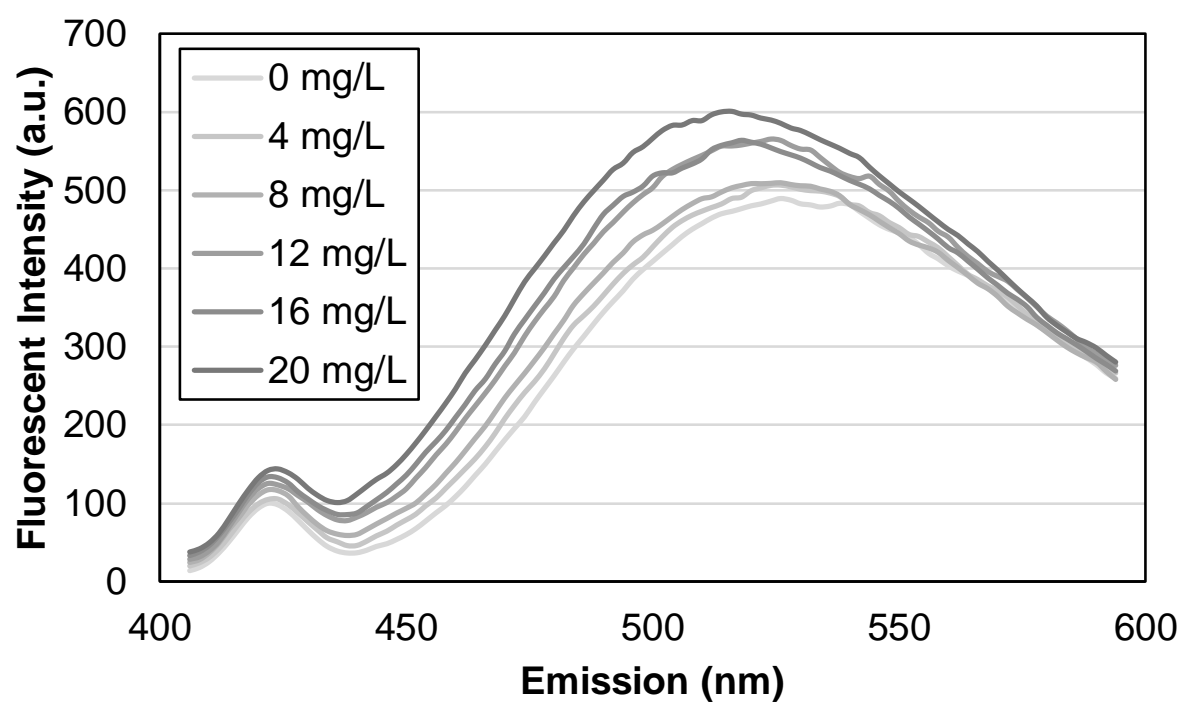

Figure 3-5: Variation in fluorescence emission spectrum of ANS (ex $370 \mathrm{~nm}$ ) at various OVA concentrations $(0-20 \mathrm{mg} / \mathrm{L})$. Increasing concentration (darker colour) corresponds to blue shift and increase in intensity.

\subsubsection{Dissolved Organic Carbon}

Dissolved organic carbon (DOC) was analyzed using a wet oxidation method based on the Standard Method 5310D on an O-I Corporation Model 1010 Analytical TOC Analyzer with a Vial Multisampler (OI Analytical, College Station, TX). Samples were first filtered through a $0.45 \mu \mathrm{m}$ filter to remove particulates before being collected into $40 \mathrm{~mL}$ amber vials and sealed with Teflon-lined septum screw caps. All samples were prepared on the day of collection, stored at $4{ }^{\circ} \mathrm{C}$, and analyzed within a week. A summary of instrument conditions and reagents are presented in Table 3-2 and Table 3-3, respectively.

Table 3-2: DOC analyzer conditions

\begin{tabular}{|l|l|}
\hline \multicolumn{1}{|c|}{ Parameter } & \multicolumn{1}{c|}{ Description } \\
\hline Acid & $200 \mu \mathrm{L}$ of $5 \%$ phosphoric acid \\
\hline Oxidant & $1000 \mu \mathrm{L}$ of $100 \mathrm{~g} / \mathrm{L}$ sodium persulphate \\
\hline Sample Volume & $15 \mathrm{~mL}$ \\
\hline Rinses per sample & 1 \\
\hline Volume per rinse & $15 \mathrm{~mL}$ \\
\hline Reaction time & $2 \mathrm{~min} 30 \mathrm{sec}$ \\
\hline Detection time & $2 \mathrm{~min}$ \\
\hline Purge gas & Nitrogen \\
\hline Loop size & $5 \mathrm{~mL}$ \\
\hline
\end{tabular}


Table 3-3: List of reagents used in DOC analysis

\begin{tabular}{|l|l|}
\hline \multicolumn{1}{|c|}{ Reagent } & \multicolumn{1}{c|}{ Supplier and Purity } \\
\hline Sulphuric acid & VWR, 98+\% \\
\hline Potassium hydrogen phthalate & Sigma, 98+\% \\
\hline Sodium persulphate & Sigma, 98+\%, anhydrous \\
\hline Phosphoric acid & Sigma, $\geq 85 \%$ \\
\hline
\end{tabular}

DOC concentrations were determined using anhydrous potassium hydrogen phthalate (KHP) as a calibration standard. The calibration solution was prepared at $10 \mathrm{mg} / \mathrm{L}$ before the analyzer dilutes it to concentrations of $5,2.5,1.25,0.625$, and $0 \mathrm{mg} / \mathrm{L}$ to form a 6-point calibration (Figure 3-6). Check standards (3 mg/L) and Milli- ${ }^{\circledR}$ blanks were analyzed after every 10 samples to ensure the calibration remains valid.

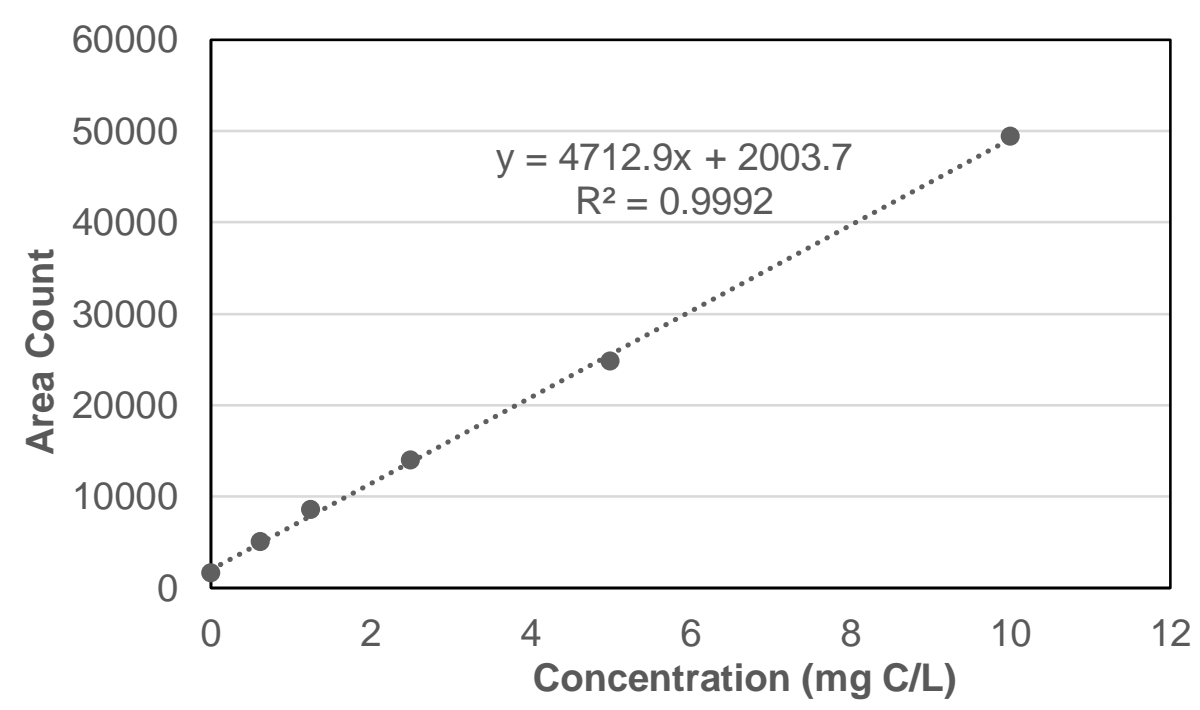

Figure 3-6: Example DOC calibration curve using potassium hydrogen phthalate 


\subsubsection{Liquid Chromatography-Organic Carbon Detection}

Liquid chromatography-organic carbon detection (LC-OCD) was used to characterize DOC based on size and structure. LC-OCD fractionates DOC into five categories: biopolymers, humic substances, building blocks, low molecular weight acids, and low molecular weight neutrals. These classifications allow for the identification of NOM components that are responsible for UF fouling and subsequently be used to evaluate their removal with fouling control strategies such as coagulation.

Water samples were filtered through a $0.45 \mu \mathrm{M}$ filter, collected in $40 \mathrm{~mL}$ carbon-free (via heat treatment in muffle furnace) sample vials and stored in $4{ }^{\circ} \mathrm{C}$ until analysis (within two weeks). The samples were analyzed at the University of Waterloo following the procedure described by Huber et al. (2011) and the collected data was processed using customized software (ChromCALC, DOC-LABOR, Karlsruhe, Germany).

\subsection{Statistical Methods}

A linear regression was used to model fouling (total, irreversible, or reversible) as a function of permeation time. A two-tailed t-test was used to determine significant differences between the fouling rate of protein solutions with and without coagulant addition at a $5 \%$ confidence level $(\alpha=0.05)$. A $15 \%$ confidence interval was selected for pilot-scale experiments to reflect the greater variability between replicates. The t-statistic was calculated in Microsoft Excel according to equation [3.1:

$$
t=\frac{b_{1}-b_{2}}{\sqrt{S E_{1}{ }^{2}+S E_{2}{ }^{2}}}>\left|t_{\alpha, n_{1}+n_{2}-4}\right|
$$

where, $b_{1}, b_{2}$ are the slopes of the two linear models

$S E_{1}, S E_{2}$ are the standard errors of the slopes

$n_{1}, n_{2}$ are the number of points in each model

The $95 \%$ confidence intervals $(C I)$ of the slopes were calculated using equation [3.2:

$$
C I_{1}=b_{1} \pm t_{0.05, n_{1}-2} \cdot S E_{1}
$$




\section{Impact of Low Coagulant Dosages on the Protein Fouling of Ultrafiltration Membranes}

\subsection{Introduction}

Ultrafiltration (UF) has become increasingly prevalent in drinking water treatment, however, its broader application is primarily hindered by fouling. Fouling increases the resistance to flow, which in turn increases energy requirements needed to ensure constant water production. Although hydraulic backwashing is regularly performed to remove accumulated foulants (i.e., hydraulically reversible fouling), it typically does not fully restore permeability. Applying chemical cleaning can remove hydraulically irreversible fouling, however, this process typically involves the use of harsh chemicals that may compromise membrane integrity (Porcelli and Judd, 2010). Thus, there is a demand for sustainable strategies to improve the hydraulic reversibility of fouling which maximizes membrane efficiency.

Natural organic matter (NOM) significantly contributes to reversible and irreversible fouling of UF membranes when applied to drinking water treatment (Howe et al., 2006). In particular, the biopolymer fraction (proteins and polysaccharides) has been identified as containing primary UF foulants (Amy, 2008; Zheng et al., 2012). While the concentration of biopolymers is of importance when predicting membrane fouling, the specific composition of biopolymers should be considered as well (Hallé et al., 2009); most existing research has only examined the contribution of the biopolymer fraction as a whole (Kimura et al., 2014; Siembida-Losch et al., 2015; Wray and Andrews, 2014). It is therefore worth investigating the types of compounds that comprise the biopolymer fraction and their relative contributions to fouling, since they may each have unique properties that influence fouling behaviour. Previous studies have demonstrated that proteins are primarily responsible for hydraulically irreversible fouling (Peiris et al., 2010; Peldszus et al., 2011; Peleato et al., 2017).

Protein-related fouling of UF membranes occurs in two stages. Initially, a monolayer of proteins is adsorbed onto the membrane surface which is largely governed by proteinmembrane interactions (Huisman et al., 2000). Subsequently, deposition and/or adsorption onto this monolayer occurs, such that protein-protein interactions become significant (Wang et al., 2013). It is therefore beneficial to gain an understanding of the physicochemical properties of proteins, including size, surface charge and hydrophobicity, since these govern 
protein interactions (i.e., fouling potential) with both the membrane and the fouling layer (Gao et al., 2011). Fouling mechanisms can be complex as a combination of competitive phenomena often exist such as size exclusion, electrostatic attraction/repulsion, and hydrophobic interactions (Huisman et al., 2000). Therefore, elucidating the characteristics and mechanisms responsible for UF fouling can potentially lead to the development of effective fouling mitigation strategies.

Applying chemical coagulation prior to UF is believed to reduce fouling by aggregating NOM to form a less resistive and more hydraulically reversible fouling layer (Barbot et al., 2008). An optimum coagulant dose for minimizing UF fouling may not be the same as that applied during conventional treatment, which often seeks to maximize turbidity removal. Previous studies have reported that UF fouling is minimized at coagulant dosages much lower ( $<1 \mathrm{mg}$ metal/L) than what is required to achieve charge neutralization (Peleato et al., 2017; Tabatabai et al., 2009; Wray and Andrews, 2014). Furthermore, a low coagulant dose $(<0.5$ $\mathrm{mg} / \mathrm{L}$ alum) has been associated with the point of diminishing returns for biopolymer removal (Wray and Andrews, 2014). Unfortunately, limited research exists regarding the effect of coagulation on protein fouling of UF membranes. Moreover, the impact of coagulation, particularly at low doses, on protein character and its fouling mechanisms is still unclear. Peleato et al. (2017) suggest that coagulation addition induces a conformational change in the protein that makes it more hydrophilic and thus less prone to fouling. Conversely, Ma et al. (2015) observed that fouling with synthetic bovine serum albumin (BSA) solutions was most severe at low coagulant concentrations due to changes in the particle size which was closer to the diameter of the membrane pores.

The main objective of this study was to specifically examine the impact of coagulation on protein fouling of UF membranes. By using synthetic protein solutions, it can be confirmed whether low coagulant doses are capable of altering the protein fraction to reduce fouling, as suggested by previous studies (Peleato et al., 2017; Wray and Andrews, 2014). Additionally, trials conducted over the course of $48 \mathrm{~h}$ with periodic backwashing allowed for better mimicking of full-scale conditions and evaluation of the effect of coagulation on the hydraulic reversibility of protein fouling. 


\subsection{Materials and Methods}

\subsubsection{Model Solutions}

Feed waters containing $20 \mathrm{mg} / \mathrm{L}$ bovine serum albumin (BSA), $20 \mathrm{mg} / \mathrm{L}$ ovalbumin (OVA), or $\beta$-lactoglobulin (BLG) were prepared as described in Section 3.1.1. These globular proteins were selected to provide a range in size and are commonly used as model membrane foulants in literature (Ko et al., 1993; Ma et al., 2014; Marshall et al., 1993).

\subsubsection{Membrane Filtration}

Bench-scale modules were fabricated in-house using commercially available hollow fibre membranes (ZeeWeed ${ }^{\circledR}$ 500, SUEZ Water Technologies \& Solutions) composed of reinforced polyvinylidene fluoride (PVDF). The membrane area in each $25 \mathrm{~cm}$-long fibre was approximately $0.0016 \mathrm{~m}^{2}$ and with a nominal pore size of $0.04 \mu \mathrm{m}$. New membranes used for each trial were prepared according to the steps outlined in Section 3.2. Intrinsic permeability of each fibre was determined (Section 8.1) to ensure that membranes were within $15 \%$ of each other. This step helped minimize the intrinsic differences among fibres from influencing the types of fouling mechanisms during permeation.

Four bench-scale systems (Figure 3-1) were operated in parallel; each was automated to cycle through the steps of a permeation cycle as described in Section 3.2. Each trial consisted of 12 permeation cycles (total of $48 \mathrm{~h}$ of permeation) or until transmembrane pressure (TMP) reached $40 \mathrm{kPa}$. Permeation and backwash flux was kept constant at $30 \mathrm{~L} \mathrm{~m}^{-2} \mathrm{~h}^{-1}$. TMP and permeate flow were recorded every $30 \mathrm{~s}$. Feed, permeate, and reject (water drained from membrane tank at the end of a permeation cycle) samples were collected at 24 and $48 \mathrm{~h}$ during each trial. Each trial was conducted in duplicate except for BLG which was only conducted once.

Membrane fouling during each permeation cycle was quantified using a resistance-inseries model that has previously been used in fouling studies (Peleato et al., 2017; Wray et al., 2014). This model defines total resistance $\left(\mathrm{R}_{\mathrm{T}}\right)$ as the sum of the intrinsic membrane resistance $\left(R_{m}\right)$ and resistance due to fouling $\left(R_{f}\right)$, both irreversible $\left(R_{i r r}\right)$ and reversible $\left(R_{r e v}\right)$. As shown in Figure S2, irreversible fouling is defined as the resistance that cannot be removed at the end of a backwash relative to the intrinsic membrane resistance. Conversely, reversible fouling is 
defined as the fouling resistance that was removed by backwash at the end of a permeation cycle.

\subsubsection{Inline Coagulation}

Inline coagulation conditions (coagulation and flocculation only) were simulated by addition of alum (General Chemical; $0.043 \mathrm{mg} \mathrm{Al} / \mathrm{mg}$ coagulant added), which was continuously rapid mixed to prevent floc settling that may alter feed water quality between permeation cycles. Coagulant doses (Table 3-1) were selected based on those identified in previous fouling minimization studies (Peleato et al., 2017; Wray and Andrews, 2014), as well as values commonly applied at full-scale UF facilities that utilize inline coagulation pretreatment (Wray et al., 2016).

\subsubsection{Protein Characterisation}

Zeta potential of the feed solution was measured as described in Section 3.4.2. Surface hydrophobicity of proteins in the feed, permeate, and reject was determined by a fluorescence assay using 1-anilinonaphthalene-8-sulfonate (ANS) as a fluorescent probe (Section 3.4.4)

\subsection{Results}

\subsubsection{Membrane Fouling}

When considering BSA and OVA solutions, a $2 \mu \mathrm{M}$ Al dose $(0.3 \mathrm{mg} / \mathrm{L}$ alum $)$ contributed to a significant reduction $(\mathrm{p}<0.05)$ in hydraulically reversible and irreversible fouling rates when compared to no coagulant addition (Figure 4-1, see Section 8.4.1 for resistance values). Increasing coagulant dose (10 and $40 \mu \mathrm{M} \mathrm{Al})$ was shown to exacerbate fouling, which may be indicative of alum and its hydrolysis products being a membrane foulant (Kimura et al., 2008). These results also indicate that irreversible fouling generally develops at a faster rate than reversible fouling. Protein fouling is a predominantly irreversible phenomenon, which is in agreement with previous membrane studies (Peiris et al., 2013; Peldszus et al., 2011). Interestingly, similar results of a low coagulant dose being effective in mitigating fouling were observed in membrane studies conducted on natural surface water (Peleato et al., 2017; Tabatabai et al., 2009; Wray and Andrews, 2014). This similarity in fouling trends between model solutions and natural waters suggests that proteins are the 
predominant membrane foulants in natural waters which is in agreement with previous studies (Peiris et al., 2013; Peldszus et al., 2011; Zheng et al., 2012).
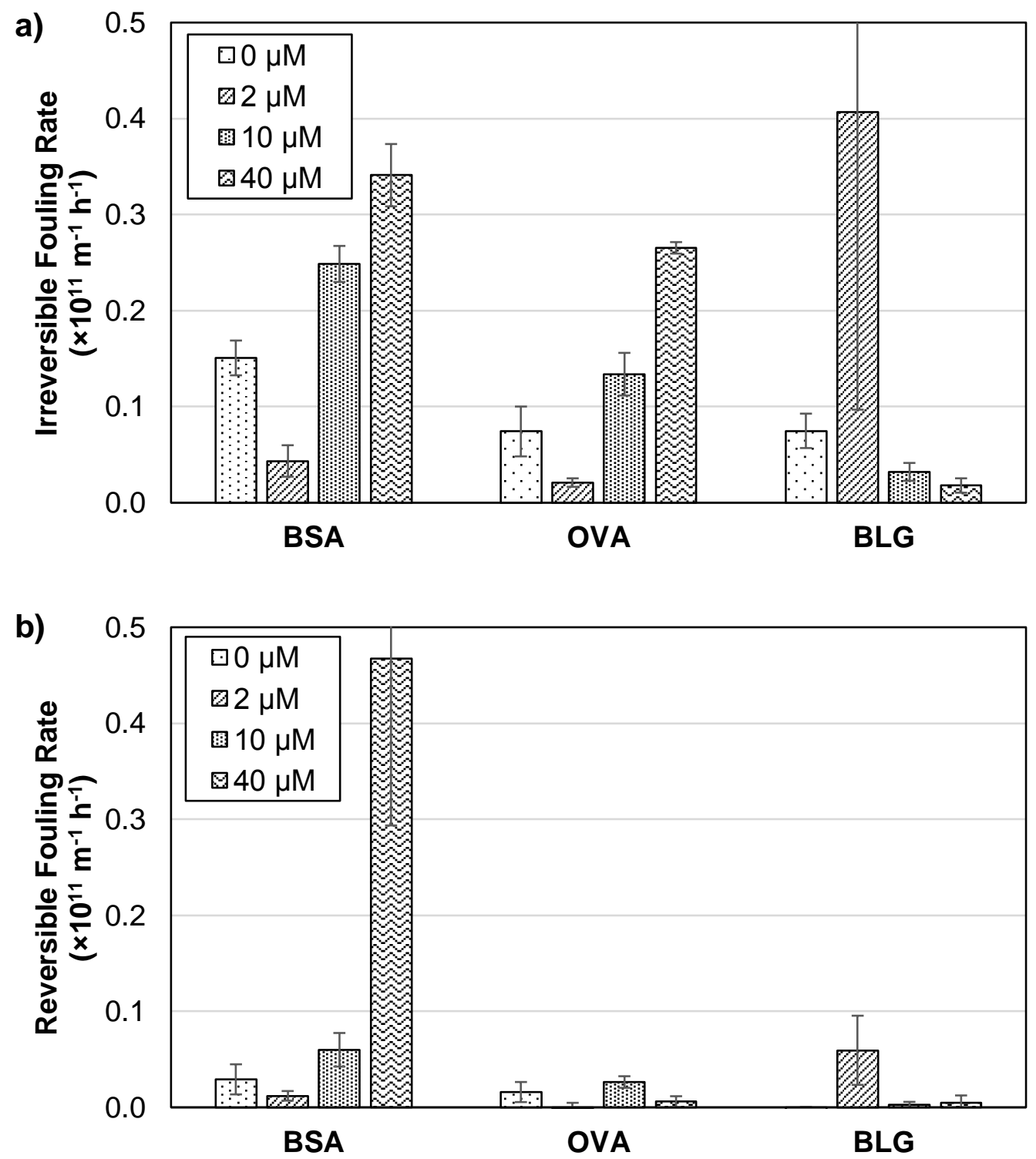

Figure 4-1: (a) Hydraulically irreversible and (b) reversible fouling rates associated with 20 $\mathrm{mg} / \mathrm{L}$ of bovine serum albumin (BSA), $20 \mathrm{mg} / \mathrm{L}$ ovalbumin (OVA), and $10 \mathrm{mg} / \mathrm{L} \beta$ lactoglobulin (BLG) for a range of coagulant doses. Vertical bars represent the $95 \%$ confidence interval calculated from the standard error of the fouling rate $(\mathrm{n}=11)$.

Contrasting fouling trends were observed for BLG where dosages of $40 \mu \mathrm{M}$ and $2 \mu \mathrm{M}$ resulted in the least and most fouling, respectively. A potential explanation may lie in the difference in character when comparing BLG and BSA/OVA. It is common for proteins to undergo conformational changes upon adsorption to a solid surface to minimize free energy 
(Rabe et al., 2011). As such, it is possible that the proteins in the surface cake layer have different properties than proteins in the bulk solution which ultimately impacts fouling behaviour. Intermediate size proteins including BSA and OVA have been reported as being 'soft', implying that they are more likely to undergo structural alterations upon surface contact unlike 'hard' proteins such as BLG (Pérez-Fuentes et al., 2017). Therefore, differences in cake layer properties may be responsible for varying fouling trends. Nonetheless, the contrasting results demonstrate that proteins do not always respond consistently to coagulant addition. Furthermore, it highlights the complexity of NOM, whereby even within the biopolymer fraction there exists a wide assortment of compounds, each with their own unique properties and response to treatment.

\subsubsection{Protein Rejection}

Proteins rejected (as \%) by the membrane for a range of alum doses after $24 \mathrm{~h}$ of permeation indicated that BSA and OVA passes through to the greatest extent when $2 \mu \mathrm{M} \mathrm{Al}$ is added (Figure 4-2a), suggesting that interactions between proteins in the bulk solution and the membrane surface/fouling layer are at a minimum. Similar trends were observed after 48 $\mathrm{h}$ of permeation as well, but not shown (see Section 8.4.2 for concentration values). As shown in Figure 4-2b, increased rejection significantly increases irreversible fouling for OVA ( $p=$ $4 \times 10^{-4}$ ), in agreement with trends suggested by Marshall et al. (1993). However, the relationship is not significant for OVA $(p=0.056)$. Nonetheless, their trends suggest less fouling comes at the expense of lower protein removal. Once again, contrasting results were observed with BLG in which an increasing alum dose was associated with greater, albeit insignificant $(p=0.20)$, protein rejection. This difference in trends suggests that the predominant fouling mechanism for BLG differs from that of BSA and OVA. It is also interesting that the magnitude of irreversible fouling for BLG is relatively lower despite similar removals as BSA and OVA, which implies a difference in fouling layer. 

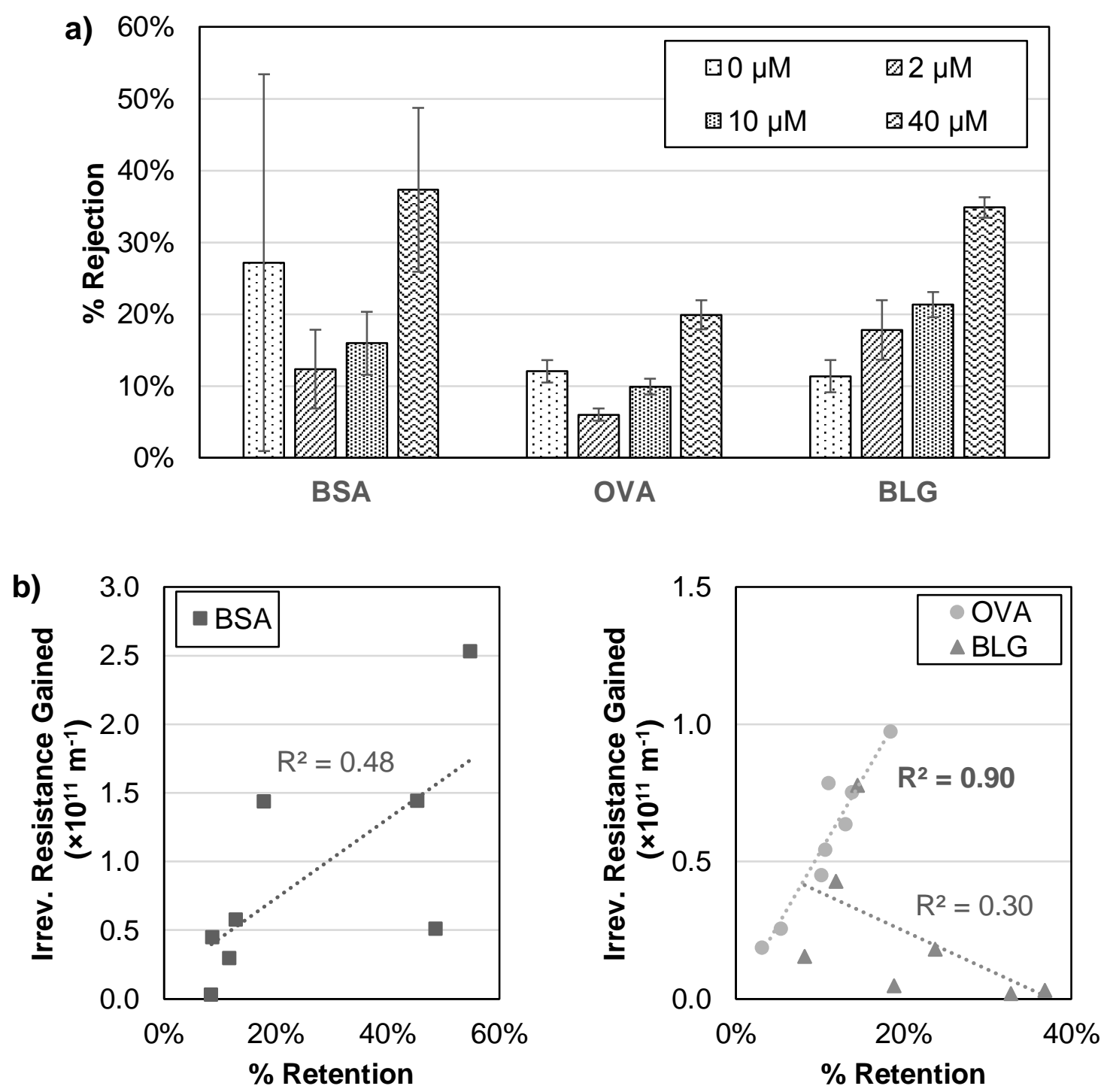

Figure 4-2: (a) Rejection of proteins (\%) by UF for a range of alum dosages (as $\mu \mathrm{M} \mathrm{Al}$ ) after $24 \mathrm{~h}$ of permeation. Similar trends were seen after $48 \mathrm{~h}$ of permeation (not shown). Vertical bars of BSA and OVA represent the standard deviation of duplicate trials. Vertical bars of BLG represent the standard deviation of duplicate analyses. (b) Relationship between rejection of proteins by UF and irreversible fouling resistance gained during a permeation cycle. Bold $\mathrm{R}^{2}$ values indicates a significant correlation $(p<0.05, \mathrm{n}=7$ or 8$)$.

\subsubsection{Protein Properties}

The underlying rationale for explaining why a low coagulant dose may be effective in mitigating protein fouling likely rests in how a protein interacts with the membrane surface. While the characteristics of a membrane are important when considering protein-membrane 
interactions, a stronger focus may be needed when considering protein properties (e.g., size, surface charge, and hydrophobicity) and how they may change following coagulation. Ma et al. (2014) demonstrated that increasing $\mathrm{AlCl}_{3}$ dose increases the average particle size of a synthetic BSA solution. With this is mind, it is anticipated that increasing coagulant dose should reduce fouling, but this was not apparent in the results of the current study where the highest coagulant doses (10 and $40 \mu \mathrm{M} \mathrm{Al})$ resulted in the most fouling. Thus, it is unlikely that size exclusion is the fouling mechanism being impacted by low coagulant doses.

Alum addition introduces aluminum cations into the water matrix which can alter the overall surface charge of proteins and its electrostatic interactions with the membrane. An inspection of zeta potential indicates that increasing coagulant dose (i.e., cation addition) generally reduces the overall surface charge of the proteins (Figure 4-3, see Section 8.4.3 for raw values). As a result, the reduced magnitude typically increases the electrostatic attraction between proteins which promote aggregation and deposition onto the membrane surface, causing more severe fouling (Choi and Dempsey, 2004). However, the fouling observed at a 2 $\mu \mathrm{M} \mathrm{Al}$ dose was less than that with no coagulant which contradicts this trend. Moreover, the change in zeta potential of OVA with increasing alum dose is lower than that of BSA despite similar fouling trends. Thus, changes in the overall surface charge attributed to coagulation do not appear to be responsible for the observed fouling trends.

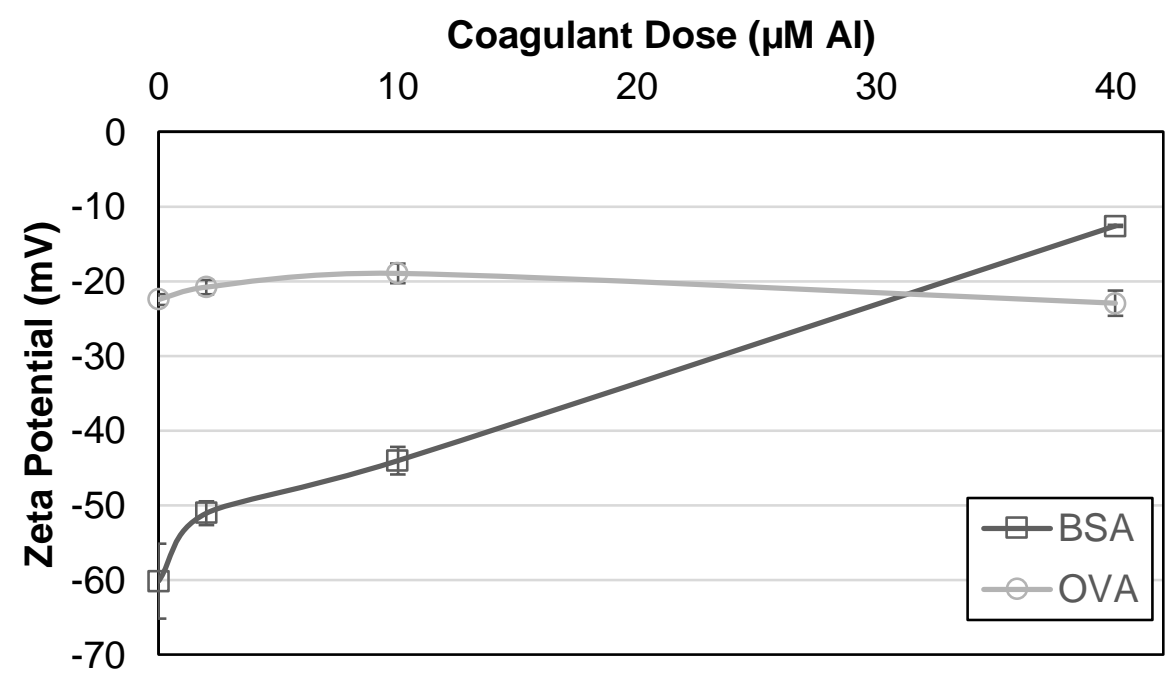

Figure 4-3: Zeta potential of BSA and OVA as a function of coagulant dose. Vertical bars represent standard deviation of triplicates. Values for BLG were not collected. Lines illustrate overall trends between measurements. 
Protein structure is highly sensitive to the polarity of its environment (Vivian and Callis, 2001). Thus, changing the ionic environment via coagulant addition can induce structural changes in proteins which can then affect their surface properties. An assessment of the surface hydrophobicity of BSA in the feed, permeate, and reject (Figure 4-4, see Section 8.4.4 for values) indicate that the proteins in the permeate tend to be more hydrophilic, which is supported by the fact that hydrophilic compounds interact less with the hydrophobic PVDF membrane. Interestingly, the hydrophobicity of permeate proteins reaches a maximum at $2 \mu \mathrm{M}$ Al, which should imply greater interactions with the membrane and more fouling, however, this was not the case. A potential explanation may be attributed to interactions between the protein and the fouling layer, not the membrane surface. Since the each trial was conducted over the course of $48 \mathrm{~h}$, it is likely that the protein-protein interactions associated with the second stage of fouling as described by Huisman et al. (2000) became dominant, dictating irreversible fouling (Wang et al., 2013). Upon adsorption, proteins often undergo conformational changes to reduce the free energy in the system (Marshall et al., 1993). Therefore, the properties of proteins in the fouling layer differ from those in the bulk solution or the properties of a clean membrane surface. Peleato et al. (2017) observed that following the addition of low coagulant doses, the surface fluorescence of fouled membranes exhibited greater tryptophan intensity than those under high doses. The increase in tryptophan intensity is associated with greater exposure of tryptophan residues, which implies increased hydrophilicity. As such, the permeate proteins under the influence of $2 \mu \mathrm{M}$ Al will interact with the fouling layer the least, resulting in less deposition and irreversible fouling.

Unfortunately, the ANS fluorescence assay did not provide observable results for OVA and BLG. A possible explanation may be that the protein concentrations in this experiment were less than half of those reported in other studies that perform ANS fluorescence assays (Alizadeh-Pasdar and Li-Chan, 2000; Cardamone and Puri, 1992; Delahaije et al., 2013; Haskard and Li-Chan, 1998). Compounded by the fact that quantum yield of ANS after binding with OVA and BLG is lower than that with BSA (Alizadeh-Pasdar and Li-Chan, 2000; Cardamone and Puri, 1992), the fluorescence response of OVA and BLG became insufficient. Laligant et al. (1991) also reported that ANS is not sensitive enough to study BLG hydrophobicity due to its low binding affinity to BLG. Although surface hydrophobicity may offer an explanation as to why low inline coagulant doses are effective in reducing UF fouling, 
further investigation into the properties of the fouling layer, the membrane surface, and the bulk protein under low coagulant dose conditions is needed.

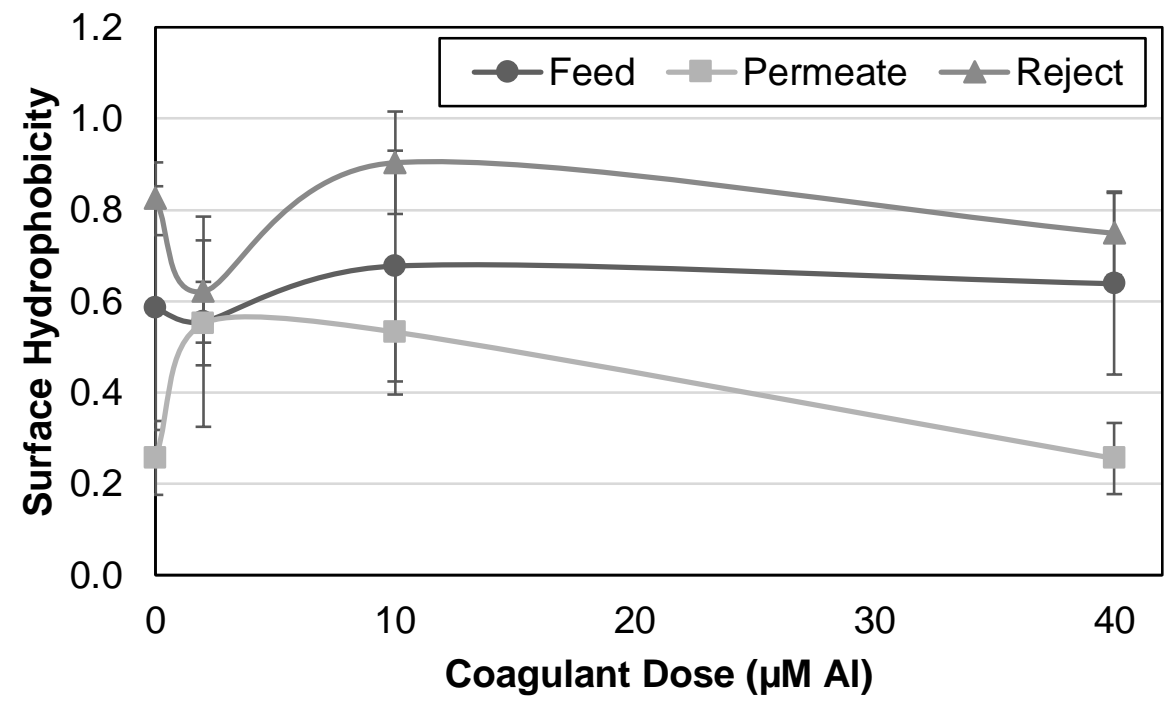

Figure 4-4: Surface hydrophobicity of BSA in feed, permeate, and reject determined using ANS fluorescence assay. Vertical bars represent the standard error of the slopes of the fluorescence intensity vs. protein concentration plot $(n=5)$. Lines illustrate overall trends between measurements. 


\subsection{Conclusions}

Ultrafiltration of three model protein solutions were conducted to better understand the fundamental mechanisms associated with membrane fouling. Results indicated that the addition of low amounts of coagulant $\left(0.3 \mathrm{mg} / \mathrm{L}\right.$ alum or $\left.2 \mu \mathrm{M} \mathrm{Al}^{3+}\right)$ significantly reduced hydraulically irreversible and reversible fouling for BSA and OVA solutions when compared to no coagulation. Previous studies focused on natural surface water have suggested that proteins may be the predominant foulant when considering biopolymers and are preferentially impacted by low coagulant dosages (Peleato et al., 2017; Wray and Andrews, 2014). Furthermore, this suggests that BSA and OVA may serve as suitable surrogates for proteins in natural waters. Although contrasting results were observed for BLG, it highlights the complexity of protein structure and how they can respond differently under the same conditions. An optimal low coagulant dose was observed, as further alum addition was shown to exacerbate reversible and irreversible fouling. Irreversible fouling was associated with greater transmission of proteins, implying fouling mitigation was not due to the formation of a more porous fouling layer. Moreover, this tradeoff must be considered when designing a treatment process, as increased organics concentrations in the UF permeate may adversely impact downstream processes.

Through the use of ANS fluorescence assays, it was observed that proteins that permeate through the membrane tend to be hydrophilic. This is likely due to the fact that hydrophilic compounds weakly interact with the hydrophobic PVDF membrane. A low coagulant dose appears to alter bulk protein conformation which in turn likely alters the character of the monolayer adsorbed onto the membrane surface. Thus, interactions between the bulk proteins and the fouling layer were weakened, resulting in less fouling. Nonetheless, further investigation into the properties of proteins and fouling layer under the influence of a low coagulant dose is necessary to better understand the complexities of protein fouling when considering UF membranes. 


\section{Impact of Phased Coagulation on Membrane Fouling}

\subsection{Introduction}

Ultrafiltration (UF) has become increasingly popular in drinking water treatment for its small footprint relative to conventional media filters and its ability to remove particulates and microorganisms consistently (Gao et al., 2011). However, its efficiency is largely constrained by fouling. The adsorption or deposition of feed water constituents onto the membrane surface reduces permeability and increases energy consumption. Thus, a significant portion of operating costs of UF is devoted to fouling control and removal strategies such as hydraulic backwashing, chemical cleaning, and coagulation.

Natural organic matter (NOM) is a major source of reversible and irreversible fouling for UF membranes. Previous research has identified biopolymers and humic substances (Jermann et al., 2007) as the primary classes of NOM responsible for UF fouling. It is suggested that UF fouling occurs in two stages. Initially, a monolayer of foulants adsorb onto the membrane surface though electrostatic and hydrophobic interactions between the foulants and the membrane surface. Afterwards, additional foulants deposit on top of this adsorbed monolayer throughout permeation (Huisman et al., 2000). Although cake resistivity increases as a results, it has been suggested that the fouling layer can also alter the selectivity of the membrane to remove smaller organic components and reduce irreversible fouling (Wray et al., 2016).

Coagulation is considered to be the most effective pretreatment method for membrane fouling reduction (Huang et al., 2009). The addition of a coagulant into feed water results in the formation of cationic species that agglomerates with the negatively charged NOM into large, settleable particles. However, coagulation pretreatment for UF membranes is often applied without flocculation and/or sedimentation (i.e., inline coagulation) to reduce the footprint of the facility (Choi and Dempsey, 2004). Inline coagulation has been shown to inhibit adsorption of foulants onto the membrane surface and increase cake layer porosity (Barbot et al., 2008). Since the sedimentation step is omitted, it is important to select a coagulant that does not have a strong affinity to the membrane surface, while ensuring the dose is sufficiently high to destabilize NOM. 
Much research has been conducted on selecting the appropriate coagulant and dose for UF applications, but little is known about how the coagulant should be applied. Previous work suggests that applying coagulant only during the first half of a permeation cycle limits fouling to a similar extent as applying coagulant throughout the cycle (Lok et al., 2017b; Pronk et al., 2016). Previous studies have reported that pre-coating coagulant precipitates onto the membrane surface prior to permeation establishes a protective layer that inhibits pore blocking (Park et al., 2002; Salinas-Rodriguez et al., 2016). It has been postulated that applying coagulant only during the initial phase of permeation is sufficient in establishing a protective fouling layer and further coagulation is not necessary (Lok et al., 2017b).

This study further investigates the effect of applying inline coagulation at different segments of a permeation cycle (phased coagulation) on membrane fouling rates. The optimization of phased coagulation can potentially reduce coagulant consumption while maintaining the same level of fouling reduction as when coagulant is applied continuously.

\subsection{Materials and Methods}

\subsubsection{Membrane Filtration}

Experiments were conducted at the pilot plant (Section 3.3) located in the Barrie Surface Water Treatment Plant (Barrie WTP) using water collected from Lake Simcoe. Each experimental trial consisted of $72 \mathrm{~h}$ of continuous permeation and backwashing. Permeation cycles were extended from $30 \mathrm{~min}$ (full-scale operation) to $2 \mathrm{~h}$ to accentuate fouling (36 cycles total). A summary of operating conditions is detailed in Table 5-1. Before each trial, a membrane integrity test (pressure hold test) was performed to ensure no breaches in the membrane fibres. Subsequently, the membrane module was chemically cleaned by soaking in $500 \mathrm{mg} / \mathrm{L} \mathrm{NaOCl}$ followed by $200 \mathrm{mg} / \mathrm{L}$ citric acid for a total of $6 \mathrm{~h}$ to restore permeability. Temperature fluctuated throughout each trial, so its effects on resistance were accounted for in the viscosity term $(\mu)$ according to equation [5.1 (Zheng et al., 2010):

$$
\mu=\frac{0.497}{(T+42.5)^{1.5}}
$$

where $T$ is the feed water temperature $\left({ }^{\circ} \mathrm{C}\right)$. 
Inline coagulation with $2 \mathrm{mg} / \mathrm{L}$ polyaluminum chloride (PACl) (PAX-XL1900, Kemira Water Solutions Canada, Inc.) was applied prior to membrane filtration. $\mathrm{PACl}$ was applied during the initial 10, 30, 60, or 120 minutes of each permeation cycle (Figure 5-1). The phased coagulation conditions studied expanded on the those studied by Lok et al. (2017b). A trial without coagulation addition was also be performed to determine the relative impact of coagulation on fouling control.

Table 5-1: Operating parameters for pilot-scale filtration experiments

\begin{tabular}{|l|c|}
\hline Operating Parameter & Value \\
\hline Total Permeation Time & $48 \mathrm{~h}$ \\
\hline Permeation Time per Cycle & $4 \mathrm{~h}$ \\
\hline Permeate Flux & $40 \mathrm{~L} / \mathrm{m}^{2} \cdot \mathrm{h}$ \\
\hline Coagulant Dose & $2 \mathrm{mg} / \mathrm{L} \mathrm{PACl}$ \\
\hline Backpulse Time & $10 \mathrm{~min}$ \\
\hline Backpulse Air Flow & $60 \mathrm{~L} / \mathrm{min}$ \\
\hline Backpulse Bubble Type & Continuous coarse \\
\hline
\end{tabular}

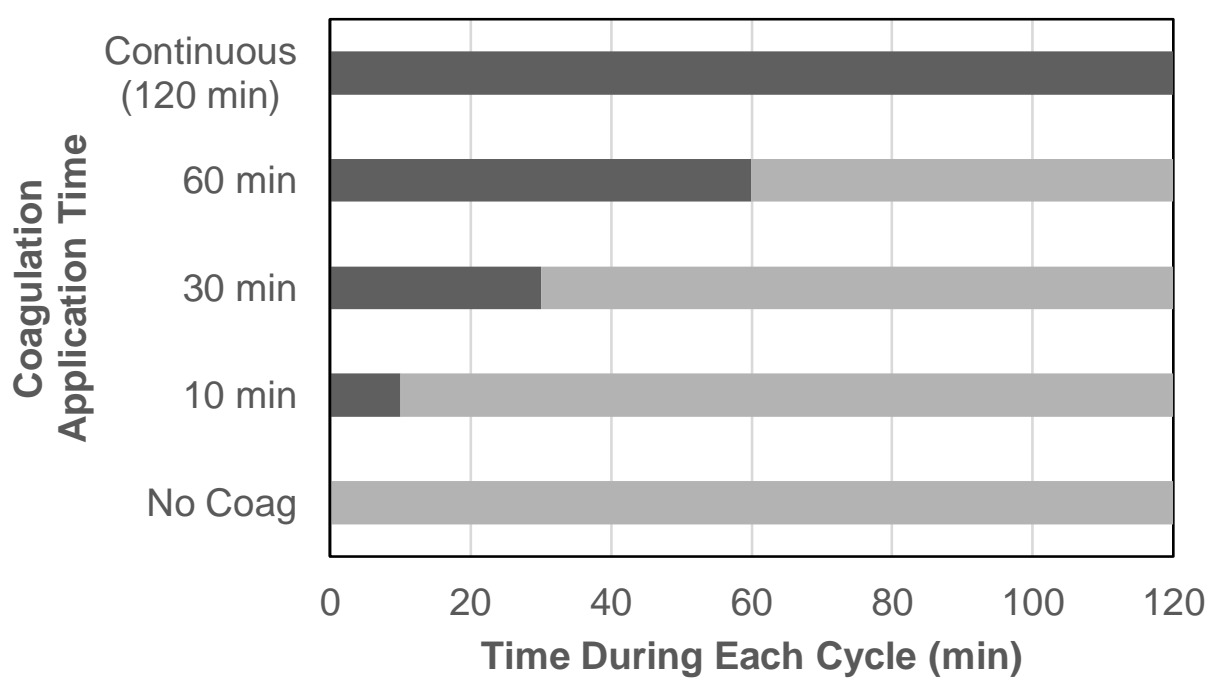

- Inline Coagulation Applied $\quad$ No Coagulation

Figure 5-1: Phased coagulation conditions of pilot-scale trials 


\subsubsection{Water Quality and Membrane Fouling}

Feed, permeate, and reject (after backwash) samples were collected after 24, 48, and $72 \mathrm{~h}$. Samples were be filtered through a $0.45 \mu \mathrm{m}$ filter prior to dissolved organic carbon (DOC) analyses as detailed in Section 3.4.5. The ultraviolet absorbance at $254 \mathrm{~nm}\left(\mathrm{UV}_{254}\right)$ of the filtered samples was measured using a UV/Vis Spectrophotometer (Agilent, Mississauga, ON). Liquid chromatography-organic carbon detection (LC-OCD) was also performed to characterize NOM and is further explained in Section 3.4.6. The proportion of each NOM fraction deposited onto the membrane following backwash $(A)$ was calculated using equation $[5.2$ :

$$
A=\left(1-\frac{C_{\text {perm }} V_{\text {perm }}+C_{\text {reject }} V_{\text {reject }}}{C_{\text {feed }} V_{\text {feed }}}\right) \times 100 \%
$$

where $C$ is the concentration of the respective NOM fraction and $V$ is the total volume of the respective water accumulated over the permeation cycle.

Membrane fouling was quantified using the resistance-in-series model as described in Section 2.2. The resistance values were adjusted to account for feed water temperature fluctuations that occur during each trial. Two-tailed t-tests will be used to determine any significant differences in fouling rate (as determined via linear regression model) with respect to continuous coagulation at an $85 \%$ confidence level. Cost estimates associated with premature membrane replacement due to chemical cleaning were performed according to the steps outlined by Li et al. (2014). 


\subsection{Results}

\subsubsection{Membrane Fouling}

The impacts of phased coagulation on membrane fouling rates were assessed by applying $\mathrm{PACl}$ during the first $0,10,30,60$, or 120 minutes of a 120 -minute permeation cycle (see Section 8.4.5 for resistance values). The reduction in coagulation application time does not significantly increase $(p>0.15)$ irreversible and total fouling rates with respect to continuous (120 min) application (Figure 5-2). In other words, any amount of coagulation addition during the permeation cycle effectively mitigates irreversible fouling. A similar result was reported by Pronk et al. (2016) whereby applying ferric chloride during the initial 50\% of a filtration cycle resulting in similar fouling performance as continuous coagulation. Despite the lack of statistical significance, irreversible and total fouling rates generally increased with decreasing coagulation time. However, the total and irreversible fouling rates following 60 minutes of phased coagulation were very close to that of continuous coagulation $(<15 \%)$. Nonetheless, long-term experiments (i.e. weeks to months) is necessary to better assess the impacts of phased coagulation, particularly with application times below 30 minutes. In contrast, no coagulant addition significantly increases $(\mathrm{p}=0.03)$ irreversible fouling rate, which supports previous studies that indicate inline coagulation improves the reversibility of UF fouling. Permeate turbidity generally remained constant ( $\sim 0.01$ NTU) regardless of coagulation time.

Biopolymers comprised of the majority of DOC retained by the membrane according to LC-OCD (see Section 8.4.6 for concentrations), which is consistent with previous results (Pronk et al., 2016; Wray et al., 2016). Over $60 \%$ of biopolymers were rejected by the membrane regardless of coagulation time while the other fractions were not well retained (Figure 5-3). Moreover, biopolymer removal remained constant over the course of the experiment (60-70\%), which suggests that the irreversible fouling layer did not alter the selectivity of the membrane. To further investigate the reversibility of fouling, the fraction of DOC remaining on the membrane after backwash was calculated by a mass balance of DOC in the feed, permeate, and reject water. No trends in DOC or biopolymer deposition between different coagulation times were observed (Figure 5-4). 

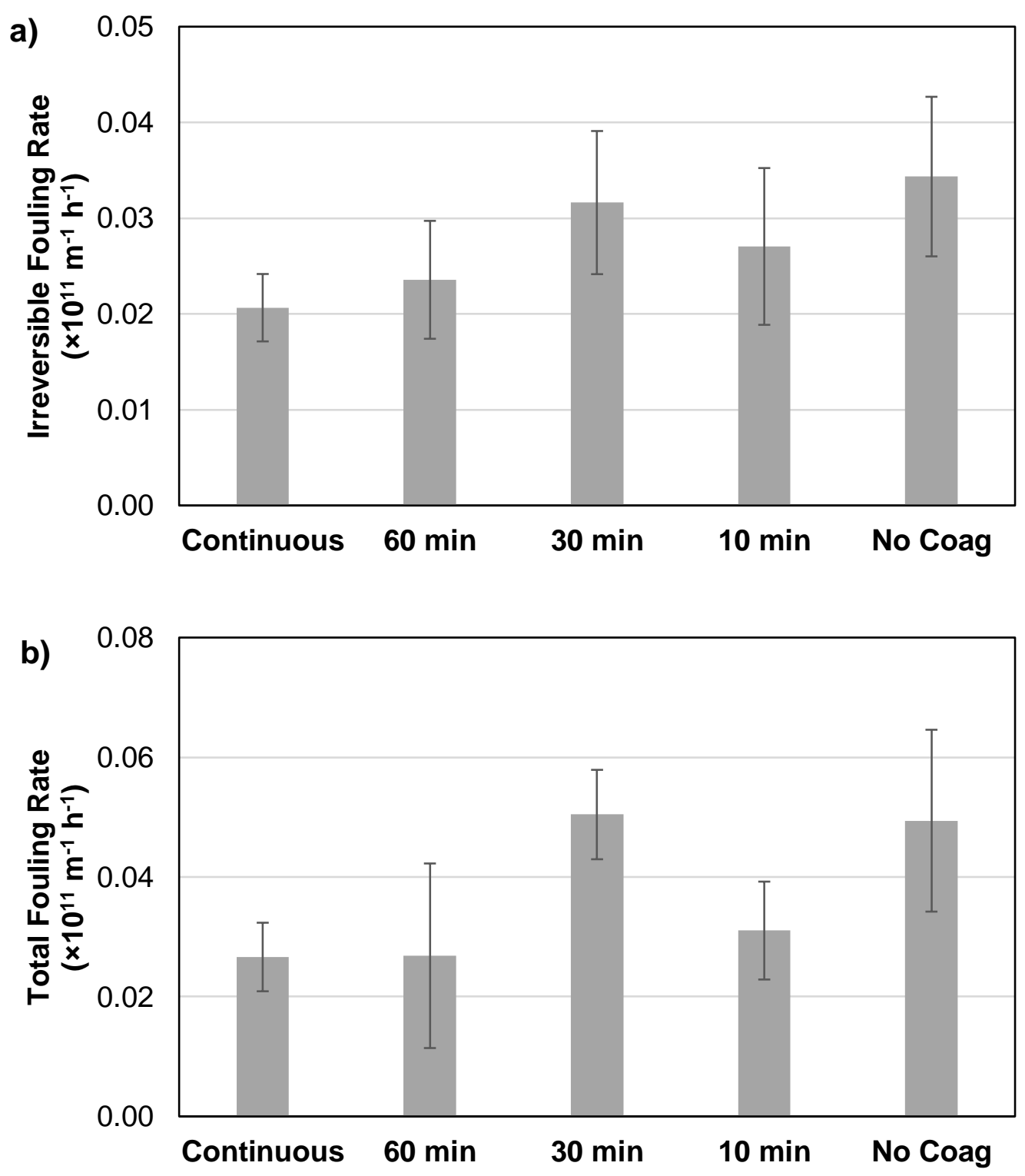

Figure 5-2: (a) Hydraulically irreversible and (b) total fouling rate of a ZW1000 UF membrane as a function of phased coagulation time. Vertical bars indicate the 85\% confidence interval of the estimated slope. 


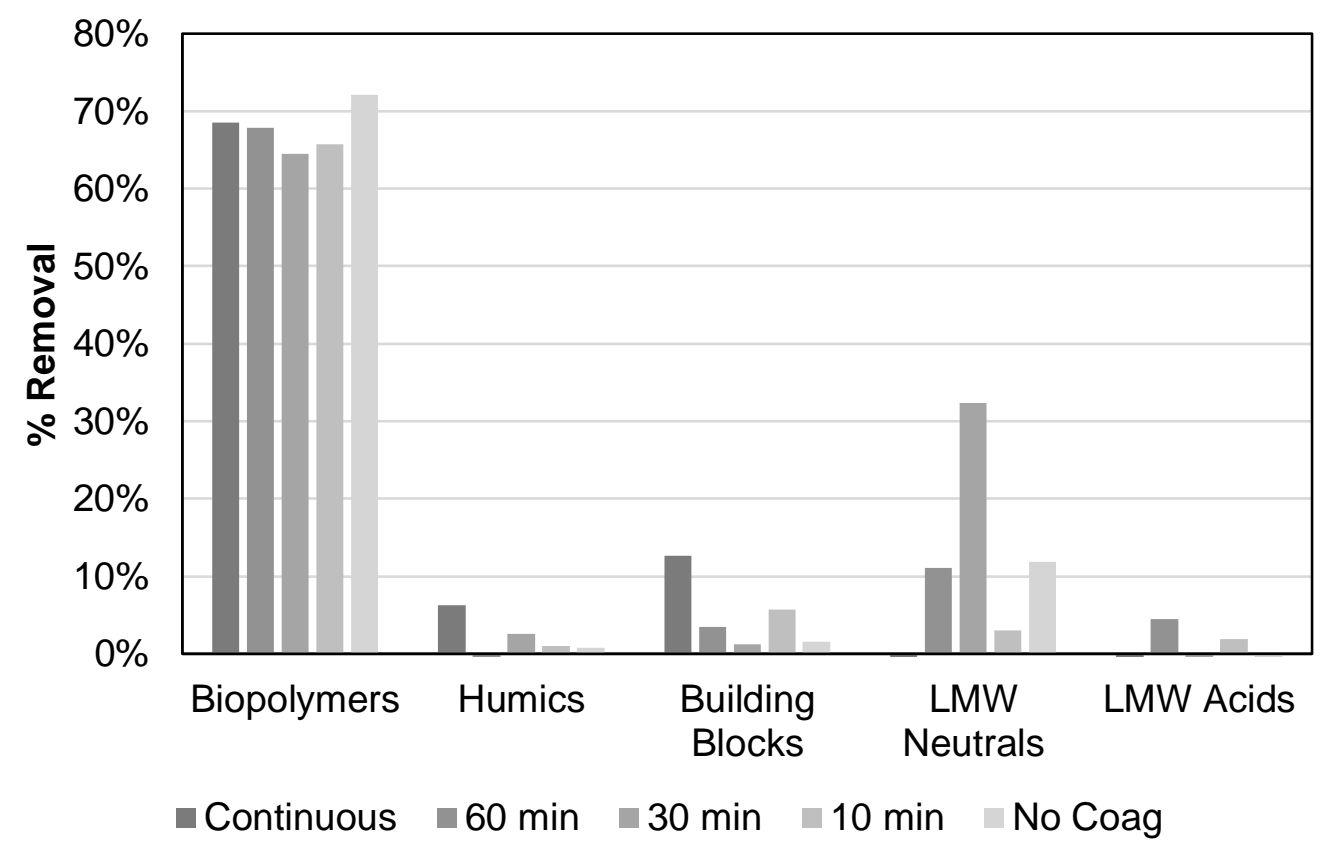

Figure 5-3: Removals of NOM fractions characterised via LC-OCD at various phased coagulation conditions after $24 \mathrm{~h}$ of permeation. Negative removals were reported as $0 \%$.

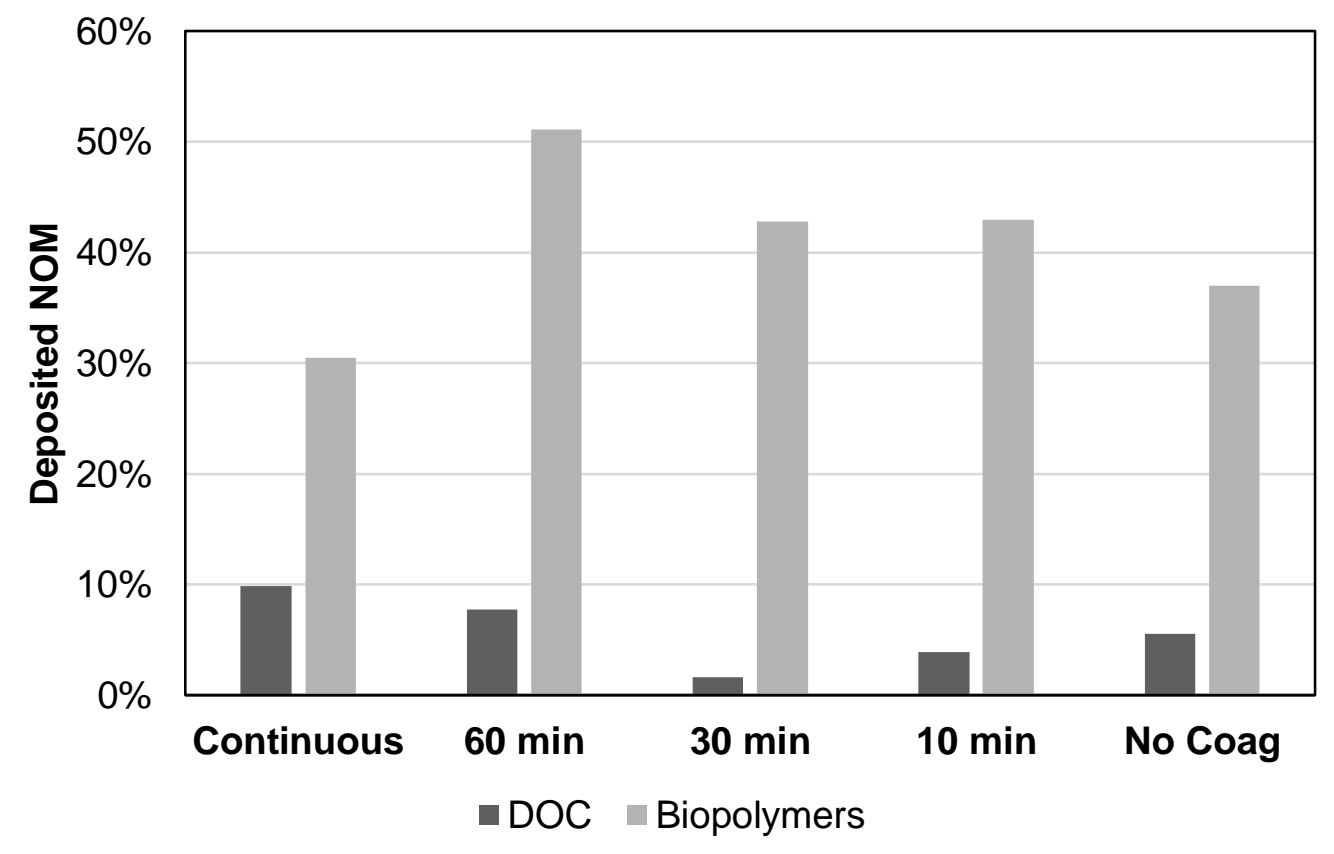

Figure 5-4: DOC and biopolymers deposited (as \% of total DOC and biopolymers in the feed solution, respectively) on the membrane after backwash after $24 \mathrm{~h}$ of permeation 


\subsubsection{Cost Analysis}

Chemical cleaning methods, such as clean in place (CIP) and chemically enhanced backwash (CEB), are often used to remove hydraulically irreversible foulants. However, they have been shown to adversely affect membrane properties, leading to shortened operational lifespan (Puspitasari et al., 2010). Since coagulation has been shown to mitigate irreversible membrane fouling, it is expected that the costs of UF operation are reduced due less frequent cleaning. The recommended cumulative lifetime chemical exposure of ZW1000 membranes is $500,000 \mathrm{ppm} \cdot \mathrm{h}$ (Cote et al., 2012). Values used in cost estimates were taken from Li et al. (2014) and sample calculations can be found in Section 8.3. Assuming CIP frequency is 6 times/year when no coagulation is applied, both continuous coagulation and 60-minute phased coagulation reduces CIP frequency by almost half (3.2 times/year), leading to a $27 \%$ reduction in replacement costs (Table 5-2). There are likely further costs savings when considering reduced total fouling rates would result in lower energy consumption from less pumping and lower use of treated water to perform backwash. In addition, utilizing a 60-min phased coagulation regime can halve coagulant costs relative to continuous coagulation which could save approximately $\$ 10,000$ annually for a facility similar to the one considered in this study (Lok et al., 2017b).

Table 5-2: Comparison of cleaning frequency, operational lifetime, and replacement costs of different phased coagulation conditions

\begin{tabular}{|c|c|c|c|c|}
\hline $\begin{array}{c}\text { Coagulation } \\
\text { Condition }\end{array}$ & $\begin{array}{c}\text { Irreversible } \\
\text { Fouling Rate } \\
\left(\times \mathbf{1 0}_{\mathbf{9}}^{\mathbf{- 1}} \mathbf{h}^{-\mathbf{1}}\right)\end{array}$ & $\begin{array}{c}\text { CIP } \\
\text { Frequency } \\
\text { (times/year) }\end{array}$ & $\begin{array}{c}\text { Operational } \\
\text { Lifetime } \\
\text { (years) }\end{array}$ & $\begin{array}{c}\text { Replacement } \\
\text { Costs (\$/year) }\end{array}$ \\
\hline No Coagulation & 3.43 & 6.0 & 11.5 & $\$ 124,143$ \\
\hline Continuous & 2.07 & 3.2 & 15.7 & $\$ 90,956$ \\
\hline $60 \mathrm{~min}$ & 2.36 & 3.3 & 15.7 & $\$ 91,262$ \\
\hline $30 \mathrm{~min}$ & 3.16 & 6.1 & 11.4 & $\$ 125,638$ \\
\hline $10 \mathrm{~min}$ & 2.71 & 3.8 & 14.7 & $\$ 97,395$ \\
\hline
\end{tabular}




\subsection{Conclusions}

Pilot experiments were conducted to assess the impact of phased coagulation on the fouling of UF membranes. Results indicate that reducing coagulation times does not significantly increase total and irreversible fouling rates with respect to continuous coagulation. On the contrary, not adding coagulant exacerbated fouling which highlights the reported benefits of inline coagulation in fouling mitigation. Through LC-OCD analysis, biopolymers were shown to be the predominant membrane foulant but no trends in its removal or accumulation could be established. Cost analysis estimates that applying coagulation continuously or during the first 60 minutes will result in almost a 50\% decrease in chemical cleaning frequency and a $27 \%$ reduction in replacement costs with respect to no coagulant addition. More savings are anticipated due to the reduced energy requirements associated with reduced rates of total fouling resistance as well as reduced coagulant costs from phased coagulation. 


\section{Summary, Conclusions, and Recommendations}

\subsection{Summary}

A bench-scale study was conducted to investigate the impact of coagulation on the fouling of three model protein solutions (BSA, OVA, and BLG) on hollow fibre UF membranes. Four coagulant doses were studied, which include dosages that were reported to mitigate UF fouling as well as those applied at full-scale UF treatment facilities. The irreversible and reversible fouling rates were compared between the various coagulation conditions. Comparisons in the surface charge and fluorescence of the proteins (with and without ANS) were made between different conditions to explain fouling trends.

A pilot-scale study was conducted to determine the impacts of phased coagulation on membrane fouling. Coagulant was applied inline for different durations of the permeation cycle and the fouling rates were compared to the continuous coagulation condition. NOM in feed, permeate, and reject water were characterized via LC-OCD and a cost analysis was conducted to estimate the savings associated with fouling mitigation.

\subsection{Conclusions}

Adding a low coagulant dose $(2 \mu \mathrm{M} \mathrm{Al}$ or $0.3 \mathrm{mg} / \mathrm{L}$ alum $)$ resulted in a significant reduction in irreversible and reversible fouling rate when compared to no coagulant addition. On the contrary, dosages above this level $(10$ and $40 \mu \mathrm{M})$ exacerbated fouling. Concentrations of proteins in the feed and the permeate indicate that less hydraulically irreversible fouling is due to the greater transmission of proteins through the membrane, implying the fouling mitigation was not primarily a function of a more porous fouling layer. Trends in particle size and zeta potential as a function of coagulant dose did not appear to explain fouling trends. However, an analysis of surface hydrophobicity suggests that low coagulant dosages induce conformational changes in bulk proteins as well as the adsorbed monolayer on the membrane surface to become less interactive with one another, leading to reduced fouling.

Phased coagulation was shown to have no significant impact on membrane fouling, whereas no coagulant addition exacerbated it. Biopolymers were shown to be the predominant membrane foulant, but no trends in their removal or accumulation on the membrane as a function of coagulation time could be observed. As a result of reduced irreversible fouling, the 
frequency of chemical cleaning for membranes under continuous or phased coagulation (first half of cycle) is expected to be approximately half of that for membranes without coagulant addition. Consequently, the reduced chemical exposure is estimated to reduce annual replacement costs by $27 \%$.

\subsection{Recommendations for Future Research}

The results of this work call for further investigation in the following areas:

1. Membranes with larger areas (i.e. flat sheet membranes or a longer hollow fibre) should be used to minimize the variance caused by intrinsic differences between membranes. This should lead to more reproducible and comparable results. The greater area would also allow for greater magnitude of protein adsorption, which will make it easier to observe an accumulation of proteins in the system via mass balance.

2. The experiment should be repeated with membranes with different properties (e.g., hydrophobicity, surface charge, functional groups). If hydrophobicity is indeed the driving force of fouling trends, then its effects should be more pronounced if a more hydrophobic membrane was used. Conversely, opposite fouling trends could be observed when using a hydrophilic membrane.

3. The reasons why the fluorescence assay did not produce results with OVA and BLG should be investigated, as it is a relatively simple and non-destructive tool to evaluate protein hydrophobicity. Testing the procedure with higher concentrations of proteins, different buffer chemistries, or a different fluorescent probe (e.g. cis-parinaric acid, PRODAN) may result in improved reproducibility. However, it must be noted that optimal conditions for fluorescence assays may not result in appreciable membrane fouling.

4. Further work should be completed to characterize the protein fouling layer under different coagulation conditions, either through qualitative (e.g. scanning electron microscopy) or quantitative (e.g., atomic force microscopy) means. There are also methods to characterize bulk proteins as well, such as circular dichroism, or nuclear magnetic resonance spectroscopy. 
5. The duration of pilot-scale experiments investigating phased coagulation should be much longer than 3 days (and preferably at full-scale condition of 30 min permeation cycles) to clearly assess the long-term feasibility of this strategy. 


\section{References}

Abdullah, S.Z., Bérubé, P.R., 2013. Assessing the effects of sodium hypochlorite exposure on the characteristics of PVDF based membranes. Water Res. 47, 5392-5399.

Alizadeh-Pasdar, N., Li-Chan, E.C.Y., 2000. Comparison of Protein Surface Hydrophobicity Measured at Various pH Values Using Three Different Fluorescent Probes. J. Agric. Food Chem. 48, 328-334.

Amy, G., 2008. Fundamental understanding of organic matter fouling of membranes. Desalination 231, 44-51.

AWWA, 2008. Microfiltration and Ultrafiltration Membranes for Drinking Water (M53). J. / Am. Water Work. Assoc. 100, 84-97.

Barbot, E., Moustier, S., Bottero, J.Y., Moulin, P., 2008. Coagulation and ultrafiltration: Understanding of the key parameters of the hybrid process. J. Memb. Sci. 325, 520-527.

Belfort, G., Davis, R.H., Zydney, A.L., 1994. Behavior of suspensions and macromolecular solution in cross flow microfiltration: A Review. J. Memb. Sci. 96, 1-58.

Cardamone, M., Puri, N.K., 1992. Spectrofluorimetric assessment of the surface hydrophobicity of proteins. Biochem. J. 282, 589-593.

Choi, K.Y.J., Dempsey, B.A., 2004. In-line coagulation with low-pressure membrane filtration. Water Res. 38, 4271-4281.

Cote, P., Alam, Z., Penny, J., 2012. Hollow fiber membrane life in membrane bioreactors (MBR). Desalination 288, 145-151.

Delahaije, R.J.B.M., Wierenga, P.A., Van Nieuwenhuijzen, N.H., Giuseppin, M.L.F., Gruppen, H., 2013. Protein concentration and protein-exposed hydrophobicity as dominant parameters determining the flocculation of protein-stabilized oil-in-water emulsions. Langmuir 29, 11567-11574.

Gao, W., Liang, H., Ma, J., Han, M., Chen, Z. lin, Han, Z. shuang, Li, G. bai, 2011. Membrane fouling control in ultrafiltration technology for drinking water production: A review. Desalination 272, 1-8. 
Hallé, C., Huck, P.M., Peldszus, S., Haberkamp, J., Jekel, M., 2009. Assessing the performance of biological filtration as pretreatment to low pressure membranes for drinking water. Environ. Sci. Technol. 43, 3878-3884.

Haskard, C.A., Li-Chan, E.C.Y., 1998. Hydrophobicity of Bovine Serum Albumin and Ovalbumin Determined Using Uncharged (PRODAN) and Anionic (ANS - ) Fluorescent Probes. J. Agric. Food Chem. 46, 2671-2677.

Howe, K.J., Clark, M.M., 2002. Fouling of microfiltration and ultrafiltration membranes by natural waters. Environ. Sci. Technol. 36, 3571-3576.

Howe, K.J., Marwah, A., Chiu, K.P., Adham, S.S., Howe, K.J., Marwah, A., Chiu, K.P., Adham, S.S., 2006. Effect of coagulation on the size of MF and UF membrane foulants. Environ. Sci. Technol. 40, 7908-7913.

Huang, H., Schwab, K., Jacangelo, J.G., 2009. Pretreatment for low pressure membranes in water treatment: A review. Environ. Sci. Technol. 43, 3011-3019.

Huber, S.A., Balz, A., Abert, M., Pronk, W., 2011. Characterisation of aquatic humic and nonhumic matter with size-exclusion chromatography - organic carbon detection - organic nitrogen detection (LC-OCD-OND). Water Res. 45, 879-885.

Huisman, I.H., Prádanos, P., Hernández, A., 2000. The effect of protein-protein and proteinmembrane interactions on membrane fouling in ultrafiltration. J. Memb. Sci. 179, 79-90.

Jermann, D., Pronk, W., Meylan, S., Boller, M., 2007. Interplay of different NOM fouling mechanisms during ultrafiltration for drinking water production. Water Res. 41, 17131722.

Kimura, K., Maeda, T., Yamamura, H., Watanabe, Y., 2008. Irreversible membrane fouling in microfiltration membranes filtering coagulated surface water. J. Memb. Sci. 320, 356362.

Kimura, K., Tanaka, K., Watanabe, Y., 2014. Microfiltration of different surface waters with/without coagulation: Clear correlations between membrane fouling and hydrophilic biopolymers. Water Res. 49, 434-443. 
Ko, M.K., Pellegrino, J.J., Nassimbene, R., Marko, P., 1993. Characterization of the adsorption-fouling layer using globular proteins on ultrafiltration membranes. J. Memb. Sci. 76, 101-120.

Laligant, A., Dumay, E., Valencia, C.C., Cuq, J.L., Cheftel, J.C., 1991. Surface Hydrophobicity and Aggregation of $\beta$-Lactoglobulin Heated near Neutral pH. J. Agric. Food Chem. 39, 2147-2155.

Lee, J.D., Lee, S.H., Jo, M.H., Park, P.K., Lee, C.H., Kwak, J.W., 2000. Effect of coagulation conditions on membrane filtration characteristics in coagulation - Microfiltration process for water treatment. Environ. Sci. Technol. 34, 3780-3788.

Li, L., Wray, H.E., Andrews, R.C., Bérubé, P.R., 2014. Ultrafiltration Fouling: Impact of Backwash Frequency and Air Sparging. Sep. Sci. Technol. 49, 2814-2823.

Lok, A., Bérubé, P.R., Andrews, R.C., 2017a. The effect of concentration factor on membrane fouling. Membranes (Basel). 7, 1-7.

Lok, A., Wray, H., Bérubé, P., Andrews, R.C., 2017b. Optimization of air sparging and in-line coagulation for ultrafiltration fouling control. Sep. Purif. Technol. 188, 60-66.

Luey, J.-K., McGuire, J., Sproull, R.D., 1991. The effect of $\mathrm{pH}$ and $\mathrm{NaCl}$ concentration on adsorption of $\beta$-lactoglobulin at hydrophilic and hydrophobic silicon surfaces. J. Colloid Interface Sci. 143, 489-500.

Ma, B., Hu, C., Wang, X., Xie, Y., Jefferson, W.A., Liu, H., Qu, J., 2015. Effect of aluminum speciation on ultrafiltration membrane fouling by low dose aluminum coagulation with bovine serum albumin (BSA). J. Memb. Sci. 492, 88-94.

Ma, B., Yu, W., Liu, H., Qu, J., 2014. Effect of low dosage of coagulant on the ultrafiltration membrane performance in feedwater treatment. Water Res. 51, 277-283.

Marshall, A.D., Munro, P.A., Trägårdh, G., 1993. The effect of protein fouling in microfiltration and ultrafiltration on permeate flux, protein retention and selectivity: A literature review. Desalination 91, 65-108.

Matilainen, A., Gjessing, E.T., Lahtinen, T., Hed, L., Bhatnagar, A., Sillanpää, M., 2011. An 
overview of the methods used in the characterisation of natural organic matter (NOM) in relation to drinking water treatment. Chemosphere 83, 1431-1442.

Park, P. kyu, Lee, C. hak, Choi, S.J., Choo, K.H., Kim, S.H., Yoon, C.H., 2002. Effect of the removal of DOMs on the performance of a coagulation-UF membrane system for drinking water production. Desalination 145, 237-245.

Peiris, R.H., Hallé, C., Budman, H., Moresoli, C., Peldszus, S., Huck, P.M., Legge, R.L., 2010. Identifying fouling events in a membrane-based drinking water treatment process using principal component analysis of fluorescence excitation-emission matrices. Water Res. 44, 185-194.

Peiris, R.H., Jaklewicz, M., Budman, H., Legge, R.L., Moresoli, C., 2013. Assessing the role of feed water constituents in irreversible membrane fouling of pilot-scale ultrafiltration drinking water treatment systems. Water Res. 47, 3364-3374.

Peldszus, S., Hallé, C., Peiris, R.H., Hamouda, M., Jin, X., Legge, R.L., Budman, H., Moresoli, C., Huck, P.M., 2011. Reversible and irreversible low-pressure membrane foulants in drinking water treatment: Identification by principal component analysis of fluorescence EEM and mitigation by biofiltration pretreatment. Water Res. 45, 5161-5170.

Peleato, N.M., Legge, R.L., Andrews, R.C., 2017. Characterization of UF foulants and fouling mechanisms when applying low in-line coagulant pre-treatment. Water Res. 126, 1-11.

Pérez-Fuentes, L., Drummond, C., Faraudo, J., Bastos-González, D., 2017. Adsorption of milk proteins ( $\beta$-casein and $\beta$-lactoglobulin) and BSA onto hydrophobic surfaces. Materials (Basel). 10, 1-25.

Porcelli, N., Judd, S., 2010. Chemical cleaning of potable water membranes: A review. Sep. Purif. Technol. 71, 137-143.

Pronk, W., Traber, J., Kaminska, G., 2016. Optimization of process parameters of the coagulation/ultrafiltration process for the reduction of membrane fouling, in: Advances in Particle Science and Separation: Meeting Tomorrow's Challenges. pp. 197-205.

Puspitasari, V., Granville, A., Le-Clech, P., Chen, V., 2010. Cleaning and ageing effect of sodium hypochlorite on polyvinylidene fluoride (PVDF) membrane. Sep. Purif. Technol. 
72, 301-308.

Rabe, M., Verdes, D., Seeger, S., 2011. Understanding protein adsorption phenomena at solid surfaces. Adv. Colloid Interface Sci. 162, 87-106.

Salinas-Rodriguez, S.G., Prabowo, A., Abushaban, A., Battes, F., Schippers, J.C., Kennedy, M.D., 2016. Pre-coating of outside-inside capillary UF membranes with iron hydroxide particles to limit non-backwashable fouling during seawater algal blooms. Desalin. Water Treat. 57, 26730-26740.

Savitzky, A., Golay, M.J.E., 1964. Smoothing and Differentiation of Data by Simplified Least Squares Procedures. Anal. Chem. 36, 1627-1639.

Siembida-Losch, B., Anderson, W.B., Wang, Y., Bonsteel, J., Huck, P.M., 2015. Effect of ozone on biopolymers in biofiltration and ultrafiltration processes. Water Res. 70, 224234.

Tabatabai, S.A.A., Kennedy, M.D., Amy, G.L., Schippers, J.C., 2009. Optimizing inline coagulation to reduce chemical consumption in MF/UF systems. Desalin. Water Treat. 6, 94-101.

Taniguchi, M., Kilduff, J.E., Belfort, G., 2003. Modes of natural organic matter fouling during ultrafiltration. Environ. Sci. Technol. 37, 1676-1683.

Vivian, J.T., Callis, P.R., 2001. Mechanisms of tryptophan fluorescence shifts in proteins. Biophys. J. 80, 2093-2109.

Wang, L., Miao, R., Wang, X., Lv, Y., Meng, X., Yang, Y., Huang, D., Feng, L., Liu, Z., Ju, K., 2013. Fouling behavior of typical organic foulants in polyvinylidene fluoride ultrafiltration membranes: Characterization from microforces. Environ. Sci. Technol. 47, $3708-3714$.

Wang, P., Wang, Z., Wu, Z., Zhou, Q., Yang, D., 2010. Effect of hypochlorite cleaning on the physiochemical characteristics of polyvinylidene fluoride membranes. Chem. Eng. J. 162, $1050-1056$.

Woo, Y.C., Lee, J.J., Oh, J.S., Kim, H.S., 2013. Effect of chemical cleaning conditions on the 
flux recovery of MF membrane as pretreatment of seawater desalination. Desalin. Water Treat. 51, 6329-6337.

Wray, H.E., Andrews, R.C., 2014. Optimization of coagulant dose for biopolymer removal: Impact on ultrafiltration fouling and retention of organic micropollutants. J. Water Process Eng. 1, 74-83.

Wray, H.E., Andrews, R.C., Bérubé, P.R., 2016. Coagulation optimization for DOC removal: Pilot-scale analysis of UF fouling and disinfection byproduct formation potential. Water Sci. Technol. Water Supply 16, 473-480.

Wray, H.E., Andrews, R.C., Bérubé, P.R., 2014. Surface shear stress and retention of emerging contaminants during ultrafiltration for drinking water treatment. Sep. Purif. Technol. 122, 183-191.

Zheng, X., Ernst, M., Huck, P.M., Jekel, M., 2010. Biopolymer fouling in dead-end ultrafiltration of treated domestic wastewater. Water Res. 44, 5212-5221.

Zheng, X., Plume, S., Ernst, M., Croué, J.P., Jekel, M., 2012. In-line coagulation prior to UF of treated domestic wastewater - foulants removal, fouling control and phosphorus removal. J. Memb. Sci. 403-404, 129-139.

Zularisam, A.W., Ismail, A.F., Salim, R., 2006. Behaviours of natural organic matter in membrane filtration for surface water treatment — a review. Desalination 194, 211-231. 


\section{Appendices}

\subsection{Procedure and Sample Calculation for Pure Water Permeability of a Membrane}

This section outlines the procedure and sample calculation followed to determine the pure water permeability of the ZW500 hollow fibre membranes used in bench-scale studies.

1. The TMP of each fibre permeating distilled water over the course of $2 \mathrm{~h}$ at three different permeate flow rates was collected

Table 8-1: Measured TMP as a function of permeate flow/flux

\begin{tabular}{|c|c|c|c|c|}
\hline Membrane & Area $\left(\mathrm{m}^{2}\right)$ & Flow $(\mathrm{mL} / \mathrm{min})$ & Flux (LMH) & TMP (kPa) \\
\hline \multirow{3}{*}{ tons } & \multirow{3}{*}{$1.56 \times 10^{-3}$} & 0.53 & 20.5 & 3.5 \\
\hline & & 0.79 & 30.4 & 5.5 \\
\hline & & 1.06 & 40.7 & 7.3 \\
\hline \multirow{3}{*}{2} & \multirow{3}{*}{$1.55 \times 10^{-3}$} & 0.53 & 20.4 & 3.7 \\
\hline & & 0.79 & 30.7 & 5.6 \\
\hline & & 1.05 & 40.7 & 7.4 \\
\hline \multirow{3}{*}{3} & \multirow{3}{*}{$1.56 \times 10^{-3}$} & 0.54 & 20.8 & 3.7 \\
\hline & & 0.79 & 30.4 & 5.6 \\
\hline & & 1.06 & 41.0 & 7.5 \\
\hline \multirow{3}{*}{4} & \multirow{3}{*}{$1.53 \times 10^{-3}$} & 0.52 & 20.6 & 3.5 \\
\hline & & 0.78 & 30.7 & 5.4 \\
\hline & & 1.04 & 40.7 & 7.3 \\
\hline
\end{tabular}

An example calculation of permeate flux $(J)$ of Membrane 1 at a TMP of $3.5 \mathrm{kPa}$ was is as follows:

$$
\begin{aligned}
J & =\frac{\frac{0.53 \mathrm{~mL}}{\mathrm{~min}} \times \frac{60 \mathrm{~min}}{h} \times \frac{L}{1000 \mathrm{~mL}}}{1.56 \times 10^{-3} \mathrm{~m}^{2}} \\
& =20.5 \frac{\mathrm{L}}{\mathrm{m}^{2} \cdot h}
\end{aligned}
$$

2. Plot permeate flux as a function of TMP as shown in Figure 8-1 to determine the slope of the line, which is the PWP 


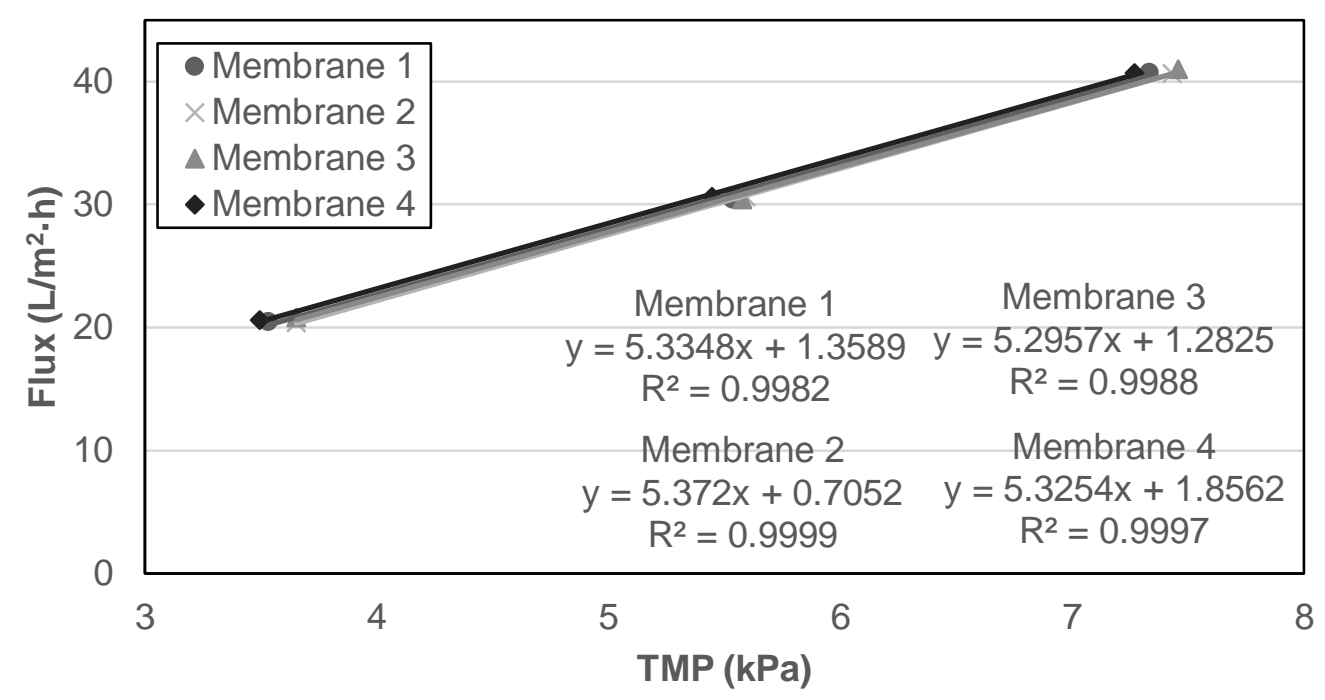

Figure 8-1: Permeate flux as a function of TMP for four ZW500 membrane fibres

3. Compare the PWP of each fibre to the average PWP and verify if it is within $15 \%$. The calculation for membrane 2 is as follows:

$$
\begin{aligned}
\% \text { PWP Diff } & =\left|\frac{P W P_{i}-P W P_{\text {avg }}}{P W P_{\text {avg }}}\right| \times 100 \% \\
& =\left|\frac{5.372-5.33}{5.33}\right| \times 100 \% \\
& =1 \%
\end{aligned}
$$




\subsection{Procedure and Sample Calculation for Surface Hydrophobicity of Proteins}

This section outlines the procedure and sample calculation followed to determine the surface hydrophobicity of model proteins using ANS as a fluorescent probe. Values used to calculated BSA surface hydrophobicity can be found in Section 8.4.4.

1. Dissolve $2.5310 \mathrm{~g}$ of ANS ammonium salt in $1 \mathrm{~L}(8 \mathrm{mM})$ of Milli- ${ }^{\circledR}$ water

2. Make a series of dilutions of the sample protein solutions to a total of $5 \mathrm{~mL}$ in test tubes with caps (Table 8-2)

Table 8-2: Example dilution scheme for ANS fluorescence assay

\begin{tabular}{|c|c|c|}
\hline $\begin{array}{c}\text { Final Protein } \\
\text { Concentration } \\
(\mathbf{m g} / \mathbf{L})\end{array}$ & Vol. of Sample $(\mathbf{m L})$ & Vol. of Buffer $(\mathbf{m L})$ \\
\hline 20 & 5 & 0 \\
\hline 16 & 4 & 1 \\
\hline 12 & 3 & 2 \\
\hline 8 & 2 & 3 \\
\hline 4 & 1 & 4 \\
\hline 0 & 0 & 5 \\
\hline
\end{tabular}

3. Add $20 \mu \mathrm{L}$ of $8 \mathrm{mM}$ ANS solution to each vial

4. Invert test tube gently once to mix solutions

5. Let stand for $10 \mathrm{~min}$

6. Set fluorometer to measure at ex/em $350 / 490 \mathrm{~nm}$ at a sufficiently high photomultiplier tube voltage $(\sim 750 \mathrm{~V})$

- Alternatively, the fluorescence spectrum from 400-600 nm emission at $350 \mathrm{~nm}$ excitation can be collected

7. Measure or zero instrument using the $0 \mathrm{mg} / \mathrm{L}$ sample

8. Measure the fluorescence of each sample three times, taking the average

9. Calculate the slope of the fluorescence intensity vs. protein concentration (Figure 8-2) 


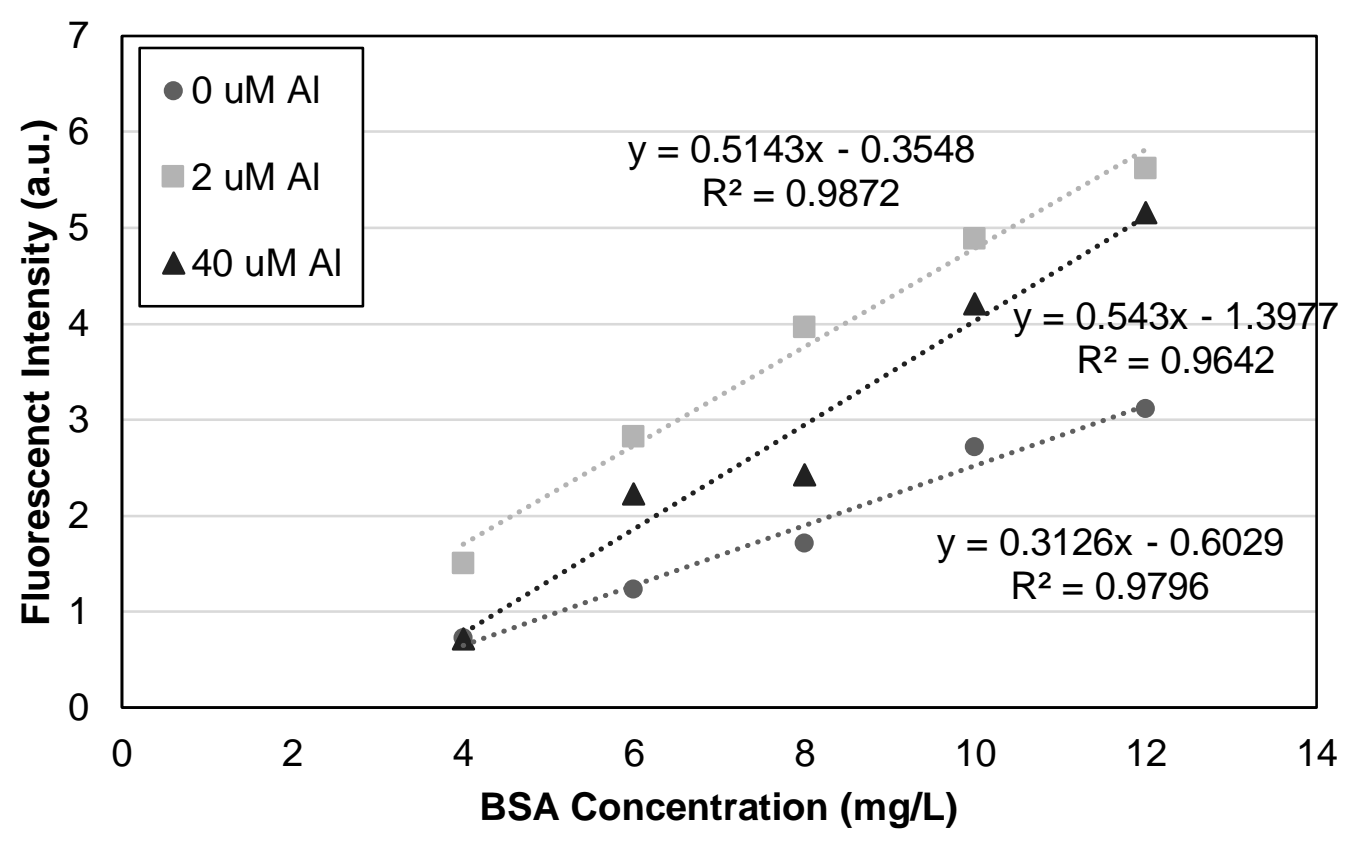

Figure 8-2: Example fluorescence intensity of BSA in the permeate as a function of protein concentration at different coagulant dosages 


\subsection{Cost Savings Estimation Procedure}

The following assumptions were made to the determine the costs savings associated with membrane replacement costs due to the reduced frequency of chemical cleaning (clean in place and chemically enhanced backwash):

1. Chemically enhanced backwash was performed daily for $0.5 \mathrm{~h}$ each with $100 \mathrm{ppm}$ sodium hypochlorite

2. Clean in place was performed 6 times/year when no coagulant is applied with $500 \mathrm{ppm}$ sodium hypochlorite and $200 \mathrm{ppm}$ citric acid, for a total of $6 \mathrm{~h}$ each

3. Membrane will be replaced when chemical exposure has reached $500,000 \mathrm{ppm} \cdot \mathrm{h}$ (total cost is $\$ 1,428,571$ )

1. CIP frequency is proportional to the irreversible fouling rate. For continuous coagulation:

$$
\begin{aligned}
\frac{\text { Fouling Rate }_{\text {continuous }}}{\text { CIP Frequency }} \text { continuous } & =\frac{\text { Fouling Rate }_{\text {none }}}{\text { CIP Frequency }} \\
\text { CIP Frequency } & \\
\text { continuous } & =\frac{\left(2.07 \times 10^{9} \mathrm{~m}^{-1} \mathrm{~h}^{-1}\right)(6 \text { times } / \text { year })}{3.43 \times 10^{9} \mathrm{~m}^{-1} \mathrm{~h}^{-1}} \\
& =3.2 \text { times } / \text { year }
\end{aligned}
$$

2. Calculate the annual chemical exposure for CIP and CEB for continuous coagulation:

$$
\begin{aligned}
\text { CIP Exposure }= & \text { Frequency } \times \text { Concentration } \times \text { Duration } \\
= & (3.2 \text { times } / \text { year })(700 \mathrm{ppm})(6 \mathrm{~h}) \\
= & 13,440 \mathrm{ppm} \cdot \mathrm{h} \\
\text { CEB Exposure } & =(365 \mathrm{times} / \text { year })(100 \mathrm{ppm})(0.5 \mathrm{~h}) \\
& =18,250 \mathrm{ppm} \cdot \mathrm{h}
\end{aligned}
$$

3. Calculate operational lifetime:

$$
\text { Lifetime }=\frac{500,000 \mathrm{ppm} \cdot \mathrm{h}}{(13,860+18,250) \mathrm{ppm} \cdot \mathrm{h} / \text { year }}=15.7 \text { years }
$$

4. Calculate replacement costs:

$$
\text { Replacement Cost }=\frac{\$ 1,248,571}{15.7 \text { years }}=\$ 90,956 / \text { year }
$$




\subsection{Raw Data}

\subsubsection{Protein Solution Fouling Resistance}
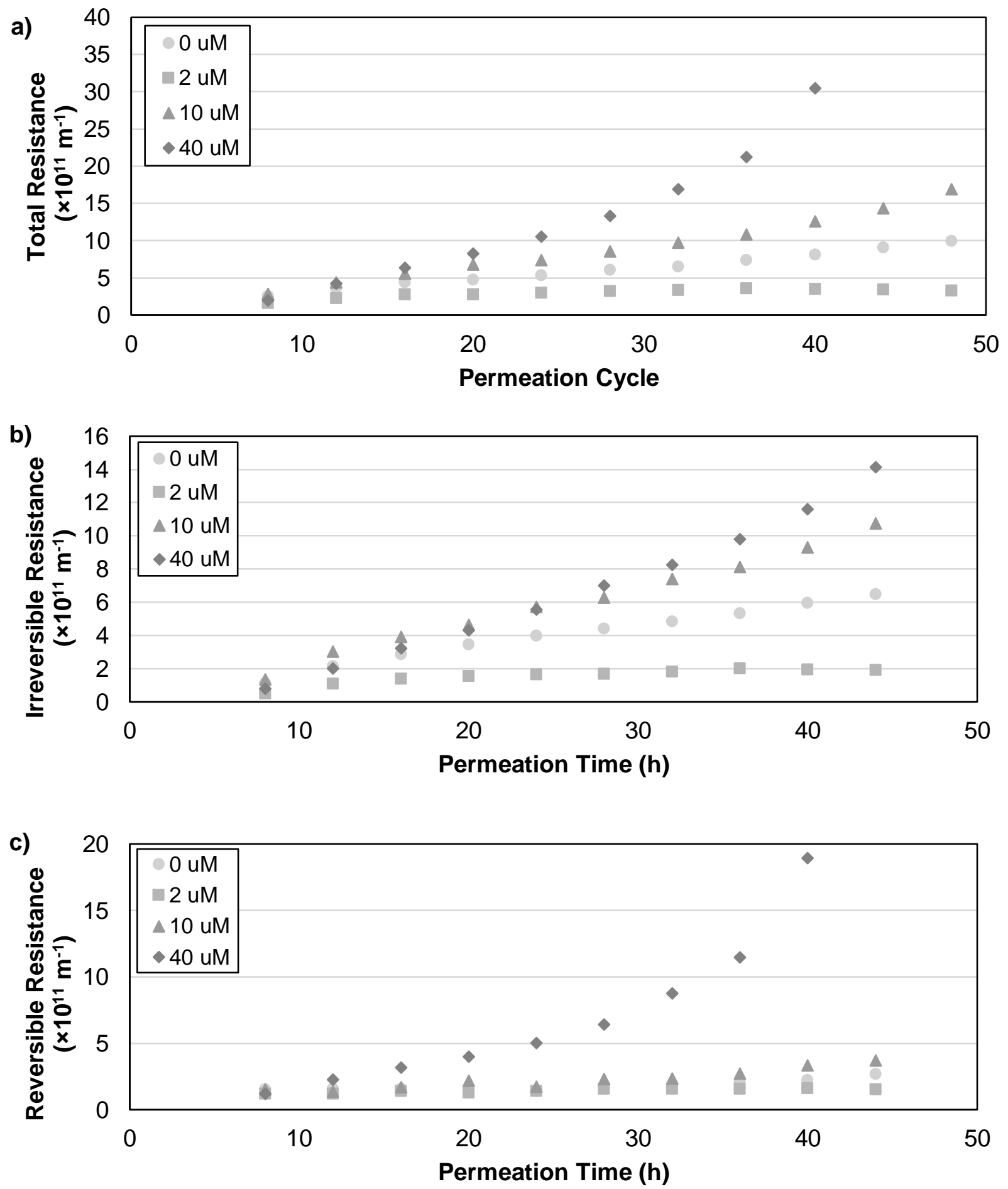

Figure 8-3: (a) Total, (b) irreversible, and (c) reversible resistance during $1^{\text {st }}$ trial of ultrafiltration of $20 \mathrm{mg} / \mathrm{L} \mathrm{BSA}$ with respect to permeation time for different coagulant dosages $(\mu \mathrm{M} \mathrm{Al})$ 

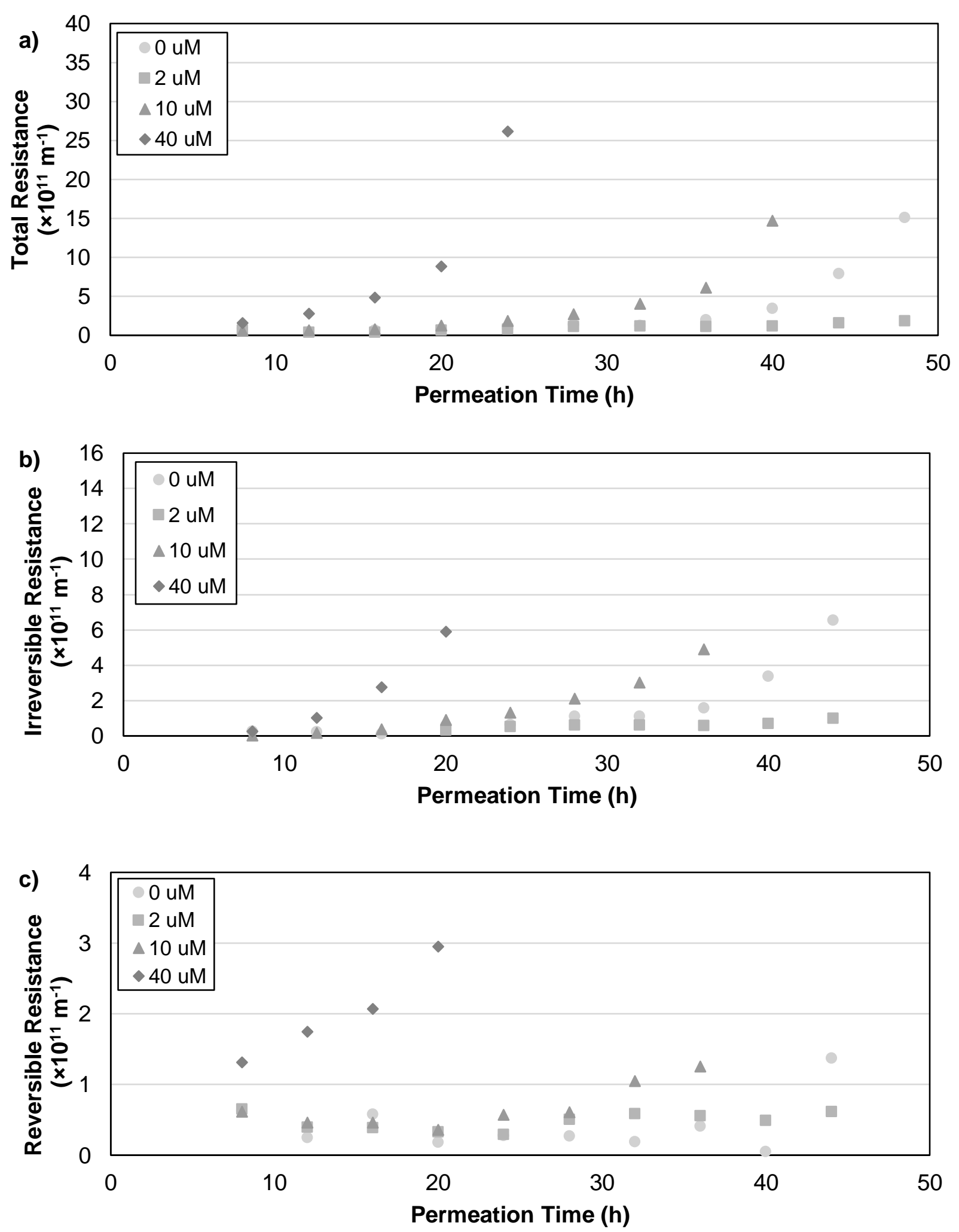

Figure 8-4: (a) Total, (b) irreversible, and (c) reversible resistance during $2^{\text {nd }}$ trial of ultrafiltration of $20 \mathrm{mg} / \mathrm{L} \mathrm{BSA}$ with respect to permeation time for different coagulant dosages $(\mu \mathrm{M} \mathrm{Al})$ 

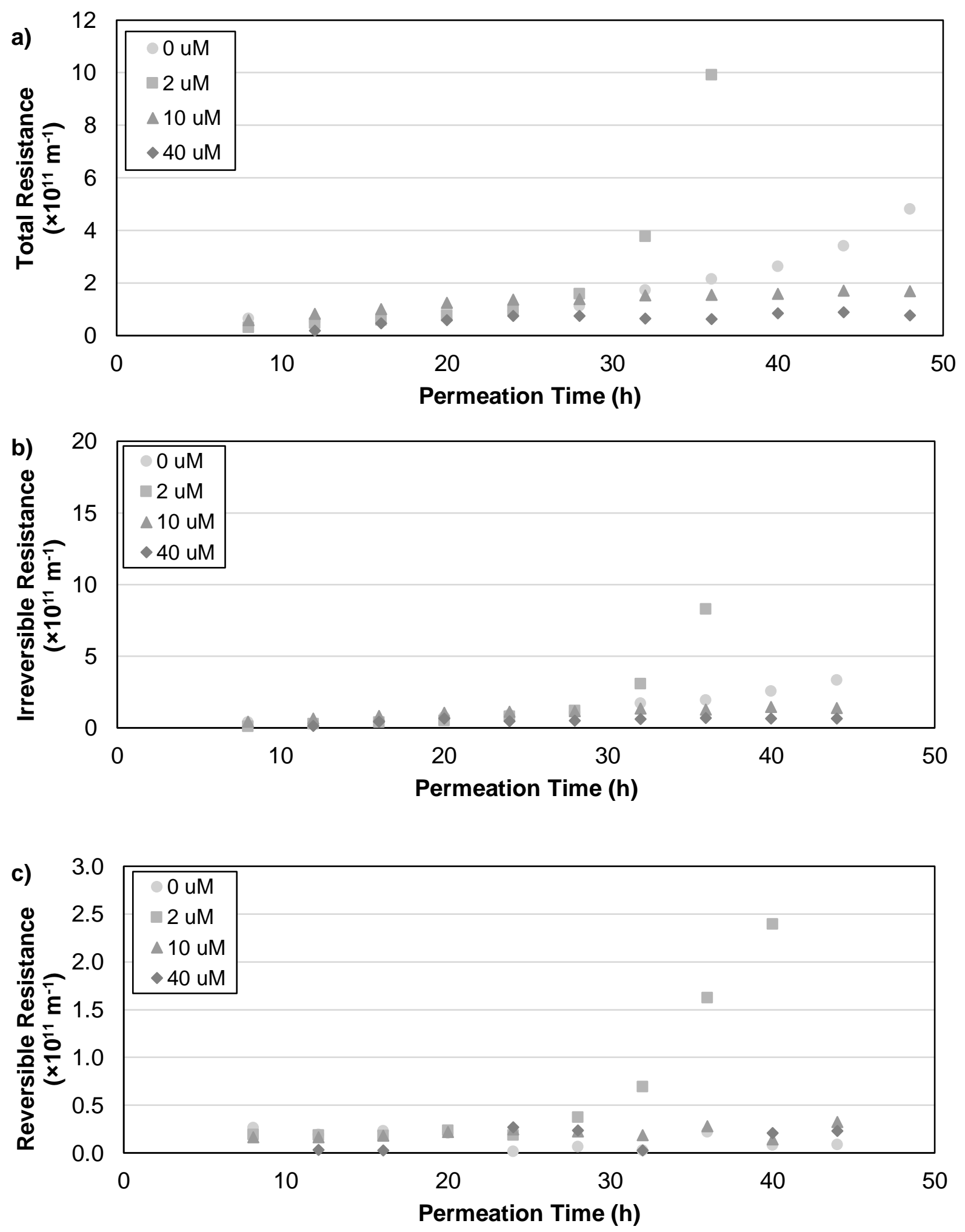

Figure 8-5: (a) Total, (b) irreversible, and (c) reversible resistance during ultrafiltration of 10 $\mathrm{mg} / \mathrm{L}$ BLG with respect to permeation time for different coagulant dosages $(\mu \mathrm{M} \mathrm{Al})$ 

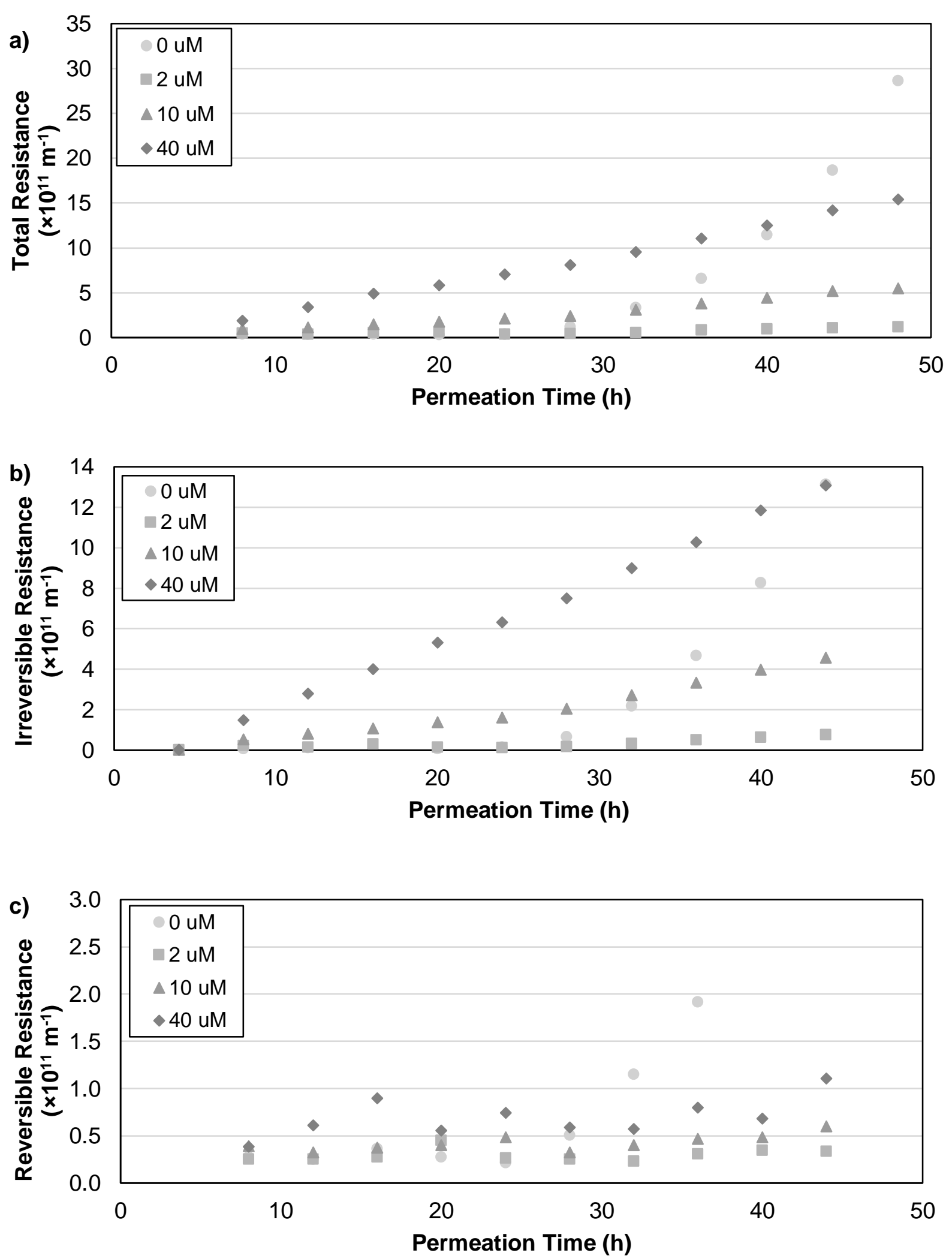

Figure 8-6: (a) Total, (b) irreversible, and (c) reversible resistance during $1^{\text {st }}$ trial of ultrafiltration of $20 \mathrm{mg} / \mathrm{L}$ OVA with respect to permeation time for different coagulant dosages $(\mu \mathrm{M} \mathrm{Al})$ 

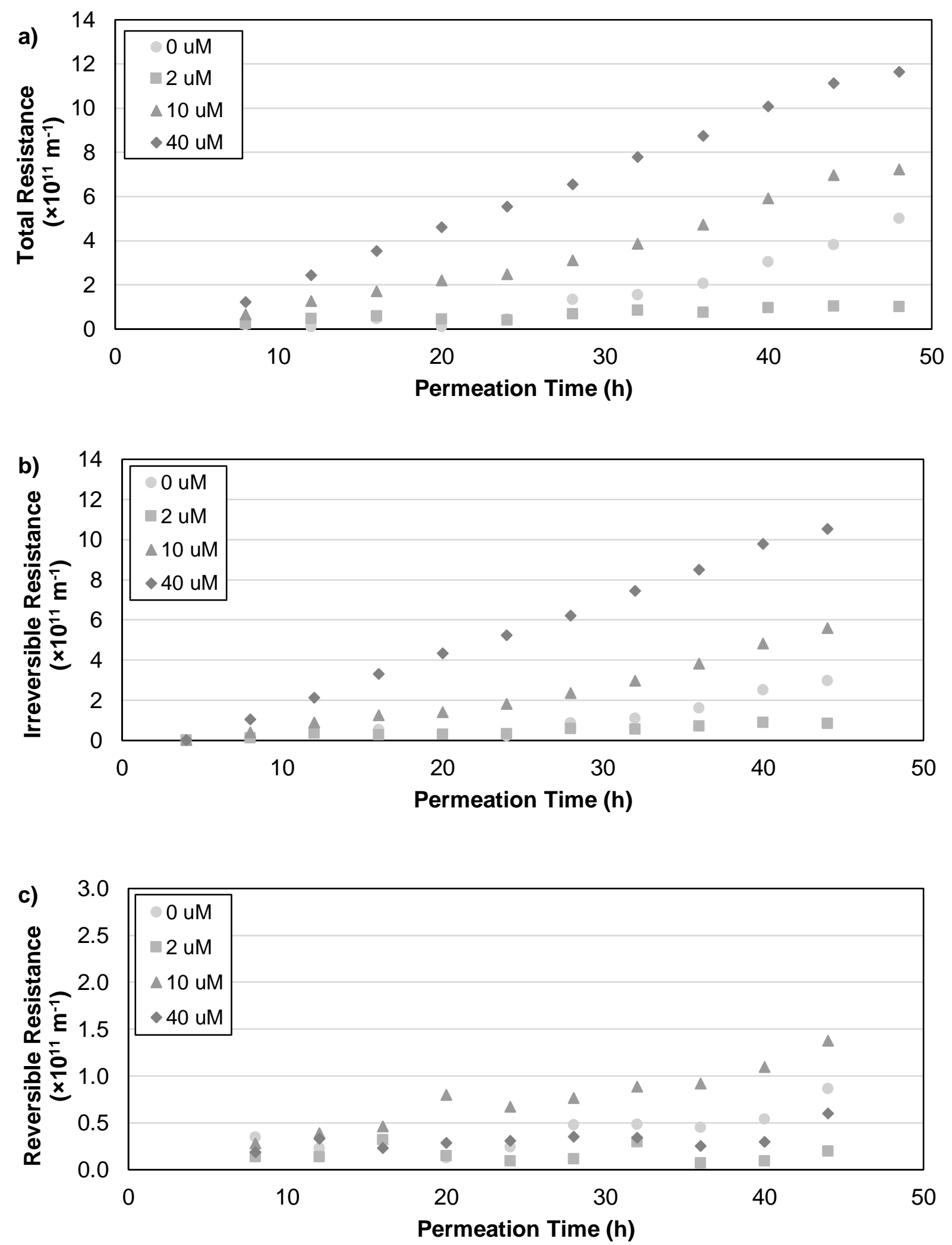

Figure 8-7: (a) Total, (b) irreversible, and (c) reversible resistance during $2^{\text {nd }}$ trial of ultrafiltration of $20 \mathrm{mg} / \mathrm{L}$ OVA with respect to permeation time for different coagulant dosages $(\mu \mathrm{M} \mathrm{Al})$ 


\subsubsection{Protein Concentrations}

Table 8-3: Concentrations (mg/L) of BSA in feed, permeate, and reject water during $1^{\text {st }}$ trial

\begin{tabular}{|c|c|c|c|c|c|c|c|}
\hline Time (h) & $\mathbf{0}$ & \multicolumn{3}{|c|}{$\mathbf{2 4}$} & \multicolumn{3}{|c|}{$\mathbf{4 8}$} \\
\hline $\begin{array}{c}\text { Water } \\
\text { Dose }\end{array}$ & Feed & Feed & Permeate & Reject & Feed & Permeate & Reject \\
\hline $\mathbf{0} \boldsymbol{\mu M}$ & 22.2 & 23.3 & 12.6 & 25.0 & 24.2 & 12.4 & 27.5 \\
\hline $\mathbf{2} \boldsymbol{\mu M}$ & 21.9 & 23.0 & 19.3 & 21.7 & 21.6 & 19.1 & 22.9 \\
\hline $\mathbf{1 0} \boldsymbol{\mu M}$ & 22.9 & 23.0 & 18.6 & 23.4 & 22.2 & 18.2 & 22.8 \\
\hline $\mathbf{4 0} \boldsymbol{\mu M}$ & 22.8 & 22.9 & 16.2 & 23.8 & 22.8 & 10.3 & 25.5 \\
\hline
\end{tabular}

Table 8-4: Concentrations ( $\mathrm{mg} / \mathrm{L}$ ) of BSA in feed, permeate, and reject water during $2^{\text {nd }}$ trial

\begin{tabular}{|c|c|c|c|c|c|c|c|}
\hline Time (h) & $\mathbf{0}$ & \multicolumn{3}{|c|}{$\mathbf{2 4}$} & \multicolumn{3}{|c|}{$\mathbf{4 8}$} \\
\hline $\begin{array}{c}\text { Water } \\
\text { Dose }\end{array}$ & Feed & Feed & Permeate & Reject & Feed & Permeate & Reject \\
\hline $\mathbf{0} \boldsymbol{\mu M}$ & 27.3 & 28.2 & 26.6 & 27.8 & 27.5 & 22.9 & 25.6 \\
\hline $\mathbf{2} \boldsymbol{\mu M}$ & 25.0 & 27.5 & 24.5 & 28.2 & 28.5 & 26.1 & 30.4 \\
\hline $\mathbf{1 0} \boldsymbol{\mu M}$ & 25.1 & 26.5 & 23.1 & 26.2 & 26.1 & 0.0 & 27.5 \\
\hline $\mathbf{4 0} \boldsymbol{\mu M}$ & 24.8 & 26.8 & 14.6 & 28.0 & 28.0 & 4.6 & $\begin{array}{c}\text { Not } \\
\text { Collected }\end{array}$ \\
\hline
\end{tabular}

Table 8-5: Concentrations ( $\mathrm{mg} / \mathrm{L}$ ) of BLG in feed, permeate, and reject water

\begin{tabular}{|c|c|c|c|c|c|c|c|}
\hline Time (h) & $\mathbf{0}$ & \multicolumn{3}{|c|}{$\mathbf{2 4}$} & \multicolumn{3}{|c|}{$\mathbf{4 8}$} \\
\hline $\begin{array}{c}\text { Water } \\
\text { Dose }\end{array}$ & Feed & Feed & Permeate & Reject & Feed & Permeate & Reject \\
\hline $\mathbf{0} \boldsymbol{\mu M}$ & 12.1 & 11.6 & 10.6 & 12.0 & 11.6 & 9.9 & 11.2 \\
\hline $\mathbf{2} \boldsymbol{\mu M}$ & 11.6 & 11.6 & 10.2 & 11.2 & 9.9 & 7.5 & 10.1 \\
\hline $\mathbf{1 0} \boldsymbol{\mu M}$ & 10.7 & 11.1 & 9.0 & 11.1 & 11.1 & 8.4 & 10.7 \\
\hline $\mathbf{4 0} \boldsymbol{\mu M}$ & 11.2 & 11.2 & 7.1 & 10.0 & 10.9 & 7.3 & 9.5 \\
\hline
\end{tabular}


Table 8-6: Concentrations (mg/L) of OVA in feed, permeate, and reject water during $1^{\text {st }}$ trial

\begin{tabular}{|c|c|c|c|c|c|c|c|}
\hline Time (h) & $\mathbf{0}$ & \multicolumn{3}{|c|}{$\mathbf{2 4}$} & \multicolumn{3}{|c|}{$\mathbf{4 8}$} \\
\hline $\begin{array}{c}\text { Water } \\
\text { Dose }\end{array}$ & Feed & Feed & Permeate & Reject & Feed & Permeate & Reject \\
\hline $\mathbf{0} \boldsymbol{\mu M}$ & 21.8 & 22.1 & 19.7 & 21.8 & 20.7 & 17.9 & 20.2 \\
\hline $\mathbf{2} \boldsymbol{\mu M}$ & 21.4 & 22.3 & 20.8 & 22.9 & 20.9 & 20.2 & 22.9 \\
\hline $\mathbf{1 0} \boldsymbol{\mu M}$ & 21.7 & 22.0 & 19.9 & 21.3 & 21.3 & 19.2 & 21.0 \\
\hline $\mathbf{4 0} \boldsymbol{\mu M}$ & 21.5 & 20.4 & 16.1 & 20.4 & 20.8 & 16.8 & 21.0 \\
\hline
\end{tabular}

Table 8-7: Concentrations (mg/L) of OVA in feed, permeate, and reject water during $2^{\text {nd }}$ trial

\begin{tabular}{|c|c|c|c|c|c|c|c|}
\hline Time (h) & $\mathbf{0}$ & \multicolumn{3}{|c|}{$\mathbf{2 4}$} & \multicolumn{3}{|c|}{$\mathbf{4 8}$} \\
\hline $\begin{array}{c}\text { Water } \\
\text { Dose }\end{array}$ & Feed & Feed & Permeate & Reject & Feed & Permeate & Reject \\
\hline $\mathbf{0} \boldsymbol{\mu M}$ & 25.4 & 25.7 & 22.3 & 25.8 & 26.0 & 23.3 & 25.9 \\
\hline $\mathbf{2} \boldsymbol{\mu M}$ & 25.6 & 24.8 & 23.5 & 24.9 & 24.7 & 23.9 & 24.8 \\
\hline $\mathbf{1 0} \boldsymbol{\mu M}$ & 26.0 & 25.8 & 23.1 & 24.2 & 24.2 & 21.5 & 24.4 \\
\hline $\mathbf{4 0} \boldsymbol{\mu M}$ & 25.8 & 24.1 & 19.6 & 23.8 & 23.5 & 20.2 & 24.5 \\
\hline
\end{tabular}

\subsubsection{Zeta Potential}

Table 8-8: Zeta potential $(\mathrm{mV})$ of BSA for different coagulant dosages

\begin{tabular}{|c|c|c|c|}
\hline $\begin{array}{c}\text { Replicate } \\
\text { Dose }\end{array}$ & $\mathbf{1}$ & $\mathbf{2}$ & $\mathbf{3}$ \\
\hline $\mathbf{0} \boldsymbol{\mu M}$ & -65.4 & -55.4 & -59.7 \\
\hline $\mathbf{2} \boldsymbol{\mu M}$ & -50.0 & -50.3 & -52.9 \\
\hline $\mathbf{1 0} \boldsymbol{\mu M}$ & -42.0 & -44.5 & -45.6 \\
\hline $\mathbf{4 0} \boldsymbol{\mu M}$ & -12.5 & -12.7 & -12.6 \\
\hline
\end{tabular}

Table 8-9: Zeta potential (mV) of OVA for different coagulant dosages

\begin{tabular}{|c|c|c|c|}
\hline $\begin{array}{c}\text { Replicate } \\
\text { Dose }\end{array}$ & $\mathbf{1}$ & $\mathbf{2}$ & $\mathbf{3}$ \\
\hline $\mathbf{0} \boldsymbol{\mu M}$ & -23.3 & -22.0 & -22.1 \\
\hline $\mathbf{2} \boldsymbol{\mu M}$ & -21.8 & -19.9 & -20.7 \\
\hline $\mathbf{1 0} \boldsymbol{\mu M}$ & -18.3 & -18.6 & -21.3 \\
\hline $\mathbf{4 0} \boldsymbol{\mu M}$ & -24.9 & -24.2 & -20.3 \\
\hline
\end{tabular}




\subsubsection{ANS Fluorescence Assay}

Table 8-10: Fluorescent intensity at ex/em 370/490 nm (average of triplicate measurements) of BSA solutions titrated with ANS

\begin{tabular}{|c|c|c|c|c|c|c|c|c|}
\hline & \multirow{2}{*}{$\begin{array}{r}\begin{array}{r}\text { Sample Time } \\
(\mathrm{h})\end{array} \\
\text { Conc. }(\mathrm{mg} / \mathrm{L}) \\
\end{array}$} & \multirow{2}{*}{$\begin{array}{c}0 \\
\text { Feed }\end{array}$} & \multicolumn{3}{|c|}{24} & \multicolumn{3}{|c|}{48} \\
\hline & & & Feed & Perm & Reject & Feed & Perm & Reject \\
\hline \multirow{5}{*}{$\mathbf{0} \boldsymbol{\mu M}$} & 2 & 0.57 & 2.67 & 0.72 & 3.23 & 2.35 & 0.91 & 3.00 \\
\hline & 4 & 2.34 & 4.27 & 1.23 & 4.55 & 4.27 & 1.33 & 4.44 \\
\hline & 6 & 3.64 & 5.97 & 1.71 & 6.48 & 5.51 & 1.75 & 6.14 \\
\hline & 8 & 5.62 & 6.78 & 2.71 & 7.10 & 6.72 & 2.19 & 8.07 \\
\hline & 10 & 5.52 & 7.22 & 3.11 & 9.19 & 6.97 & 3.05 & 9.43 \\
\hline \multirow{5}{*}{$2 \mu \mathrm{M}$} & 2 & 0.78 & 3.21 & 1.51 & 3.03 & 2.53 & 1.65 & 2.38 \\
\hline & 4 & 2.74 & 4.81 & 2.83 & 4.17 & 3.35 & 3.06 & 3.41 \\
\hline & 6 & 4.06 & 6.18 & 3.96 & 6.48 & 4.14 & 3.91 & 5.07 \\
\hline & 8 & 6.53 & 7.78 & 4.89 & 6.82 & 6.29 & 4.87 & 6.27 \\
\hline & 10 & 8.06 & 8.93 & 5.62 & 8.44 & 6.61 & 6.26 & 7.16 \\
\hline \multirow{5}{*}{$10 \mu \mathrm{M}$} & 2 & 0.71 & 2.53 & 0.97 & 3.05 & 2.69 & 1.72 & 3.22 \\
\hline & 4 & 2.81 & 4.16 & 2.33 & 5.09 & 5.05 & 3.05 & 4.53 \\
\hline & 6 & 4.49 & 6.00 & 3.25 & 6.86 & 6.36 & 4.21 & 6.71 \\
\hline & 8 & 7.04 & 7.31 & 4.33 & 7.90 & 7.12 & 5.37 & 8.35 \\
\hline & 10 & 8.32 & 8.34 & 5.81 & 9.37 & 8.42 & 5.88 & 10.35 \\
\hline \multirow{5}{*}{$40 \mu \mathrm{M}$} & 2 & 0.92 & 2.68 & 0.72 & 2.34 & 2.79 & 0.93 & 2.53 \\
\hline & 4 & 2.50 & 3.47 & 2.23 & 4.39 & 4.43 & 1.39 & 4.17 \\
\hline & 6 & 3.35 & 5.88 & 2.43 & 5.65 & 6.21 & 1.74 & 5.54 \\
\hline & 8 & 6.06 & 6.83 & 4.21 & 6.54 & 6.85 & 2.24 & 7.34 \\
\hline & 10 & 7.47 & 7.02 & 5.16 & 8.72 & 7.96 & 3.06 & 8.43 \\
\hline
\end{tabular}

*Blank intensity already subtracted from values 


\subsubsection{Pilot-Scale Fouling Resistance}
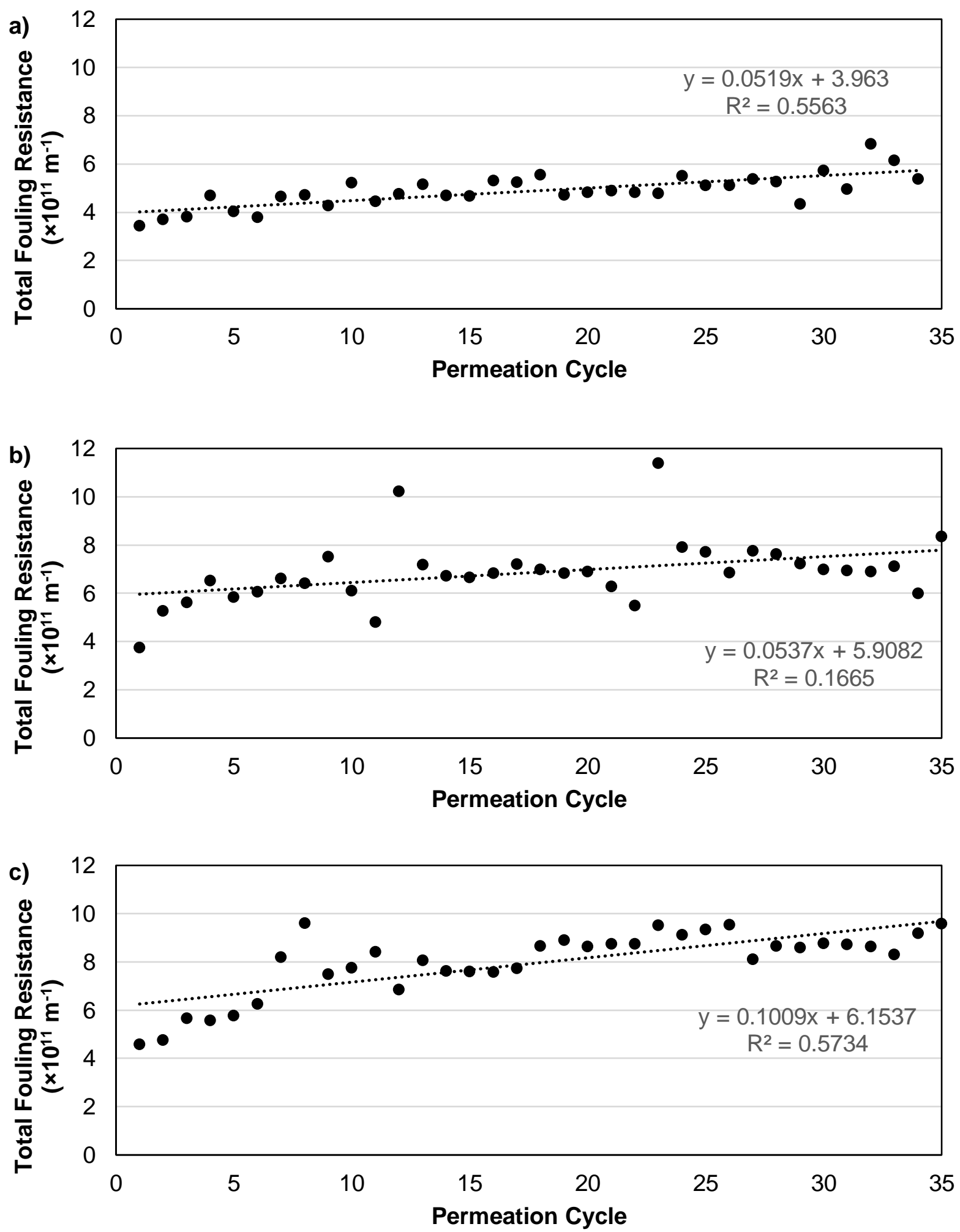

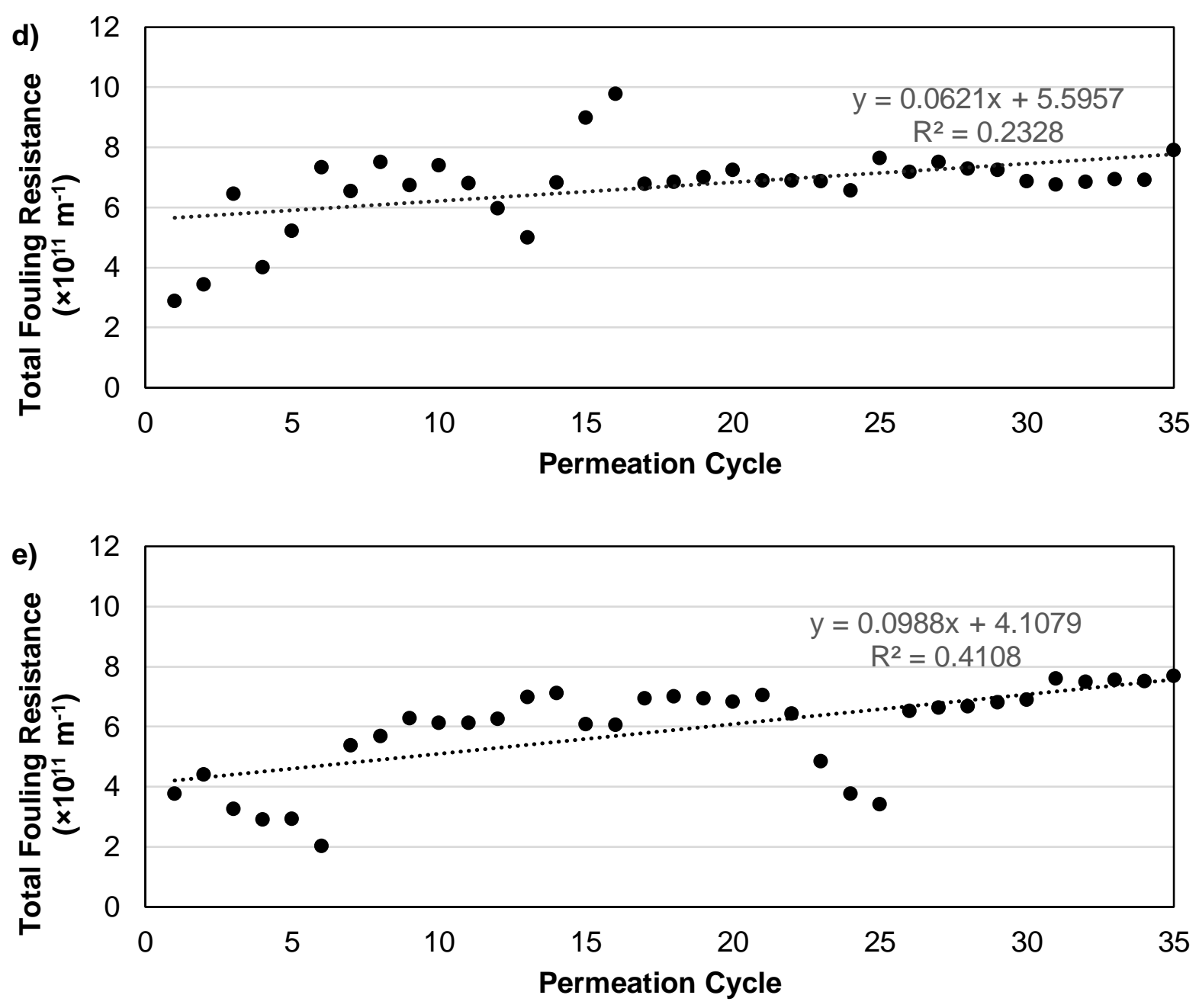

Figure 8-8: Total fouling resistance for (a) continuous, (b) $60 \mathrm{~min}$, (c) $30 \mathrm{~min}$, (d) $10 \mathrm{~min}$, and (e) no coagulant addition times during each permeation cycle 

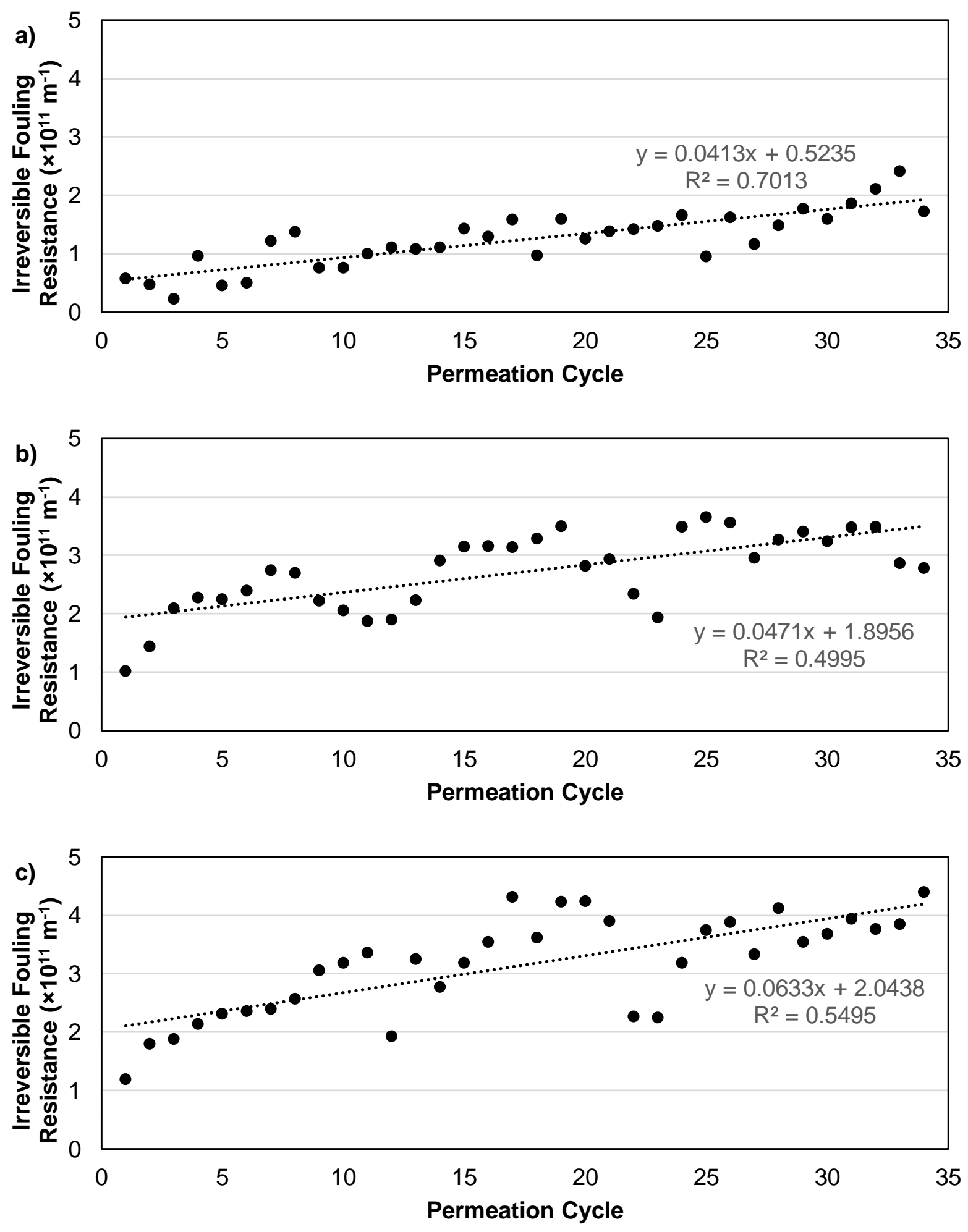

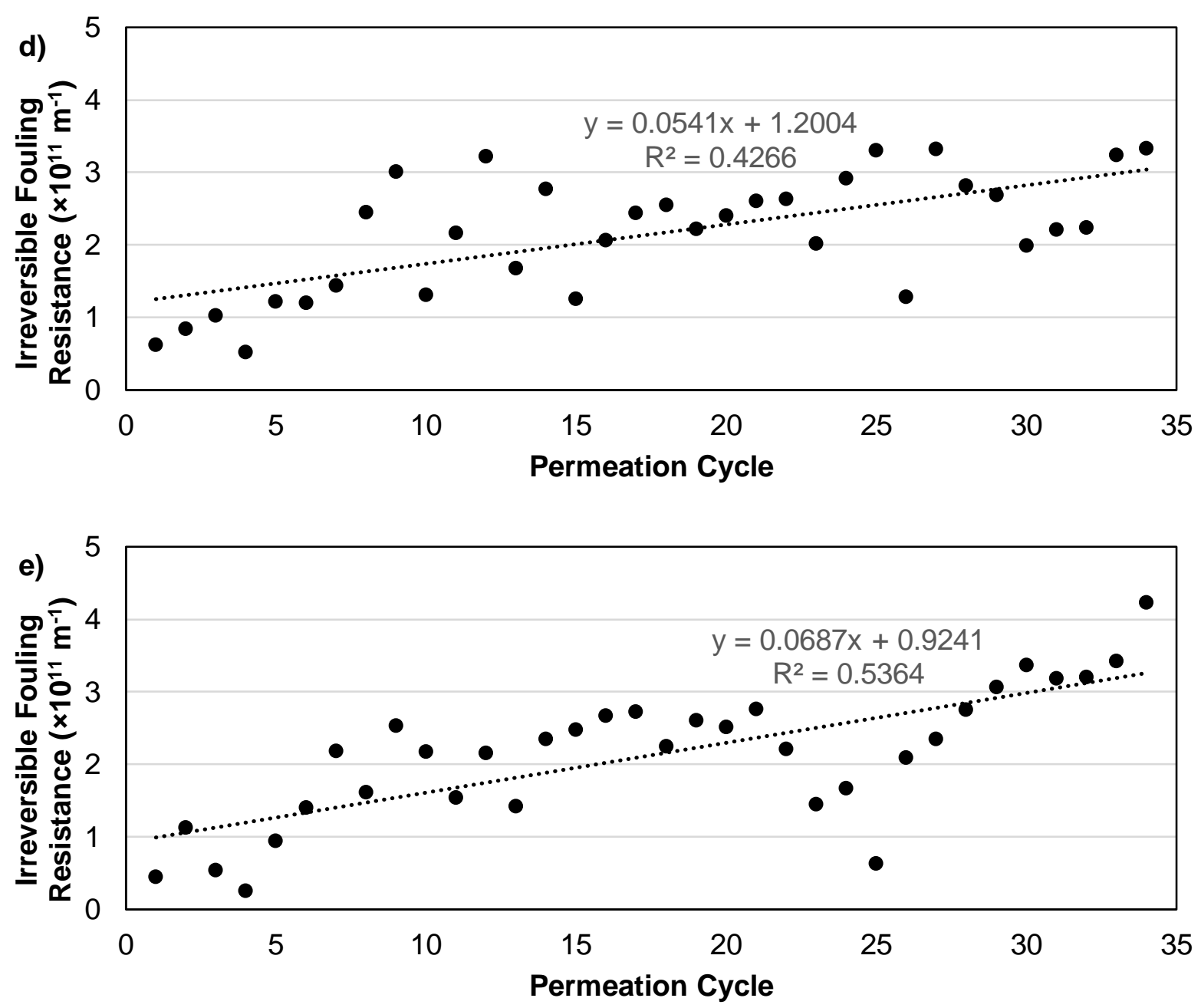

Figure 8-9: Irreversible fouling resistance for (a) continuous, (b) $60 \mathrm{~min}$, (c) $30 \mathrm{~min}$, (d) 10 min, and (e) no coagulant addition times during each permeation cycle 


\subsubsection{LC-OCD Results}

Table 8-11: Concentration ( $\mu \mathrm{g} / \mathrm{L}$ ) of NOM fractions (via LC-OCD) in feed, permeate, and reject water for different phased coagulation conditions

\begin{tabular}{|c|c|c|c|c|c|c|c|}
\hline & $\begin{array}{l}\text { Sample- } \\
\text { Time }\end{array}$ & DOC & Biopolymers & $\begin{array}{c}\text { Humic } \\
\text { Substances }\end{array}$ & $\begin{array}{c}\text { Building } \\
\text { Blocks }\end{array}$ & $\begin{array}{c}\text { LMW } \\
\text { Neutrals }\end{array}$ & $\begin{array}{l}\text { LMW } \\
\text { Acids }\end{array}$ \\
\hline \multirow{9}{*}{ 告 } & Feed 24 & 4150 & 554 & 2244 & 783 & 323 & 104 \\
\hline & Perm 24 & 3516 & 174 & 2104 & 684 & 337 & 146 \\
\hline & Reject 24 & 18689 & 14434 & 2768 & 854 & 827 & 117 \\
\hline & Feed 48 & 4038 & 604 & 2259 & 736 & 287 & 113 \\
\hline & Perm 48 & 3560 & 172 & 2261 & 752 & 308 & 95 \\
\hline & Reject 48 & 18012 & 14096 & 2685 & 798 & 854 & 202 \\
\hline & Feed 72 & 3999 & 520 & 2358 & 735 & 292 & 106 \\
\hline & Perm 72 & 3656 & 186 & 2184 & 785 & 280 & 99 \\
\hline & Reject 72 & 15956 & 11613 & 2503 & 886 & 986 & 225 \\
\hline \multirow{9}{*}{$\begin{array}{l}\text { ఏ } \\
\stackrel{\Xi}{\Xi}\end{array}$} & Feed 24 & 4185 & 578 & 2203 & 764 & 320 & 99 \\
\hline & Perm 24 & 3767 & 186 & 2215 & 738 & 284 & 94 \\
\hline & Reject 24 & 10196 & 6778 & 2386 & 712 & 934 & 118 \\
\hline & Feed 48 & 3967 & 529 & 2262 & 733 & 279 & 97 \\
\hline & Perm 48 & 3712 & 187 & 2187 & 765 & 255 & 94 \\
\hline & Reject 48 & 9124 & 5909 & 2412 & 574 & 732 & 87 \\
\hline & Feed 72 & 4099 & 585 & 2231 & 730 & 273 & 95 \\
\hline & Perm 72 & 3682 & 174 & 2198 & 721 & 255 & 94 \\
\hline & Reject 72 & 9724 & 6818 & 2352 & 703 & 571 & 106 \\
\hline \multirow{9}{*}{ } & Feed 24 & 3965 & 599 & 2134 & 880 & 409 & 91 \\
\hline & Perm 24 & 3790 & 213 & 2078 & 870 & 276 & 105 \\
\hline & Reject 24 & 10785 & 8362 & 2412 & 620 & 524 & 109 \\
\hline & Feed 48 & 4116 & 574 & 2227 & 754 & 296 & 95 \\
\hline & Perm 48 & 3743 & 244 & 2149 & 815 & 250 & 97 \\
\hline & Reject 48 & 12721 & 10043 & 2362 & 722 & 441 & 113 \\
\hline & Feed 72 & 4235 & 577 & 2241 & 735 & 290 & 97 \\
\hline & Perm 72 & 3773 & 182 & 2175 & 790 & 259 & 99 \\
\hline & Reject 72 & \multicolumn{6}{|c|}{ Analysis Omitted } \\
\hline \multirow{9}{*}{$\stackrel{\Xi}{\stackrel{\Xi}{\Xi}}$} & Feed 24 & 3991 & 544 & 2189 & 789 & 307 & 92 \\
\hline & Perm 24 & 3700 & 187 & 2166 & 744 & 297 & 90 \\
\hline & Reject 24 & 12552 & 8234 & 2760 & 767 & 834 & 106 \\
\hline & Feed 48 & 3968 & 486 & 2175 & 790 & 346 & 96 \\
\hline & Perm 48 & 3640 & 185 & 2173 & 733 & 241 & 90 \\
\hline & Reject 48 & 13502 & 12024 & 2646 & 969 & 669 & 94 \\
\hline & Feed 72 & 4048 & 559 & 2244 & 778 & 308 & 87 \\
\hline & Perm 72 & 3710 & 186 & 2257 & 770 & 260 & 87 \\
\hline & Reject 72 & 13737 & 11177 & 2720 & 908 & 500 & 94 \\
\hline
\end{tabular}




\begin{tabular}{|c|c|c|c|c|c|c|c|}
\hline & $\begin{array}{l}\text { Sample- } \\
\text { Time }\end{array}$ & DOC & Biopolymers & $\begin{array}{c}\text { Humic } \\
\text { Substances }\end{array}$ & $\begin{array}{l}\text { Building } \\
\text { Blocks }\end{array}$ & $\begin{array}{c}\text { LMW } \\
\text { Neutrals }\end{array}$ & $\begin{array}{l}\text { LMW } \\
\text { Acids }\end{array}$ \\
\hline \multirow{9}{*}{ 葛 } & Feed 24 & 4206 & 562 & 2177 & 810 & 338 & 92 \\
\hline & Perm 24 & 3785 & 157 & 2160 & 797 & 297 & 97 \\
\hline & Reject 24 & 16454 & 13565 & 2703 & 800 & 720 & 95 \\
\hline & Feed 48 & 4051 & 493 & 2198 & 740 & 311 & 94 \\
\hline & Perm 48 & 3674 & 187 & 2111 & 793 & 280 & 92 \\
\hline & Reject 48 & 16332 & 11894 & 2543 & 828 & 874 & 105 \\
\hline & Feed 72 & 4113 & 528 & 2235 & 742 & 293 & 94 \\
\hline & Perm 72 & 3693 & 173 & 2248 & 723 & 233 & 92 \\
\hline & Reject 72 & 17707 & 12850 & 2672 & 940 & 735 & 105 \\
\hline
\end{tabular}

